\title{
WestVirginiaUniversity
}

THE RESEARCH REPOSITORY @ WVU

Graduate Theses, Dissertations, and Problem Reports

2020

\section{An Interactive Mobile Equipment Task-Training with Virtual Reality}

Lazar Zujovic

Lazar Zujovic, zujovic.lazar@gmail.com

Follow this and additional works at: https://researchrepository.wvu.edu/etd

Part of the Mining Engineering Commons

\section{Recommended Citation}

Zujovic, Lazar, "An Interactive Mobile Equipment Task-Training with Virtual Reality" (2020). Graduate Theses, Dissertations, and Problem Reports. 7653.

https://researchrepository.wvu.edu/etd/7653

This Thesis is protected by copyright and/or related rights. It has been brought to you by the The Research Repository @ WVU with permission from the rights-holder(s). You are free to use this Thesis in any way that is permitted by the copyright and related rights legislation that applies to your use. For other uses you must obtain permission from the rights-holder(s) directly, unless additional rights are indicated by a Creative Commons license in the record and/ or on the work itself. This Thesis has been accepted for inclusion in WVU Graduate Theses, Dissertations, and Problem Reports collection by an authorized administrator of The Research Repository @ WVU. For more information, please contact researchrepository@mail.wvu.edu. 
An Interactive Mobile Equipment Task-Training with Virtual Reality

Lazar Zujovic

\author{
Thesis submitted to the \\ Benjamin M. Statler College of Engineering and Mineral Resources \\ At West Virginia University \\ in partial fulfillment of the requirements \\ for the degree of \\ Master of Science \\ In \\ Mining Engineering
}

Vladislav Kecojevic, Ph.D., Chair

Berk Tulu, Ph.D.

Gary Winn, Ph.D.

Department of Mining Engineering

Morgantown, West Virginia 2020

Keywords: Heavy Equipment Operators; Interactive Training; 360-degree Images and Videos; Content Management System; Virtual Reality; Virtual Tours

Copyright 2020 Lazar Zujovic 


\begin{abstract}
An Interactive Mobile Equipment Task-Training with Virtual Reality
\end{abstract}

\title{
Lazar Zujovic
}

Improving the quality of equipment training for the Heavy Equipment Operators (HEO) is a critical task in the ever-lasting effort to improve safety and eliminate equipment-related injuries in mining environments. Traditional miner training includes the use of hardcopy documents and video instructions. However, modern mobile and computer technology offers tremendous potential to improve the training process.

One major responsibility for the heavy-machine operators is proper machine inspection. Establishing new training methods that utilize modern technologies - such as 360-degree images, videos, and Virtual Reality - and implementing computers for training purposes have a potential to help new operators learn how to conduct proper machine inspections in a more efficient and technically correct way. This technology could potentially provide a higher knowledge retention rate for heavy machine operators.

This study utilizes a 360-degree camera, open-source platform WordPress ${ }^{\mathrm{TM}}$, and the software Unity3D in order to create materials and tools for the HEOs training, which in turn will help trainees to better understand the pre-shift machine inspection. The outcomes of this research are organized into three major phases: Gathering materials, Computer-Based Task-Training (CBTT) software, and Virtual Reality (VR) application. The 360-degree images/videos, 2D images, and sounds were first gathered, edited, and incorporated into the CBTT and VR applications. The major feature of the CBTT, developed with WordPress ${ }^{\mathrm{TM}}$, is its training template with instructions on creating a new training course for the HEOs. The training courses developed for this study cover seven different machines that are widely used in surface mines. Also, the CBTT software is optimized for use on mobile devices (such as smart-phones and tablets). The VR applications for the same machines are developed with one of the most popular game engines Unity3D. To interact with the virtual world, a trainee can use the Head-Mounted Display (HMD) Oculus Rift CV 1, which establishes full immersion while performing the virtual tour of a selected 
machine. If used without HMD, applications become non-immersive desktop versions and can be controlled by using a mouse and keyboard. The user-friendly interface and multimedia environment are comfortable to handle, flexible, and potentially more convenient to use than paper-based documents.

The CBTT and VR applications were developed, tested, and implemented at a surface coal mine in the southern United States. 
An Interactive Mobile Equipment Task-Training with Virtual Reality

Lazar Zujovic

\author{
Thesis submitted to the \\ Benjamin M. Statler College of Engineering and Mineral Resources \\ At West Virginia University \\ in partial fulfillment of the requirements \\ for the degree of \\ Master of Science \\ In \\ Mining Engineering \\ Department of Mining Engineering
}

APPROVAL OF THE EXAMINING COMMITTEE

Vladislav Kecojevic, Ph.D., Chair

Berk Tulu, Ph.D.

Date

Gary Winn, Ph.D. 


\section{Table of Contents}

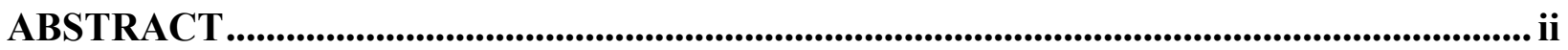

Table of Contents ................................................................................................................................................ $\mathrm{V}$

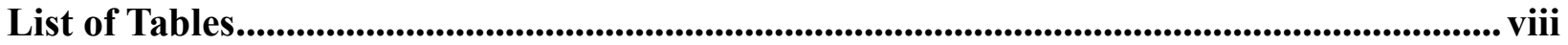

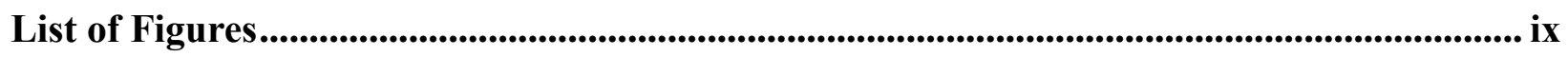

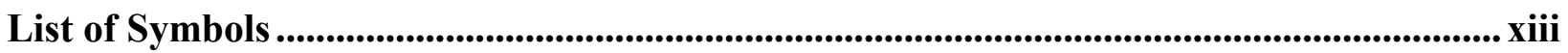

Acknowledgements ................................................................................................................................. xiv

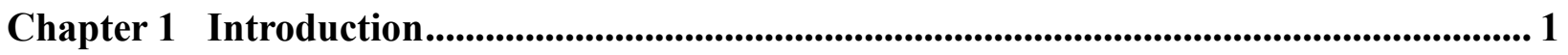

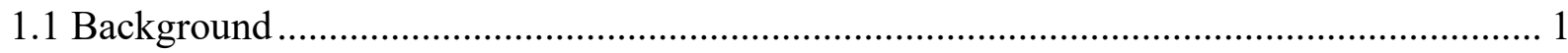

1.2 Problem Statement .......................................................................................... 4

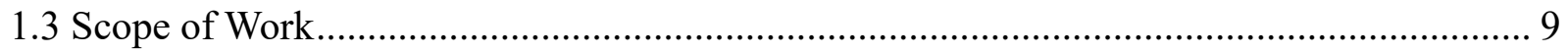

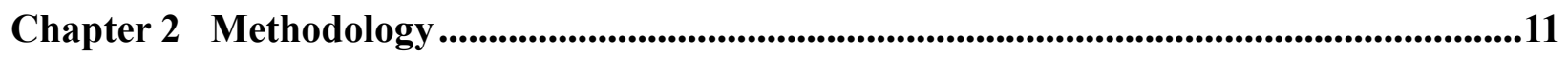

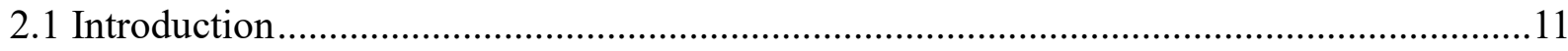

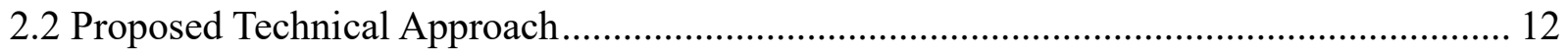

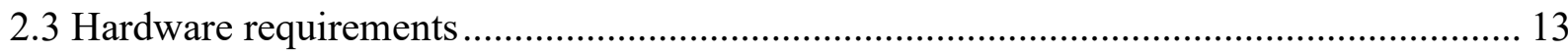

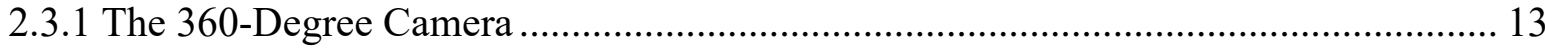

2.3.2 Head-Mounted Display (HMD) ................................................................. 14

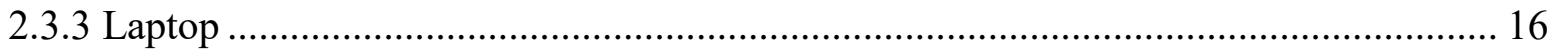

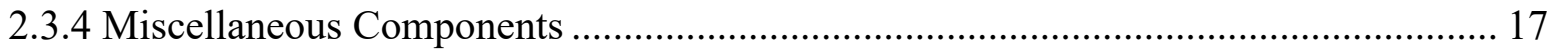

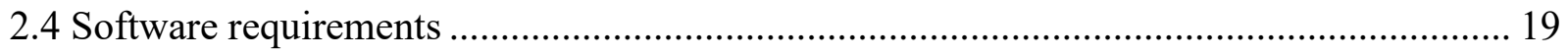

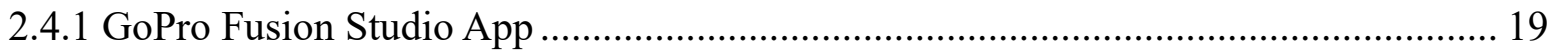


2.4.2 Unity 3D

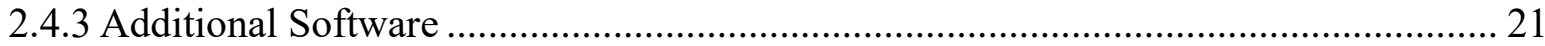

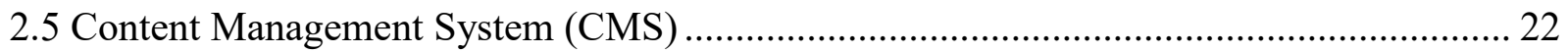

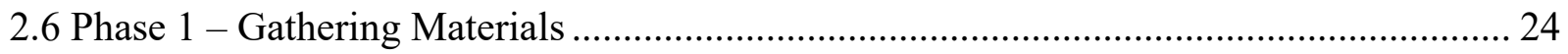

2.6.1 360-degree Images - Camera Positions............................................................................ 25

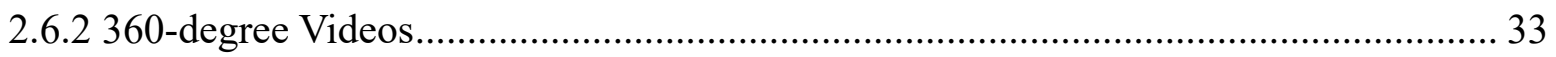

2.7 Phase 2 - Computer-Based Task-Training (CBTT) ……………………………............. 37

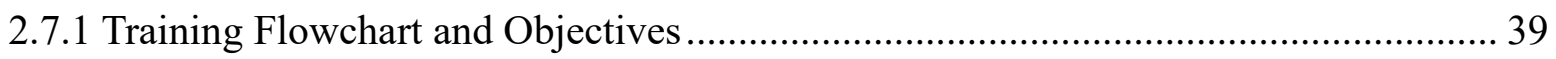

2.7.2 Permission Levels and User Roles........................................................................ 43

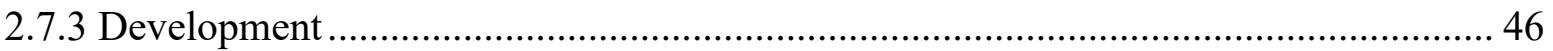

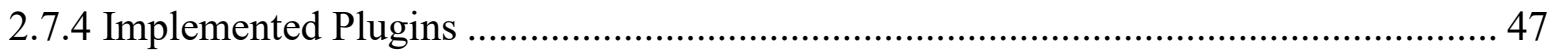

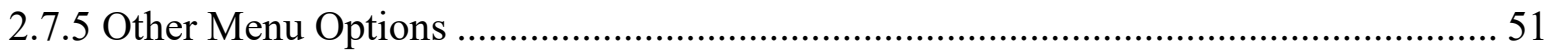

2.8 Phase 3 - Virtual Reality Application ........................................................................... 51

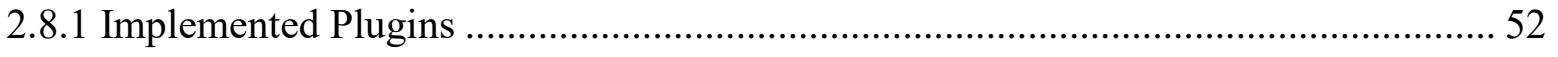

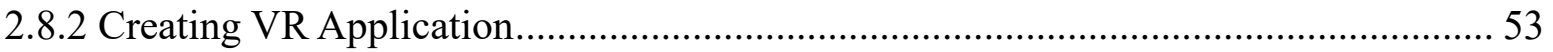

Chapter 3 Results and Discussion ........................................................................................................ 56

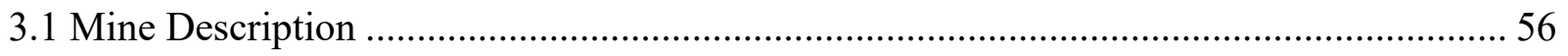

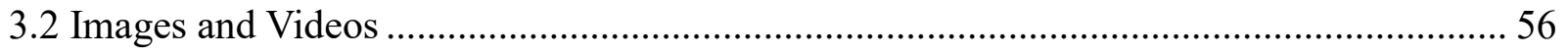

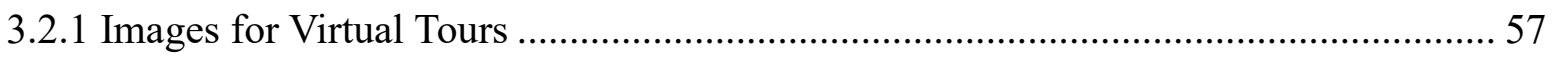

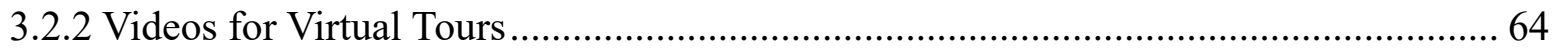




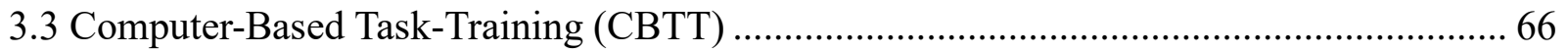

3.3.1 Creating the New Computer-Based Task-Training ........................................... 67

3.3.2 Select Location and Machine........................................................................ 75

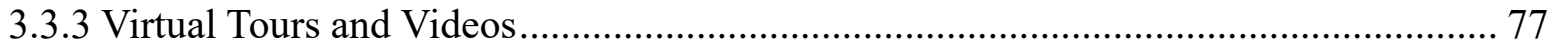

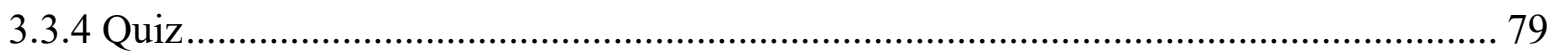

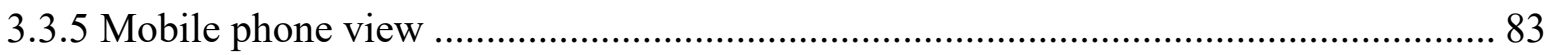

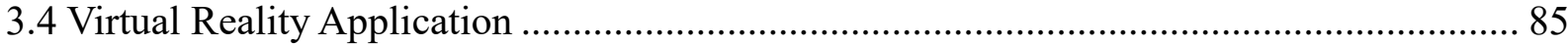

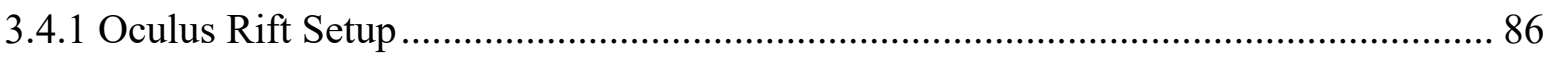

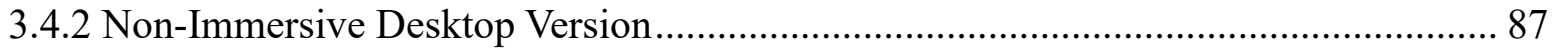

Chapter 4 Summary, Conclusion, and Recommendations for Future Research ................ 90

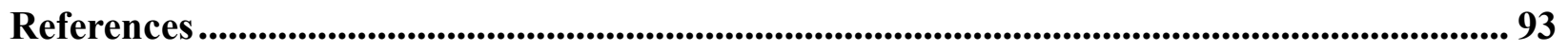




\section{List of Tables}

Table 1 - Camera positions for Haul-truck .................................................................... 26

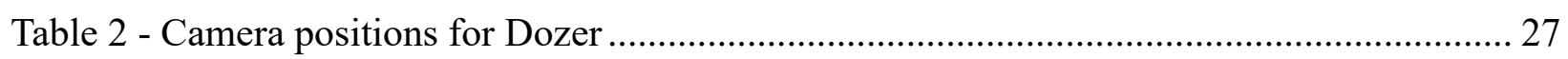

Table 3 - Camera positions for Scraper......................................................................... 29

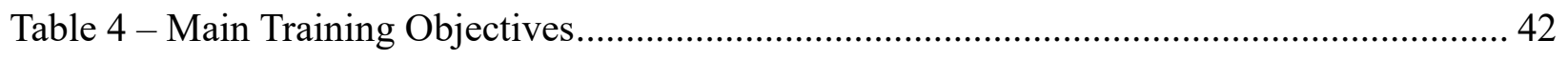

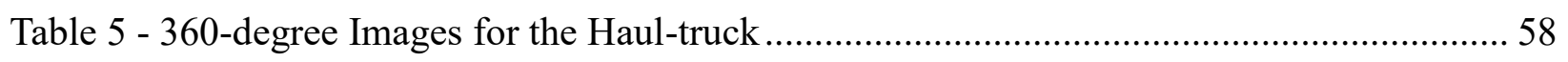

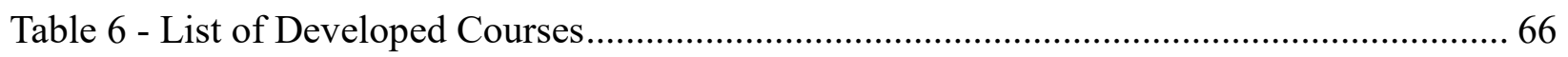




\section{List of Figures}

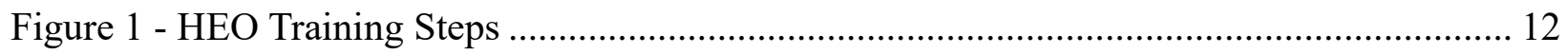

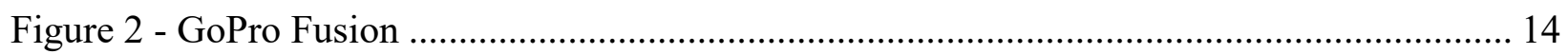

Figure 3 - a) Oculus Rift CV 1 (Niora, 2019); b) Google Cardboard (Google, 2019)............. 15

Figure 4 - a) Oculus Touch Left and Right Hand Controller (Accessories, 2019); b) Sensor for

Oculus Rift (Accessories, 2019) .................................................................................... 15

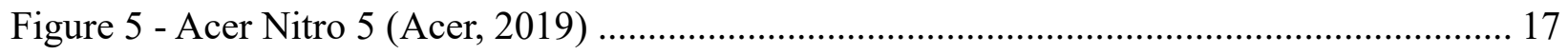

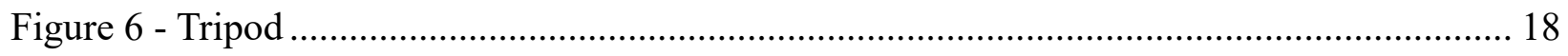

Figure 7 - Camera Mounts ........................................................................................... 18

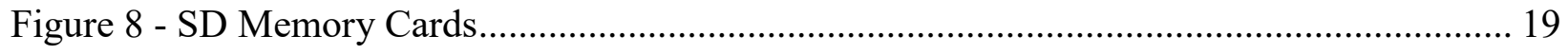

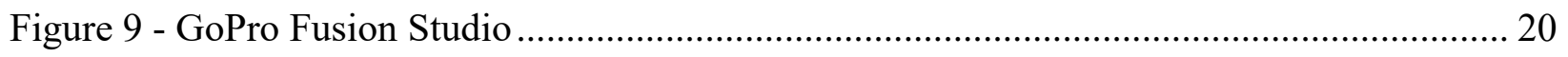

Figure 10 - Web Content Management System (Manoj \& Asoke, 2016) ................................. 23

Figure 11 - Camera Positions for Haul-Trucks .............................................................. 25

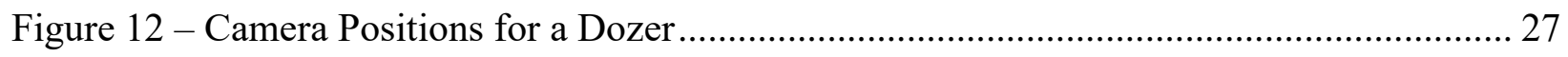

Figure 13 - Camera Positions for a Scraper ................................................................. 28

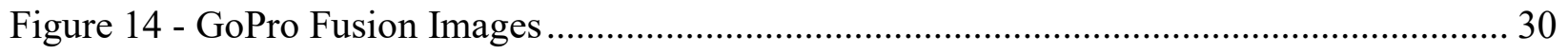

Figure 15 - Image Processing; a) Two images to be stitched; b) 360-degree image; c) Removed

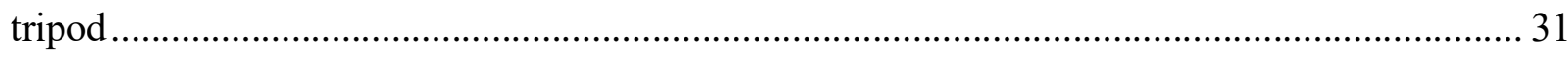

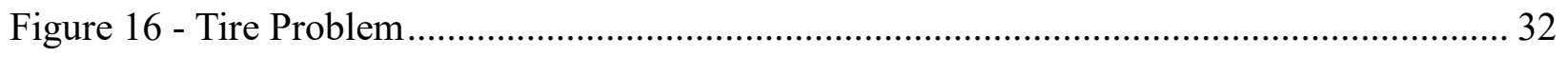

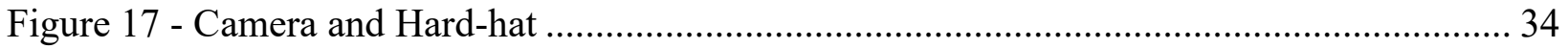


Figure 18 - Video Screenshots. a) Approaching the truck; b) Fire extinguisher check; c) Under the haul-truck; d) Rear side of the Haul-truck ..................................................................... 35

Figure 19 - Camera Position for SVP Videos for Haul-trucks ............................................. 36

Figure 20 - Camera Position for SVP Videos for Dozers ................................................... 36

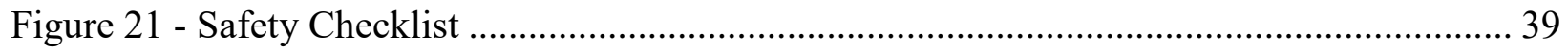

Figure 22 - Computer-Based Task-Training ....................................................................... 41

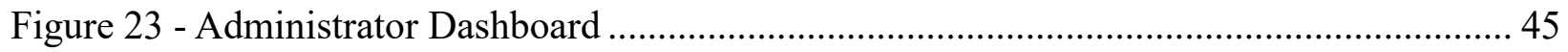

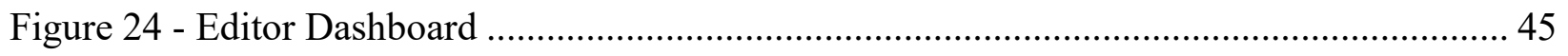

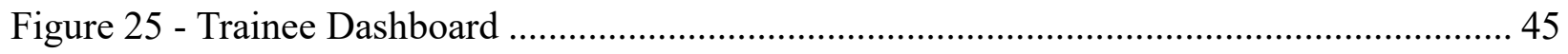

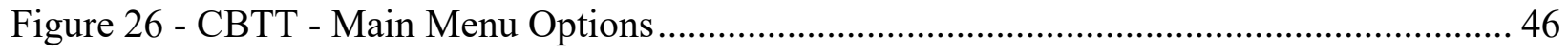

Figure 27 - Plugin for Creating Virtual Tours - iPanorama 360 .......................................... 47

Figure 28 - Plugin for Creating a New Quiz................................................................... 49

Figure 29 - Plugin for Inserting 360-degree Videos - Wpvr ............................................... 49

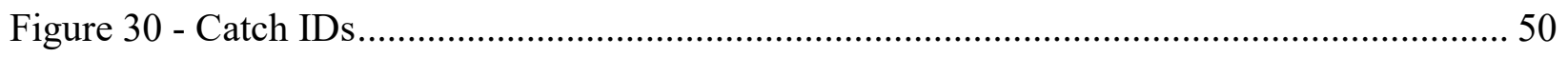

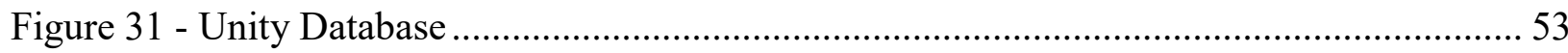

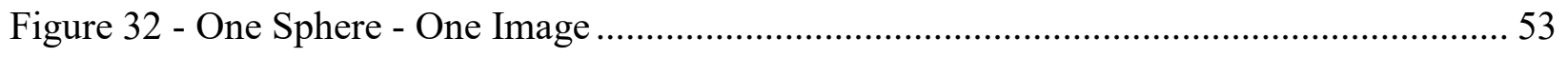

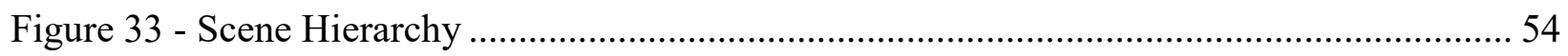

Figure 34 - Creating New Virtual Tour ........................................................................ 55

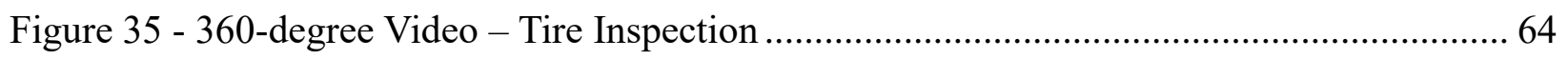

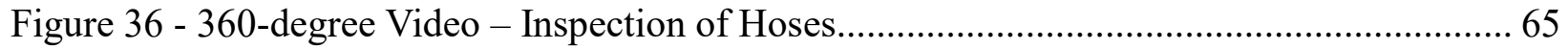


Figure 37 - 360-degree Video - Three Points of Contact 65

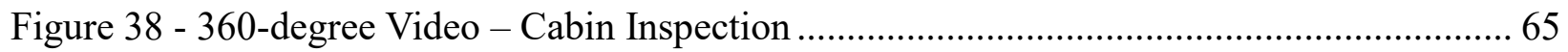

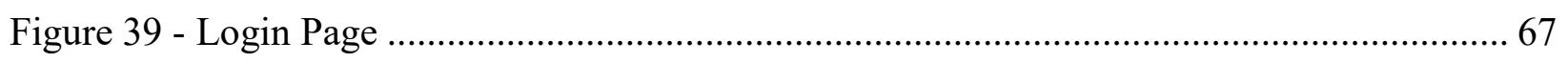

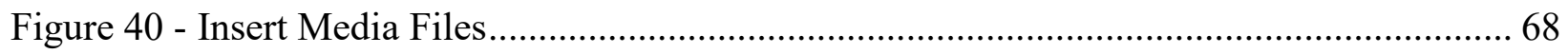

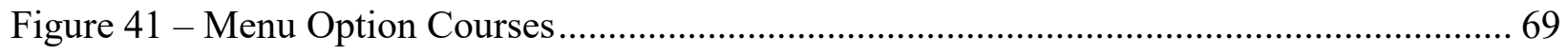

Figure 42 - Step 1 - Create New Course ……………........................................................... 70

Figure 43 - Step 3 - Create New Post................................................................................ 71

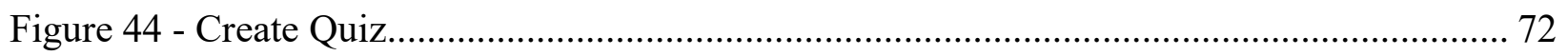

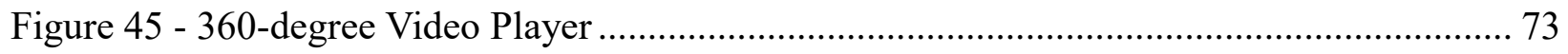

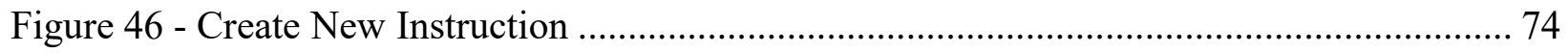

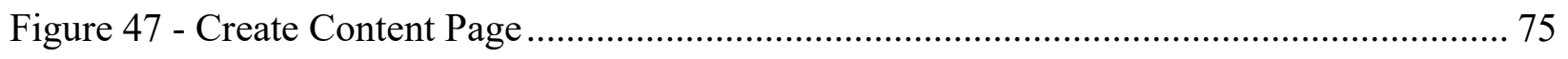

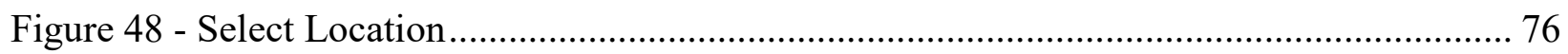

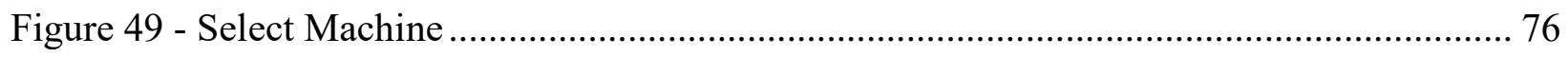

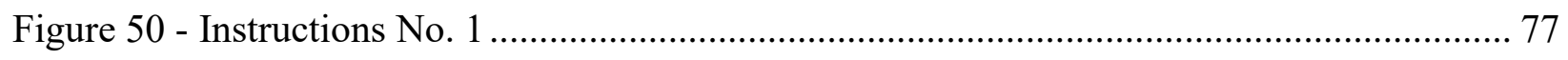

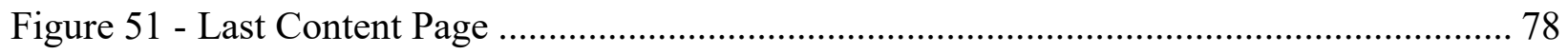

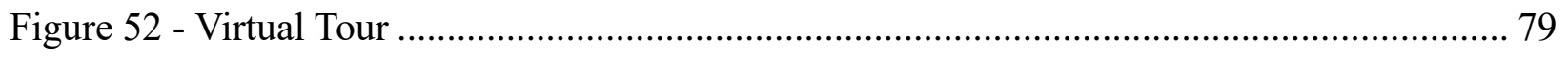

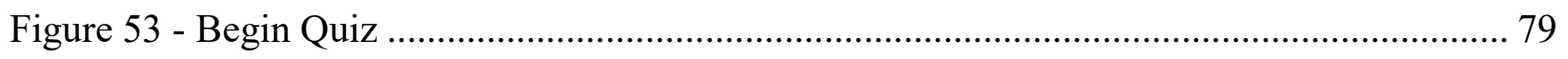

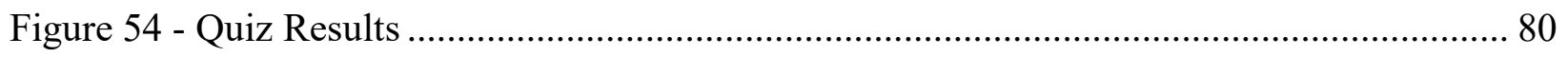

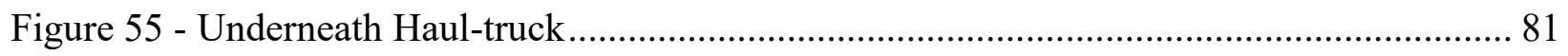


Figure 56 - Rear Side of Haul-truck

Figure 57 - View on Mobile Devices 83

Figure 58 - Mobile View - Select a Course Figure 59 - Mobile View - Editor's Mode.... 84

Figure 60 - VR applications 85

Figure 61 - VR application with Oculus Rift CV1 86

Figure 62 - User Interaction...... 87

Figure 63 - Non-immersive Mode 88

Figure 64 - Non-immersive Mode - Cabin.................................................................. 88

Figure 65 - Speedometer 89

Figure 66 - Tire Problem. 89 


\section{List of Symbols}

Computer-Based Task-Training CBTT

Heavy Equipment Operator HEO

Virtual Reality

Consumer Version $\quad$ CV

Head-Mounted Display $\quad$ HMD

Content Management System $\quad$ CMS

Content Management Application CMA

Content Delivery Application $\quad$ CDA

Application Programming Interfaces $\quad$ API

Moving Viewport $\quad$ MVP

Static Viewport $\quad$ SVP

Quizzes and Surveys Master $\quad$ QSM

Surface Miner $\quad$ SM 


\section{Acknowledgements}

It was my great privilege to work with my advisor and mentor, Dr. Vladislav Kecojevic. His help, guidance, and patience during this journey gave me the strength to complete the thesis. I want to thank him for being great mentor, for his efforts in helping me, and for the opportunities he gave me.

I had the honor of working with Dr. Dragan Bogunovic, who provided me with valuable input, inspiration, and motivation during the completion of this study. His suggestions were as important as his friendship.

I thank the coal mining industry for providing me with financial assistance and for giving me this chance to complete my graduate studies.

I would also like to thank my committee members, Dr. Berk Tulu and Dr. Gary Winn, who extended their valuable time and energy to review my thesis.

I am extremely grateful to everyone in my family, as they provided me with absolute support and guidance throughout this educational journey. 


\section{Chapter 1}

\section{Introduction}

\subsection{Background}

Maintaining safe worksites is one of the major goals for mining companies and for all people working in mines. Keeping the mine secure and maintaining a safe environment is the responsibility of everyone involved - upper and lower management, maintenance, heavy equipment operators (HEO), and other employees. Apart from operating a machine, HEOs have another crucial task: proper machine inspection. Operators should perform machine inspections prior to every shift (pre-shift inspections) and once or more during their shifts (i.e. after break). It is the trainer's duty to provide effective and efficient training to the new HEOs on the inspection process. Machine inspections differ for each type of machine and include, but are not limited to, inspections of the body, tires, rims, bolts, leaks, oil and/or fuel accumulations, oil levels, tracks, blade, ripper, cabin, etc. Failure to perform a proper pre-shift machine inspection can result in a domino effect, leading to more serious problems or incidents.

Depending on the type of machine one is operating, each HEO must be trained on how to perform a thorough pre-shift inspection of the machine. Operators need to be task-trained and familiar with the procedures, commands, main parts of the machines, terminology, and recommendations for working with the machines. Heavy equipment operators assigned to a task in which they have no previous experience should be adequately trained in safety and health aspects of the safe machine inspection, as well as safe operating procedures (Mine Safety Associates, 2007). When conducting 
the task-training for HEOs, the following Mine Safety and Health Administration (MSHA) guidelines should be considered (MSHA, 2019):

- Task training is performed on all machines and job duties;

- Adequate task training records are completed for all task training;

- Task training is provided when there is a change to the equipment, process, or condition;

- There is adequate time set aside to complete thorough training;

- HEO should have the ability to demonstrate the knowledge of company and federal health and safety procedures applicable to all tasks;

- HEO should receive knowledge of any required maintenance and service equipment;

- HEO should understand how and where to report any problems or malfunctions;

- HEO should have the ability to demonstrate proper startup and shutdown procedures of equipment;

- HEO should have received the proper skills necessary to perform the task in a safe manner;

- HEO should demonstrate safe operating procedures and know the proper procedures to address any change to the equipment, process, or condition.

One significant factor that still contributes to on-site injuries is a lack of training and/or improper equipment inspection (McMahan et al., 2008). Having adequate, high-quality, stable, and applicable training is paramount not only for the operators of mining equipment, but also for the entire mine personnel. Therefore, all HEOs must achieve an appropriate level of knowledge to inspect and operate the mining equipment safely in different conditions. Colin (2017) indicates that a pre-job safety analysis can reduce the probability of an incident occurring. The author further 
explains Neil George's five point safety system as the "straightforward and structured tool for assessing miner's workplace, equipment and work procedures." The second of the five points addresses questions about the safety of a workplace and its equipment. Workplace and equipment examination should require its own specific checklist.

Kowalski and Vaught (2002) stated that numerous changes in mining population, such as diversity of experience, variety in age, and ethnicity, require implementing more modern methods of training. The training should be given new measures and more technological means due to the growing use of computers. Establishing new training based on the fundamentals of modern technology and focusing on computer learning can potentially provide trainees with a higher knowledge retention rate. It can also potentially reduce and consequently eliminate equipmentrelated injuries. 


\subsection{Problem Statement}

Current task-training for equipment operators is primarily paper-based, but there is potential in switching to other modes of more engaging training (Bruke et al, 2006). Patterson and Shappell (2010) analyzed human factors and decision-based errors in mining incidents; their study showed that machine operators often misjudge risks. Since paper-based training outlined for heavy machine operators often consists of dozens of pages, it is very difficult for trainees to learn important information only by reading. Adding unnecessary volume to the outlines creates an environment of "pencil whipping," or filling out the training document (i.e. safety checklist or form) even though the safety inspection was partially performed or even skipped entirely, as people lose the incentive to read the entire lengthy document. Trainees may fail to ensure the safety of the machinery if they express their understanding of proper pre-shift inspection without actually reading the instruction properly. Bahn (2013) investigated emerging hazards in mine work environments, suggesting further training is required in risk identification in order to manage hazards. There is also a possibility of misunderstanding procedures if the trainees do not get to see the machine before going out in the field. Such training with paper-based modules can, therefore, increase hazardous situations in the workplace. In addition, as active work areas get farther away from the office, supervisors or instructors must spend more time driving to the office to print out the task-training outlines. Another important issue is the lack of standardization in the process of pre-shift inspections. Pre-shift inspection length varies noticeably depending on the type of machine; it also depends on an operator's awareness of proper machine check procedure. Both observation and interviews have confirmed that pre-shift inspections for a dozer CAT D10 last around 10-15 minutes, if no defects are revealed. For the haul-trucks, pre-shift inspections would 
also last 10-15 minutes. For more complex machines, such as the Surface Miner, machine inspections last from 15-30 minutes.

Different examples of the implementation of both non-immersive and immersive training applications have been explored through previous research. Fahy (2004) states that there are several advantages to Computer-Based Training (CBT) and Internet-Based Training (IBT); for instance, travel time can be reduced, cost lowered, materials can be easily revised and updated, greater efficiency can be reached, etc. All these factors are present and valuable in the HEO's training process in mining industry. Time necessary to conduct proper and efficient machine inspection is measurable in minutes, but brings a lot of added value to the entire system. Thus, standardizing the HEO's training and emphasizing safety through 360-degree images and videos of what should be done, how it should be done, and how long it should take to inspect the machine can bring a high value to the entire process. These additions can help to minimize mistakes and improve training efficiency.

Researchers have developed non-immersive training prototypes which can be run only on standard PCs (Wyk and Villiers, 2009). Polcar and Horejsi (2015) stated that the PC workstation is a suitable platform for taking virtual tours controlled by the participants themselves. On one hand, nonimmersive Virtual Reality (VR) PC systems are not providing full immersion into the VR world. On the other hand, Wyk and Villers (2019) indicated that these systems are a low-cost option for high resolution design, training, and education applications. Upcoming HEOs can familiarize themselves with the machinery or system they will operate in the future before going out in the field and seeing the machine in-person. Therefore, one part of this research involves the development and use of virtual tours of mining equipment, built with 360-degree images and 360degree videos. These tours can prepare trainees in advance of commencing workplace inspections. 
However, there is no real substitution for the hands-on training, which means that each and every heavy-machine operator should also receive on-site training in addition to any computer-based training.

Although the researchers mentioned earlier discussed computer-based training, it is still important to address the use of new open source platforms for creating training software. It is important not only for providing different training courses, but also for creating completely new templates for training on particular machines. Therefore, implementing multimedia Computer-Based TaskTraining (CBTT) and Virtual Reality (VR) content, including 360-degree images and videos, 2D images, sounds, and text, can improve the overall training process.

With the new Computer-Based Task-Training system, supervisors no longer need to travel long distances to the office, print the paperwork, and then return to the operator. On the contrary, the new task-training outlines and training courses can be available instantaneously on a mobile device. Therefore, there is a possibility that operators will be able to bring the Computer-Based Task-Training out into the field on mobile devices. This can allow an operator to be present at the actual machine while simultaneously taking the CBTT on a mobile device. Of course, they could also perform the training course in designated exercise rooms.

Full immersion into a VR world, as another part of this research project, can be achieved through the use of Virtual Reality applications and VR headsets. Nowadays, the use of the Virtual Reality is widely present in different fields, such as military, medical, education, engineering, etc. (Squelch, 2001). Mallett and Unger (2007) stated that technological improvements allow growth in mine safety and health methods, discussing several approaches for Virtual Reality in future mine training. 
Wyk and Villiers (2009) stated that the primary goal of developing VR environments in the mining industry is to allow mine personnel to experience different activities and processes that might be expected in their everyday activities. In this context, one daily activity that each heavy-equipment operator can expect to perform is pre-shift machine inspection.

Kizil and Joy (2001) inferred that VR training can reduce cost of delivering trainings by decreasing learning time and lost time, reducing the need for extra equipment, and lowering travel expenses. Kizil and Joy (2001) also stated that additional benefits of VR technology for training are prevention of injury and reduction of near misses. Such technology is promising in improving safety records and saving lives. Clearly there is no substitute for real life, on-the-job training; however, the use of a VR system alongside real life training can greatly increase the effectiveness of the training, worker's awareness, and training safety as a whole, all while reducing costs at the same time. Another significant advantage of using VR is that mistakes made during training will not result in the damage of any equipment. This feature of VR is very useful, as it reflects on making future work and safety tasks easier to perform without risking damage to expensive mining technology. In conclusion, training will no longer be dictated by the amount of time skilled operators have to spend with new employees; instead, HEOs can now complete a portion of their training on a computer or mobile devices to become familiarized with their new jobs.

Computer 3D models for VR using computer graphics can be designed and created in different software (i.e. CAD systems). Such models can construct an imitation of reality that is very similar to the real-world workspace. There are various examples of training in the mining industry that use Virtual Reality. Wyk and Villiers (2009) developed training prototypes of fatal incident reconstruction, as well as pedestrian, driver, and smelting hazards. Non-immersive prototypes for standard PCs were created to contend with a large number of trainees and less-developed 
immersive technology. McMahan et al. (2010) developed Virtual Environments for surface mining training, which investigated two types of primary machinery—haul trucks and conveyor systems. In McMahan's research project models and animations of the haul truck were developed using Studio $^{\mathrm{TM}}$. Hui (2017) developed VR training for drilling in underground mines in two VR systems: (1) Screen-based general VR system, and (2) Head-Mounted Display-Based (HMD) intuitive system. Of these two options, a higher immersion is achieved with HMD with a shell and a smart phone. Hui (2017) also suggested that the development of the input/output devices and VR engine can greatly influence the promotion of Virtual Reality in the mining industry.

Today, higher immersion can be achieved due to the expansion of the Head-Mounted Displays available, such as Oculus Rift, Oculus Quest, HTC VIVE, etc. These systems are single VR headsets, different from the separated VR headsets which require a smartphone. The entertainment and video game industries boosted the use of these type of headsets, which are now spreading to different areas both in corporate and research environments (Hui, 2017). The affordability of these new products can further expand the use of Virtual Reality applications for training purposes.

Additionally, there has been a great expansion in the development of 360-degree cameras. Many of these cameras are consumer models, which are relatively easy to use. 360-degree cameras have a wider field of view in comparison to normal cameras. Liu et al. (2017) stated that the 360-degree camera captures an entire 360-degree scene that can then be wrapped into one 3D sphere. This sphere can be used to create Virtual Tours. The development of these cameras has raised the popularity of several models from different companies (i.e. GoPro Fusion, Samsung Gear 360). By using a 360-degree camera to capture images and videos, instead of building the models from scratch, it becomes relatively easy to obtain real images and videos to create Virtual Tours. This is a different approach for reaching higher realism in the VR world. The above-mentioned authors 
used computer models instead of real images. The building models were not performed in this research; instead, both 360-degree images and videos are combined with 2D images, sounds, and text, all of which is then applied into the interactive Computer-Based Task-Training software and VR application.

\subsection{Scope of Work}

Mining is by nature a potentially dangerous branch of industry, even in the wake of many improvements on safety measures, systems, programs, and software. The overall objective of this research project is to improve the HEO training process by using modern technology in the training process.

There is one commonality between the Computer-Based Task-Training, which can run on both computers and mobile devices, and the training application in VR for both desktop and HeadMounted Display: both aim to help make mines an injury-free workspace.

Specific aims of this study are as follows:

i. Use the camera to capture 360-degree images and 360-degree videos to create Virtual Reality content;

ii. Design and develop the interactive Computer-Based Task-Training for different mining equipment (Trucks, Dozers, Scrapers, etc.);

iii. Design Virtual Reality application;

iv. Utilize computers for knowledge assessment through quizzes; 
v. Establish the use of Computer-Based Training on a mobile device (i.e. smartphone, tablet); and

vi. Develop a set of instructions on how to create this type of training for another machine.

The new Computer-Based Task-Training allows instant access to training information, skipping the unnecessary production of paper outlines. The application enables training courses to be taken on a desktop PC. The user can interact with the non-immersive Computer-Based Desktop Software by using a mouse and keyboard. It can also be used in the field, as the training software can be uploaded to an online server and adjusted for use on mobile devices (smartphones and tablets). Another important goal is to possibly develop a training course from the template for new machines or to make changes or improvements to the existing training course.

Another portion of the training process is the Desktop Virtual Reality application. This application is compatible with Desktop PC and the Oculus Rift Consumer Version (CV 1). The Oculus is useful not only for watching training content but also for directly engaging with the VR world. Oculus Rift is an advanced VR headset and can provide full immersion of a trainee into a VR world.

Both systems, Computer-based (Internet-based) and Desktop/VR based, work independently from each other. Thus, an instructor can use both systems, or choose which system to use depending on the experience of a trainee or the type of training (new task-training or refresher training) (MSHA, 2019). 


\section{Chapter 2}

\section{Methodology}

\subsection{Introduction}

The objective of this research is to design and develop Computer-Based Task-Training (CBTT) and Virtual Reality application, using existing materials and creating new ones for the training purposes of the Heavy-Equipment Operators at a surface coal mine in the southern United States. Through this research, multiple platforms were considered for developing training applications for different heavy machines.

There are a few free platforms, such as WordPress ${ }^{\mathrm{TM}}$, Joomla ${ }^{\mathrm{TM}}$, and Wix ${ }^{\mathrm{TM}}$, that are suitable for creating the computer-based programs that can be run on local servers or particular websites. In this project, the open-source platform WordPress ${ }^{\mathrm{TM}}$ was used to develop CBTT for the HEO training. WordPress ${ }^{\mathrm{TM}}$ is a Content Management System (CMS) for creating, modifying, and publishing computer-based applications on specified domains (WordPress Features, 2018). In addition, different programming languages were used to provide support in creating the training software. The programming languages used for this purpose are PHP, CSS, and JavaScript. Free game engines such as Unity3D and Unreal Engine were also considered as possible candidates for developing the virtual reality application; consequently, Unity3D was chosen to create the VR

application in this research. Three experienced operators tested the developed software and reported universally positive feedback. The average age of the experienced operator was 50 years and their average experience was 20 years. 


\subsection{Proposed Technical Approach}

No computer models were created and used for this research; instead, the 360-degree content was created with a 360-degree camera. The machine images and videos, captured with this type of camera, are completely real to life. By using the new Computer-Based Task-Training and VR, future operators will have an opportunity to observe the machine in detail through the image or video format. Additionally, trainees will have the opportunity to read and listen to valuable training information while performing the CBTT and VR application.

Figure 1 shows the main steps for a trainee during this training process.

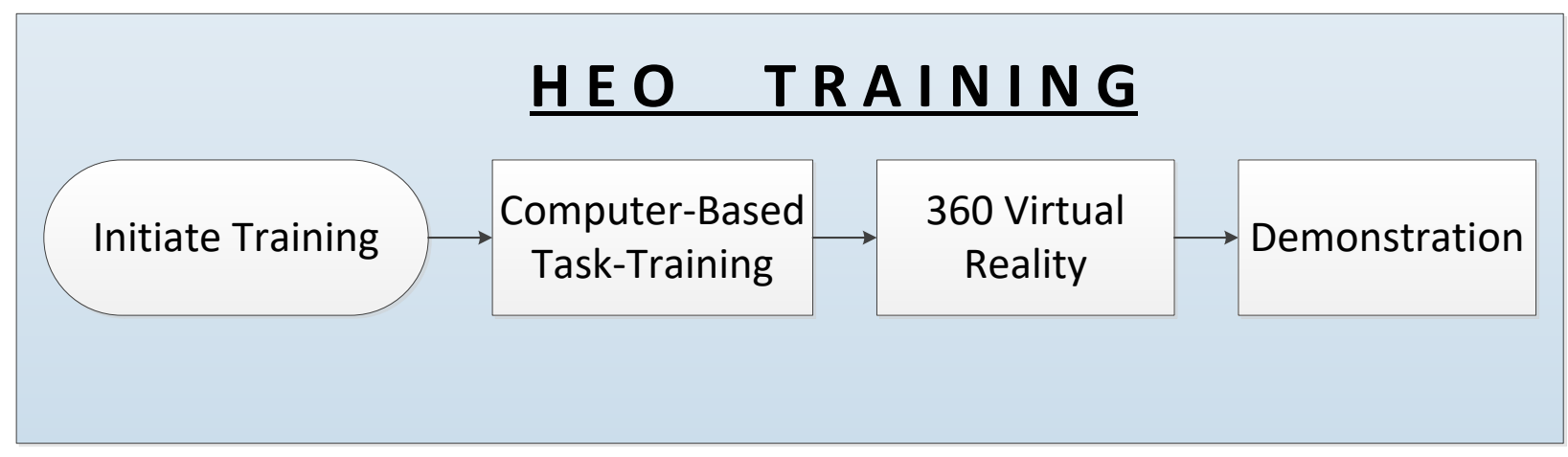

Figure 1 - HEO Training Steps

After initiating the training, there were three major phases in the proposed HEO Training: (1) Gathering the materials; (2) Computer-Based Task-Training (CBTT); and (3) Virtual Reality (VR) application.

Each of these phases will be explained in the following sections. In order to develop the interactive training courses, it was necessary to capture 360-degree content (images and videos) and collect other training materials to incorporate them into the Computer-Based Task-Training and VR application. 


\subsection{Hardware requirements}

Hardware for this project consisted of several separate components:

- 360-degree camera

- Head-Mounted Headsets (HMD) for Virtual Reality

- $\quad$ PC or laptop that can play VR content with HMD

- Miscellaneous components

Each of the required hardware components was used for the phases of gathering, developing, and reproducing the training content.

\subsubsection{The 360-Degree Camera}

First, this study chose an appropriate camera for capturing 360-degree images and videos. There is a large number of 360-degree cameras currently available on the market. GoPro Fusion (Figure 2) is one such camera that is capable of performing the tasks required by this research and is also an easy model to use.

The GoPro Fusion is a spherical camera marketed by GoPro Company in November 2017. It is one of the best consumer cameras for creating VR content. It consists of two 180-degree lenses, one on the front and one on the rear, and it can shoot videos and 18-megapixels still images. The two lenses simultaneously capture two images (GoPro Fusion, 2018) which can then be stitched together to create one 360-degree image. The GoPro Fusion uses two memory cards — one for each lens. 


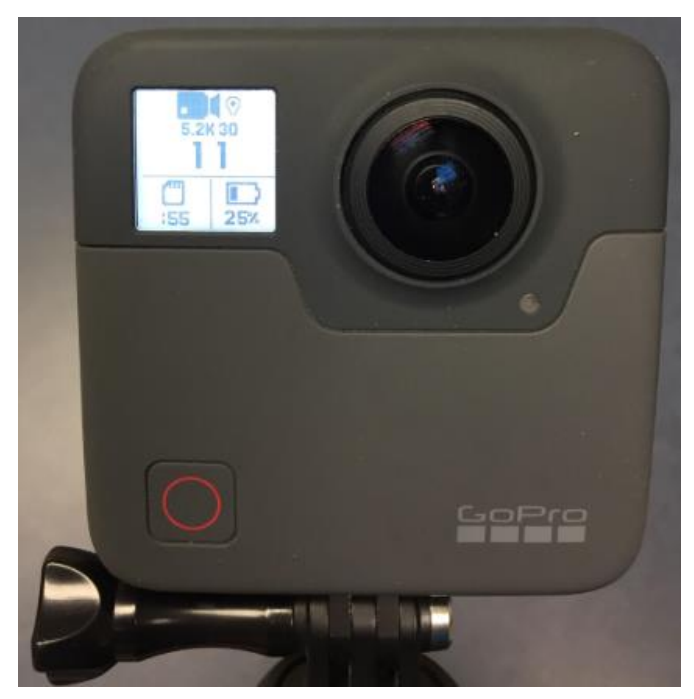

Figure 2 - GoPro Fusion

The camera creates video at up to $5.2 \mathrm{~K}$ resolution. The camera also records spatial audio without any additional microphone; this feature is helpful while using the video in VR, as it allows users to hear audio that is compatible with their viewing experience. The battery of the GoPro is capable of recording for around 80 minutes, at 30 or 60 frames per second (fps).

\subsubsection{Head-Mounted Display (HMD)}

Several types of Head-Mounted Displays can be used as single headsets for the VR systems. Some examples of single headsets are Oculus Rift (Figure 3a), HTC VIVE, Oculus Quest, etc. Additionally, there are many types of separated headsets that require a compatible smartphone (i.e. Google cardboard). Google cardboard is shown in Figure 3b. HMDs provide higher immersion than separated headsets with a smartphone. 


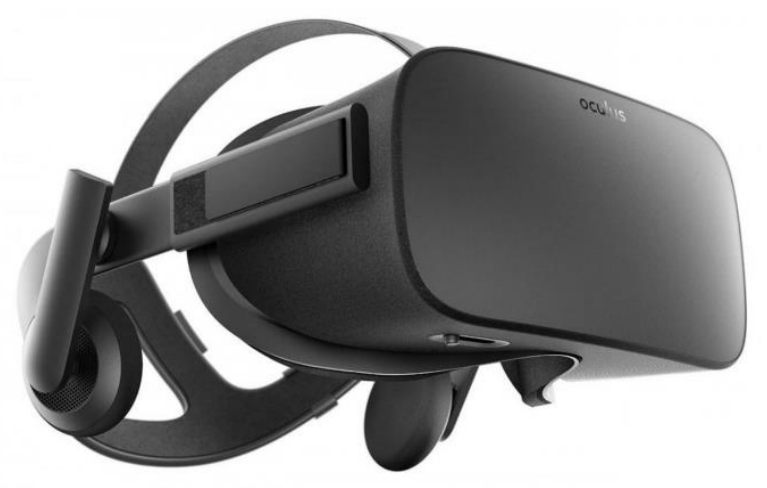

Figure 3 - a) Oculus Rift CV 1 (Niora, 2019);

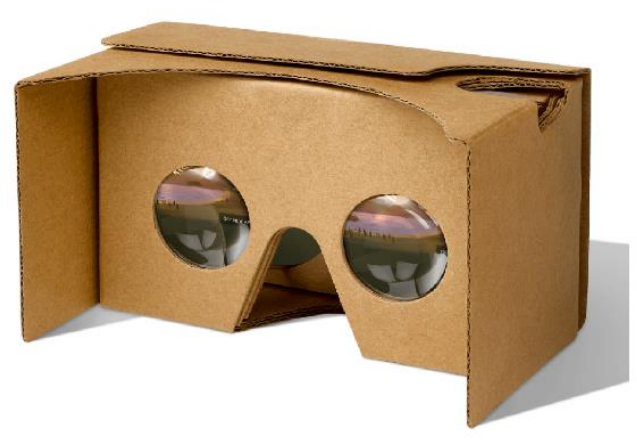

b) Google Cardboard (Google, 2019)

This research project used Oculus Rift Consumer Version (CV 1) as the hardware for the VR system. This HMD has two joysticks and two sensors. The joysticks (Figure 4a) are used to control one's position and to manipulate objects in Virtual Reality World. Sensors (Figure 4b) track the position and translate the user's movements in VR (Accessories, 2019). A PC or laptop capable of supporting the Oculus is necessary to run the Oculus Rift CV1 for VR.
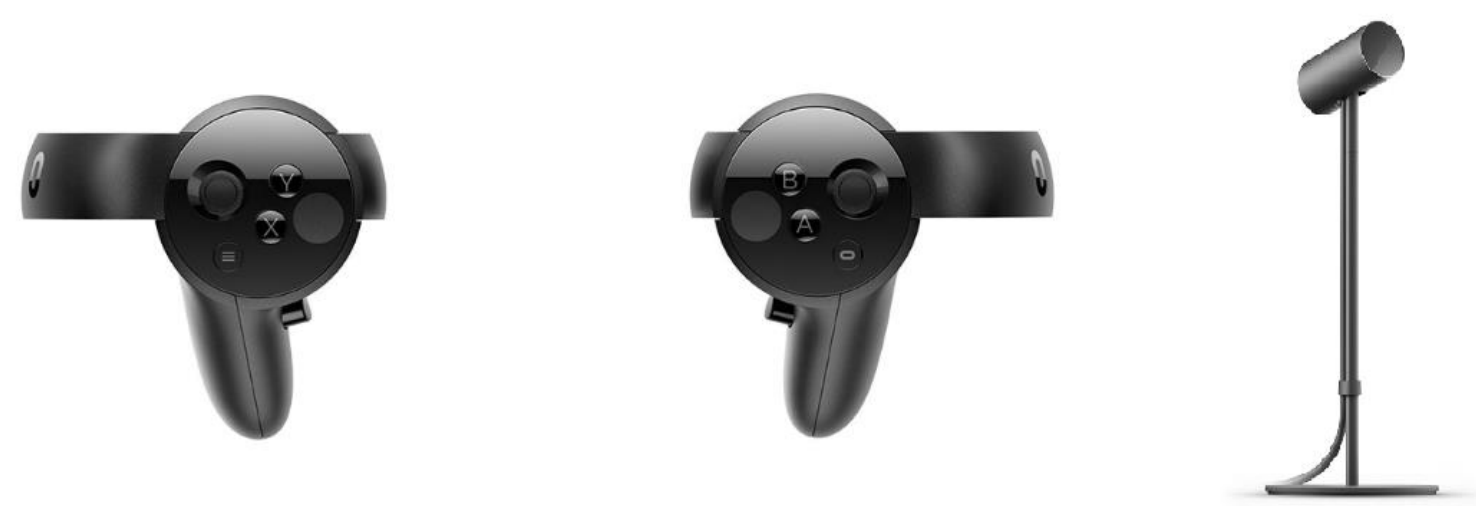

Figure 4 - a) Oculus Touch Left and Right Hand Controller (Accessories, 2019); b) Sensor for Oculus Rift (Accessories, 2019)

The requirements proposed by Oculus (Oculus, 2019) to ensure that Oculus Rift CV 1 runs properly are as follows: 
- Graphics Card: NVIDIA GTX 1050 Ti / AMD Radeon RX 470 or greater

- CPU: Intel i3-6100 / AMD Ryzen 3 1200, FX4350 or greater

- Memory: 8GB+RAM

- Video Output: Compatible HDMI 1.3 video output

- USB Ports: 1x USB 3.0 port, plus 2x USB 2.0 ports

- OS: Windows 8.1 or newer

\subsubsection{Laptop}

The laptop used in this project was an Acer Nitro 5. This laptop is compatible with the Oculus Rift and therefore Virtual Reality. This laptop, presented in Figure 5, is a low-end gaming laptop with the following configuration:

- Processor: Intel Core i5-8300H;

- Graphics card: NVIDIA GeForce GTX 1050ti;

- Memory: 8G DDR4 RAM / 256GB SSD;

- 15.6 Inch FHD (1920 x 1080) resolution;

- Windows 10 Home.

As such, this laptop meets the minimum requirements and also has an "Oculus ready" label from the manufacturer (Acer, 2019). 


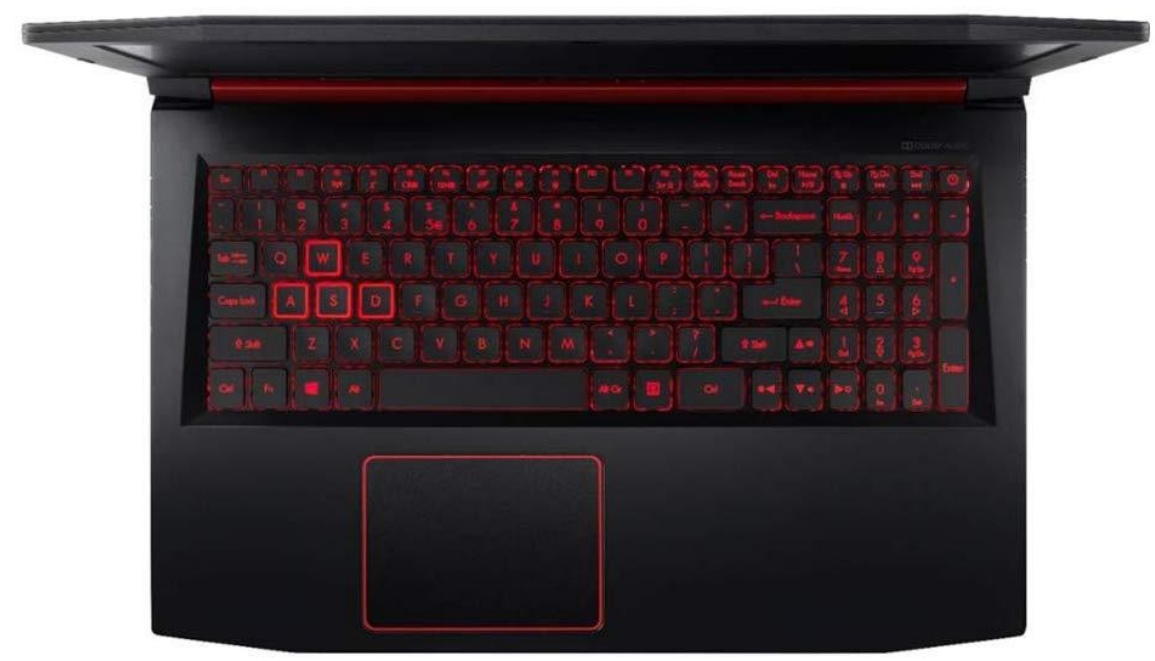

Figure 5 - Acer Nitro 5 (Acer, 2019)

\subsubsection{Miscellaneous Components}

Apart from the main equipment, there are some other components that assisted in the process of gathering materials for this study. These components were camera tripods, camera mounts, and SD memory cards.

Camera tripods were used to mount the camera at the necessary height. For capturing images, which were used in the process of creating the virtual tours of the machines, the camera was placed on a tripod at around 6 feet from the ground. The height of the tripod was chosen to imitate the user's viewpoint; in other words, the user's "eyes" would be in a similar position as it would be in reality while standing in front of the machine. The tripod used in this project is presented in Figure 6. 


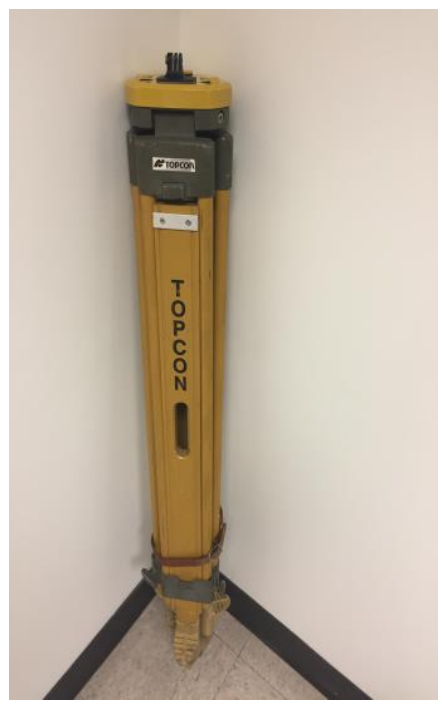

Figure 6 - Tripod

Various types of camera mounts (Figure 7) established connections between the camera and a tripod or helmet. All mounts were easily able to stick to the tripod.

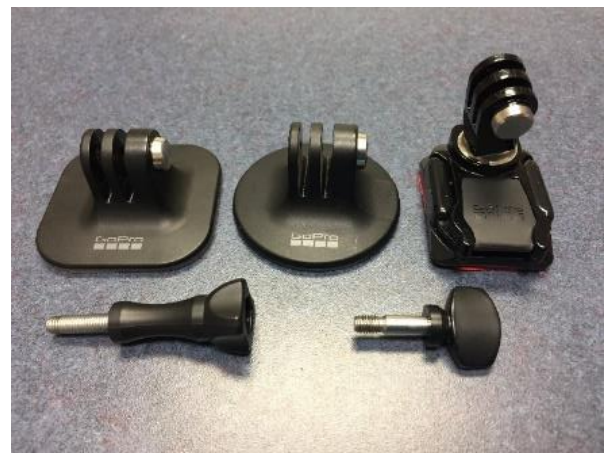

Figure 7 - Camera Mounts

The GoPro Fusion camera required 2 SD memory cards to store images and videos. The location of the memory cards (SD1 and SD2) is presented in Figure 8. 


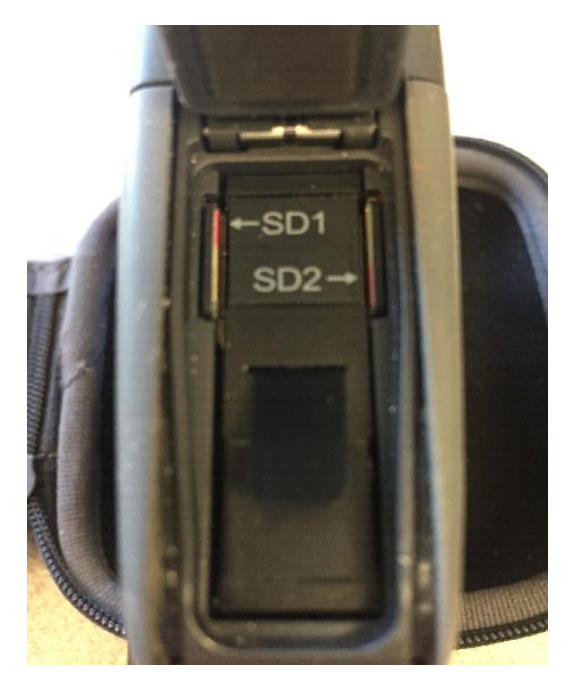

Figure 8 - SD Memory Cards

\subsection{Software requirements}

Software that was used in the phases of creating, editing, and developing the training content were as follows:

- GoPro Fusion Studio

- Unity 3D

- Additional Software

\subsubsection{GoPro Fusion Studio App}

The GoPro Fusion Studio App software, presented in Figure 9, was used to stitch the images and videos captured with the GoPro Fusion camera. This software allows one to stitch and render spherical images and videos, adjust colors, load content from the folder directly from the camera, and set footage stabilization (GoPro, 2019). As stated in section 2.3.1, the camera creates two images or videos simultaneously_ one with the front lens and one with the back lens. Both images 
and videos are imported into the software. After a few easy steps, the process creates a 360-degree image or video. This panoramic image or video can then be edited, compressed, imported, and used in the Computer-Based Task-Training and VR application.

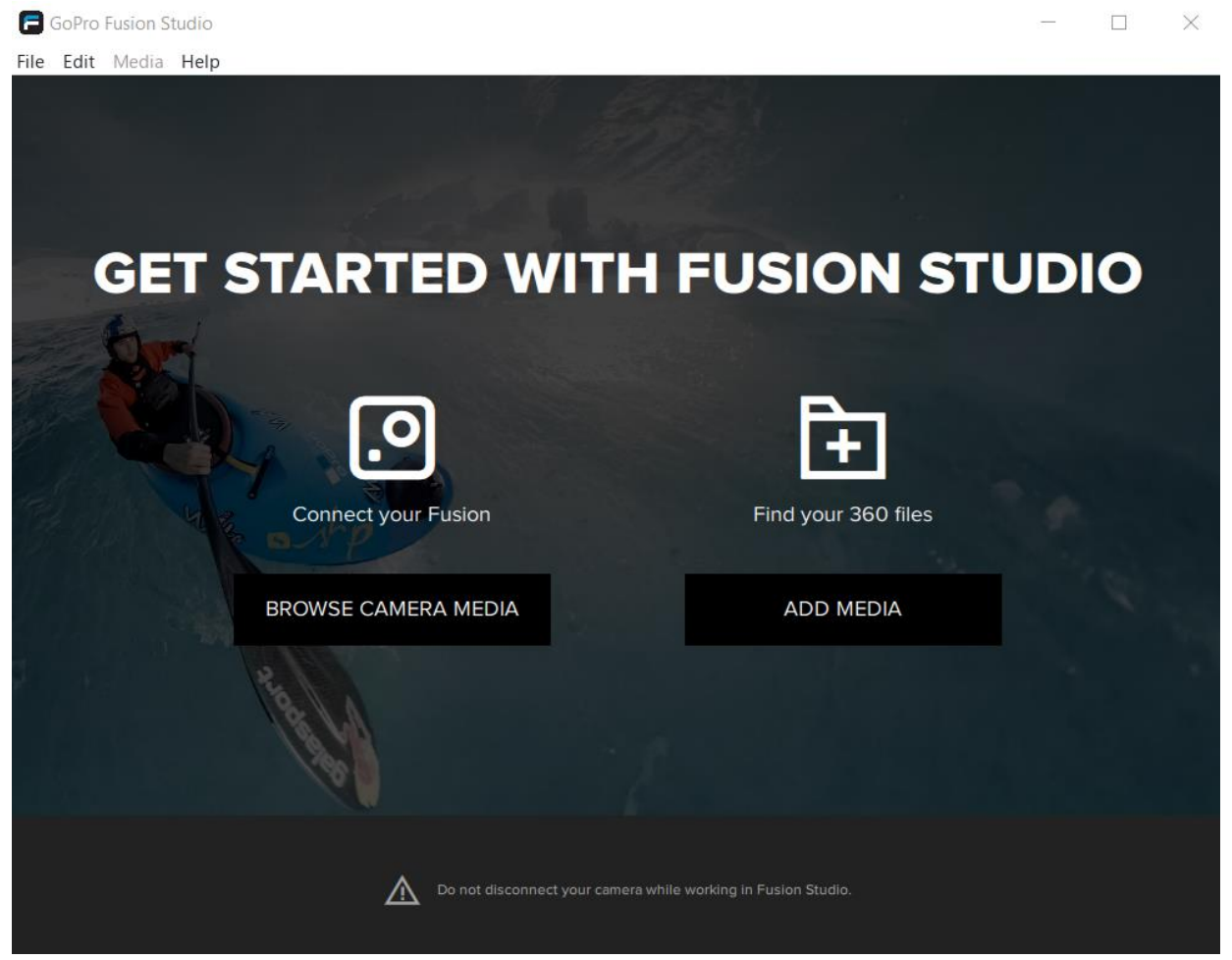

Figure 9 - GoPro Fusion Studio

\subsubsection{Unity 3D}

With the increasing popularity of video games, the Unity3D software has become one of the most popular game engines (Haas, 2014). Unity3D is a free software and game development tool. In addition to Unity $3 \mathrm{D}$, there are other game engines that could be used for this project, such as "Unreal Engine" and "Game Maker". However, as described by Christopoulou and Xinogalos (2017), Unity3D is considered suitable for beginners due to its "simpler user interface" and many instructional videos and examples. Also, Unity has a vast amount of different assets, some of which 
are free, and some of which must be purchased. These assets can be found on the Unity Asset Store.

Unity's game engine allows one to build games and applications that can be run as a desktop or VR versions of the same application (Wang et al., 2010). In addition, developments in portable VR hardware were followed up by the evolution and popularization of game engines (software used to develop VR applications and games) that are more accessible and user-friendly (Christopoulou and Xinogalos, 2017). This research project used an asset from the Unity Asset Store called "Mobile VR Tour 360". This asset was modified to meet the requirements of the research project. The Unity Asset Store also has another asset titled "Oculus Integration" which, after installation, allows the use of the Oculus Rift CV 1 Head-Mounted Display; this feature has also been used in this research project. The Unity3D version used for creating the VR application in this research was 2018.3.8f1.

\subsubsection{Additional Software}

For creating and improving training materials and software, some additional pieces of software have been used. Among these software, notable mentions are as follows:

- Image editor: "Online PhotoTool", a free online image editor. For the purpose of this particular project, this tool was used for removing the tripod from the 360-degree images.

- Video editor: "OpenShot", the free video editor used for combining video recordings and sound clips.

- Video compressor: "HandBrake", a free desktop software that was used as the video compressor for this project. Videos created with the GoPro Fusion camera are large memory files that can be compressed with this software.

- Text to speech converter: "Natural Readers", an online tool that was used to convert any text into speech. 


\subsection{Content Management System (CMS)}

Open source content management systems (CMS) have become a very popular and widely used set of tools for creating, modifying, editing, and publishing the content of web-based systems (Rohilla, 2017). A CMS represents a computer application that enables content by using a central interface; this allows one to build an online computer program that is easier to use and has much more to offer than a regular website. For example, content management systems can be used for user and media management. There are two primary components of a content management system: Content Management Application (CMA) and Content Delivery Application (CDA) (Manoj and Asoke, 2016). The Content Management Application assists in creating, modifying and deleting the content. As such, a person who is managing the content (as an administrator) can create new content and organize existing content, even without having prior programming skills. The Content Delivery Application updates the website and allows its content to be utilized. Some of the advantages of the CMS are: time-saving in terms of creating the content; the possibility to create strong passwords; and themes and plugins that can be used to boost the process of creating or changing the web CMS.

Figure 10 explains the web content management system. A person who is creating and organizing the content utilizes coding skills, manipulates the database (by inserting new materials such as images, videos, sound files, and text), and uses different plugins and templates to create the website. Therefore, the application, database, and server are establishing the back-end. Such an application can then be presented in a front-end environment. Here, the term "front-end" alludes to the user interface; the visitors can only directly interact with the website to see the data, objects, and other content inserted by the content organizer. Even though front-end and back-end serve different purposes in the process of creating web applications, both should be user-friendly and 
easily accessible. After set-up, the CMS generally does not require requisite technical skills. The content manager can create, sustain, and organize the website without having coding knowledge. Such knowledge is, of course, helpful for improving the quality of the website.

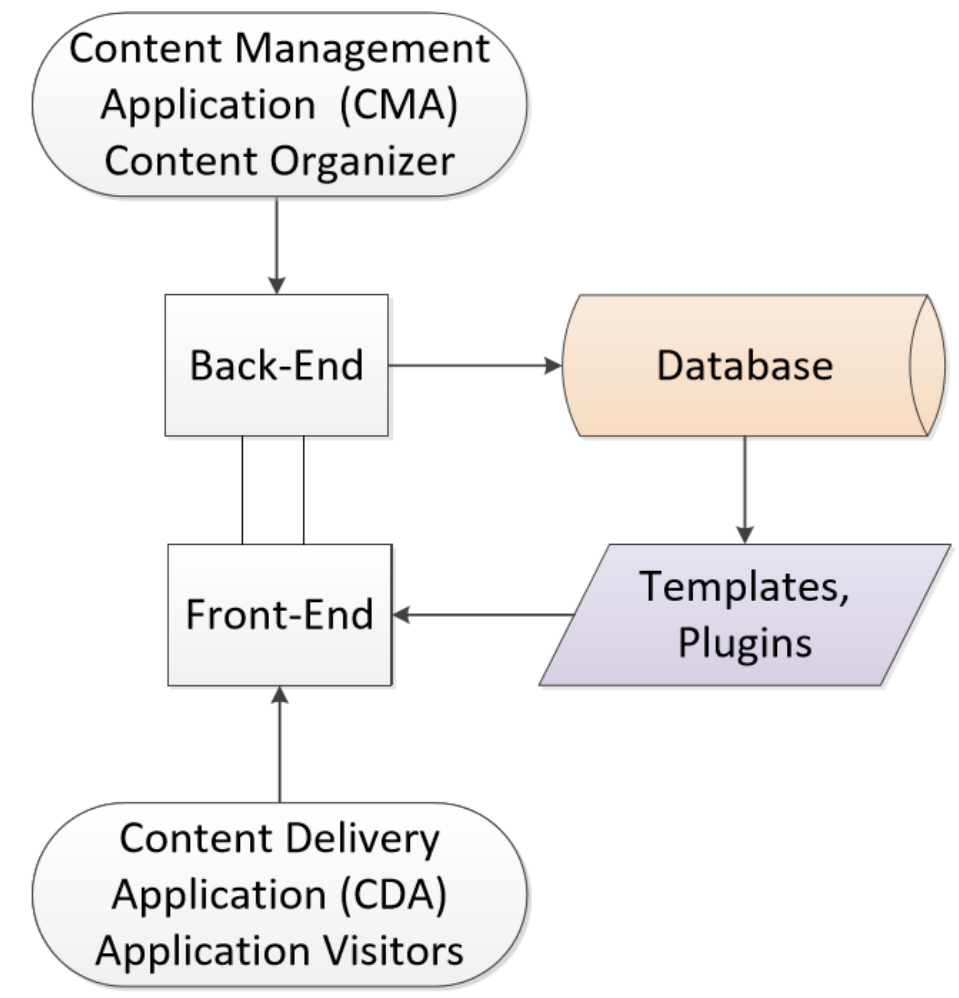

Figure 10 - Web Content Management System (Manoj and Asoke, 2016)

Today, with the high expansion of digital data and computer technology, a few open source content management systems are publicly available and can be used for creating and publishing web-based software. CMS itself offers a compressive solution for creating various types of websites and organizing their content. For example, blogging sites, portals, e-commerce sites, and enterprise websites can be developed with content management systems. Some of the currently popular CMS are WordPress, Drupal, Magento, OpenChart, Wix, and Joomla. This study chose WordPress to create the Computer-Based Task-Training application. Around a third of all websites are run on 
WordPress, which is a popular CMS with a user-friendly interface (WordPress Features, 2018). No programming experience is needed to work in WordPress. WordPress offers thousands of opensource plugins that can be utilized during the process of developing the application. By using this vast variety of plugins, WordPress offers tremendous potential for building a more efficient webbased program for the end-user. Plugins allow users to create content with ease. Insertion of the new content, application modifications, and improvements can be done not only on PCs, but also on mobile devices.

\subsection{Phase 1 - Gathering Materials}

Phase 1 began with a mine visit and information gathering from management personnel about training for heavy equipment operators. The mine provided a written document stating the requirements for the project. Additionally, training manuals for different machines were handed out. The training manuals contained information about the particular machines located at the mine site and included explanations of the guidelines for the training of the Heavy Machine Operators.

After reading the training outline in the office, the trainee traveled to the site with the instructor to be introduced to the machine. It was important for the instructor to define crucial machine parts and the procedures for performing a pre-shift inspection. This entire process was done with the full cooperation of management and the mining machine operators. Required training outlines were also provided.

The goal, as explained previously, was to develop interactive training courses and a template that will include written materials and other advanced forms of training content. As a major part of the future training, researchers needed to capture 360-degree images and videos of different machines. Those images and videos were captured using the GoPro Fusion. The required number of camera 
positions and 360-degree images were decided based on the machine type and existing training manuals. Therefore, the number of images varies based on machine dimensions and their complexities.

\subsubsection{0-degree Images - Camera Positions}

Red, blue, and yellow circles in Figure 11 mark the camera positions when capturing 360-degree images of haul-trucks. There were sixteen images taken for this machine. A photographer could capture more or fewer images depending on how much detail they wish to cover.

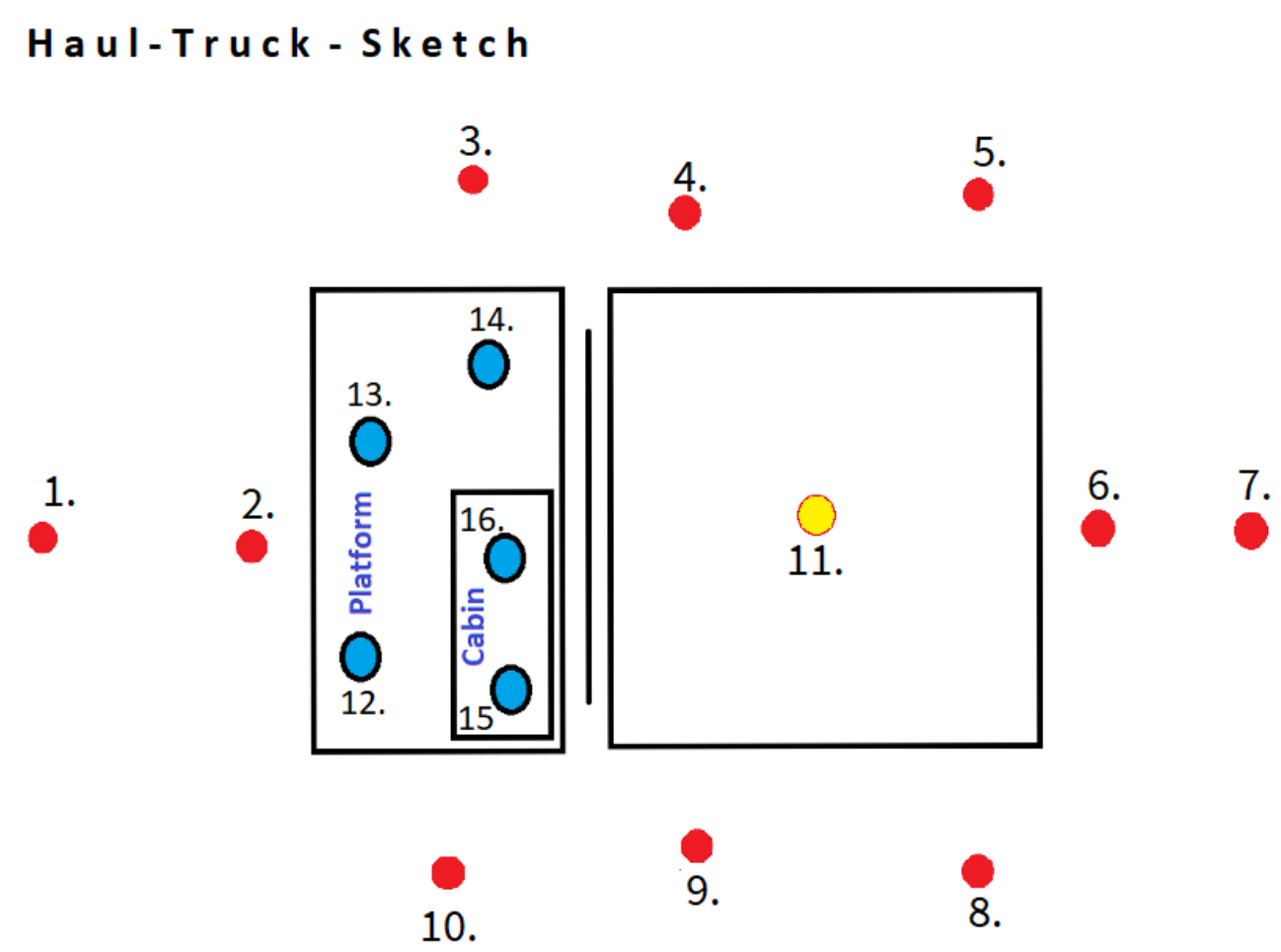

Figure 11 - Camera Positions for Haul-Trucks 
Table 1 gives a brief explanation for camera positions during the process of capturing 360-degree images of haul-trucks.

Table 1 - Camera positions for Haul-truck

\begin{tabular}{|c|c|}
\hline Position Number & Explanation \\
\hline Position 1 - Red circle & Front side of a haul-truck from a distance. \\
\hline Position 2 - Red circle & $\begin{array}{l}\text { Close look at the devices located at the front of the haul } \\
\text { truck. }\end{array}$ \\
\hline Position 3 - Red circle & $\begin{array}{l}\text { Right side of the machine with the right front tire and steps } \\
\text { for mounting the machine. }\end{array}$ \\
\hline Position 4 - Red circle & $\begin{array}{l}\text { Right side of the machine with the hydraulic tank along with } \\
\text { the front and rear tires. }\end{array}$ \\
\hline Position 5 - Red circle & Right rear side of the machine along with the right rear tire. \\
\hline Position 6 - Red circle & $\begin{array}{l}\text { Rear side of the haul-truck offering details for the rear side } \\
\text { of the machine. }\end{array}$ \\
\hline Position 7 - Red circle & $\begin{array}{l}\text { Rear side of the haul-truck; provides a view of the box and } \\
\text { tires from the distance. }\end{array}$ \\
\hline Position 8 - Red circle & $\begin{array}{l}\text { Left side of the machine; offers a closer look at the rear left } \\
\text { tire. }\end{array}$ \\
\hline Position 9 - Red circle & $\begin{array}{l}\text { Left side of the machine; gives a view of the fuel tank along } \\
\text { with the front and rear tires. }\end{array}$ \\
\hline Position 10 - Red circle & $\begin{array}{l}\text { Left side of the machine; gives a closer look at the front left } \\
\text { tire. }\end{array}$ \\
\hline Position 11 - Yellow circle & View from underneath the machine. \\
\hline Position 12 - Blue circle & Platform, in front of the cabin. \\
\hline Position 13 - Blue circle & Platform, middle. \\
\hline Position $14-$ Blue circle & Platform, fire suppression. \\
\hline Position 15 - Blue circle & Cabin, driver's seat. \\
\hline Position $16-$ Blue circle & Cabin, buddy seat. \\
\hline
\end{tabular}

Figure 12 illustrates the camera positions while capturing 360-degree images of Dozers. 


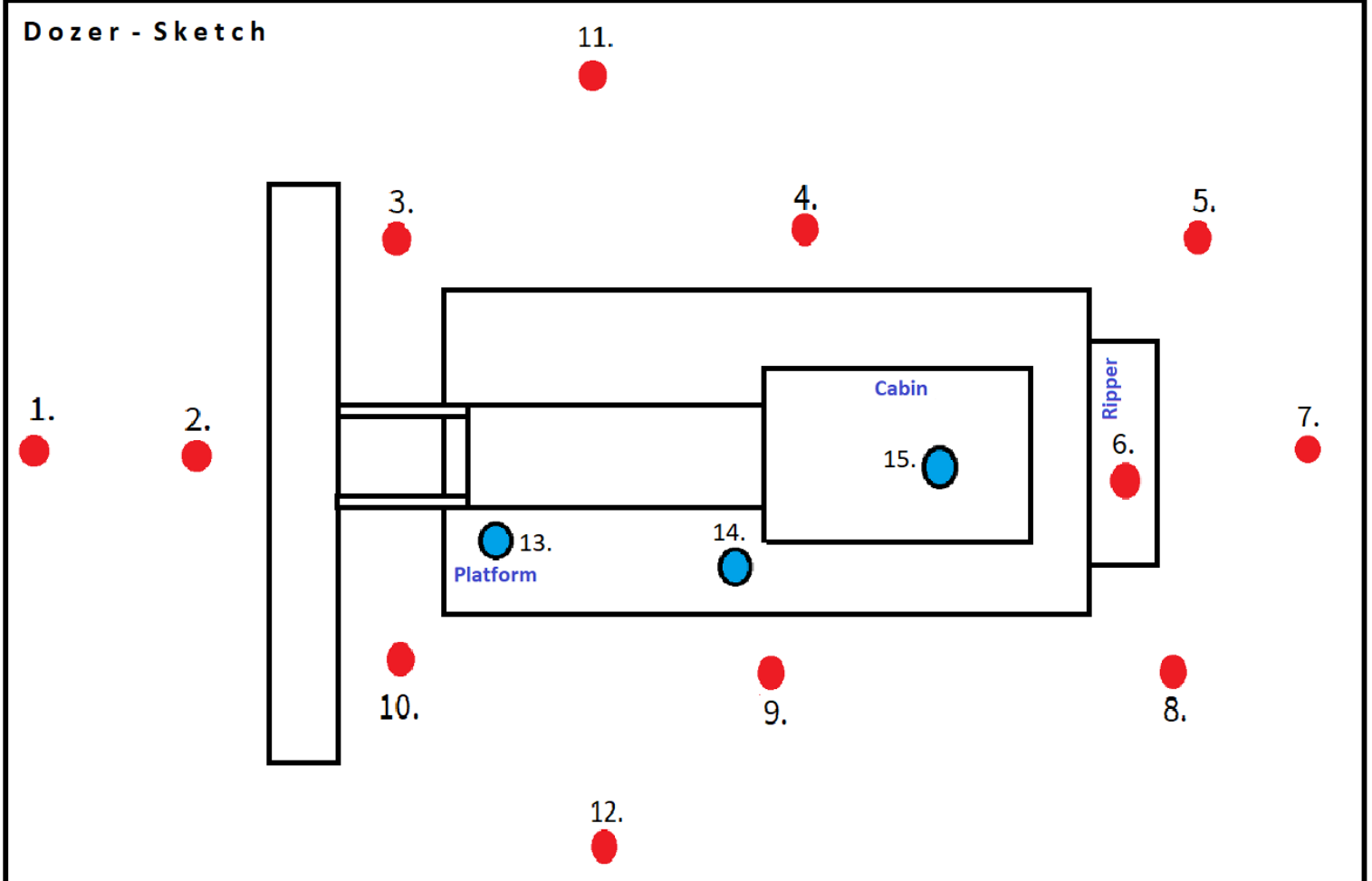

Figure 12 - Camera Positions for a Dozer

Table 2 gives a brief explanation of camera positions during the process of capturing 360 -degree images of a Dozer.

Table 2 - Camera positions for Dozer

\begin{tabular}{|c|l|}
\hline Position Number & \multicolumn{1}{c|}{ Explanation } \\
\hline Position 1-Red circle & Front side of a dozer from a distance. \\
\hline Position 2 - Red circle & $\begin{array}{l}\text { Closer look at the devices located at the front of a dozer } \\
\text { blade. }\end{array}$ \\
\hline Position 3- Red circle & $\begin{array}{l}\text { Right side of the machine with the lift cylinder, plus rear } \\
\text { side of the blade. }\end{array}$ \\
\hline Position 4-Red circle & Right side of the machine. \\
\hline Position 5 - Red circle & Rear right side of the machine with the ripper. \\
\hline Position 6-Red circle & $\begin{array}{l}\text { Ripper platform, where the different hydraulic hoses are } \\
\text { located. }\end{array}$ \\
\hline
\end{tabular}




\begin{tabular}{|c|l|}
\hline Position $7-$ Red circle & Rear side of the machine with the ripper. \\
\hline Position 8 - Red circle & Rear left side of the machine with the ripper. \\
\hline Position $9-$ Red circle & Left side of the machine. \\
\hline Position $10-$ Red circle & $\begin{array}{l}\text { Left side of the machine with the lift cylinder, plus rear side } \\
\text { of the blade. }\end{array}$ \\
\hline Position $11-$ Red circle & Right side of the machine with a far look on the machine. \\
\hline Position $12-$ Red circle & Left side of the machine with a far look on the machine. \\
\hline Position $13-$ Blue circle & Fire suppression trigger. \\
\hline Position $14-$ Blue circle & Dozer platform with a look at the engine compartment. \\
\hline Position 15- Blue circle & Dozer cabin. \\
\hline
\end{tabular}

Figure 13 illustrates the camera positions for capturing 360-degree images of scraper.

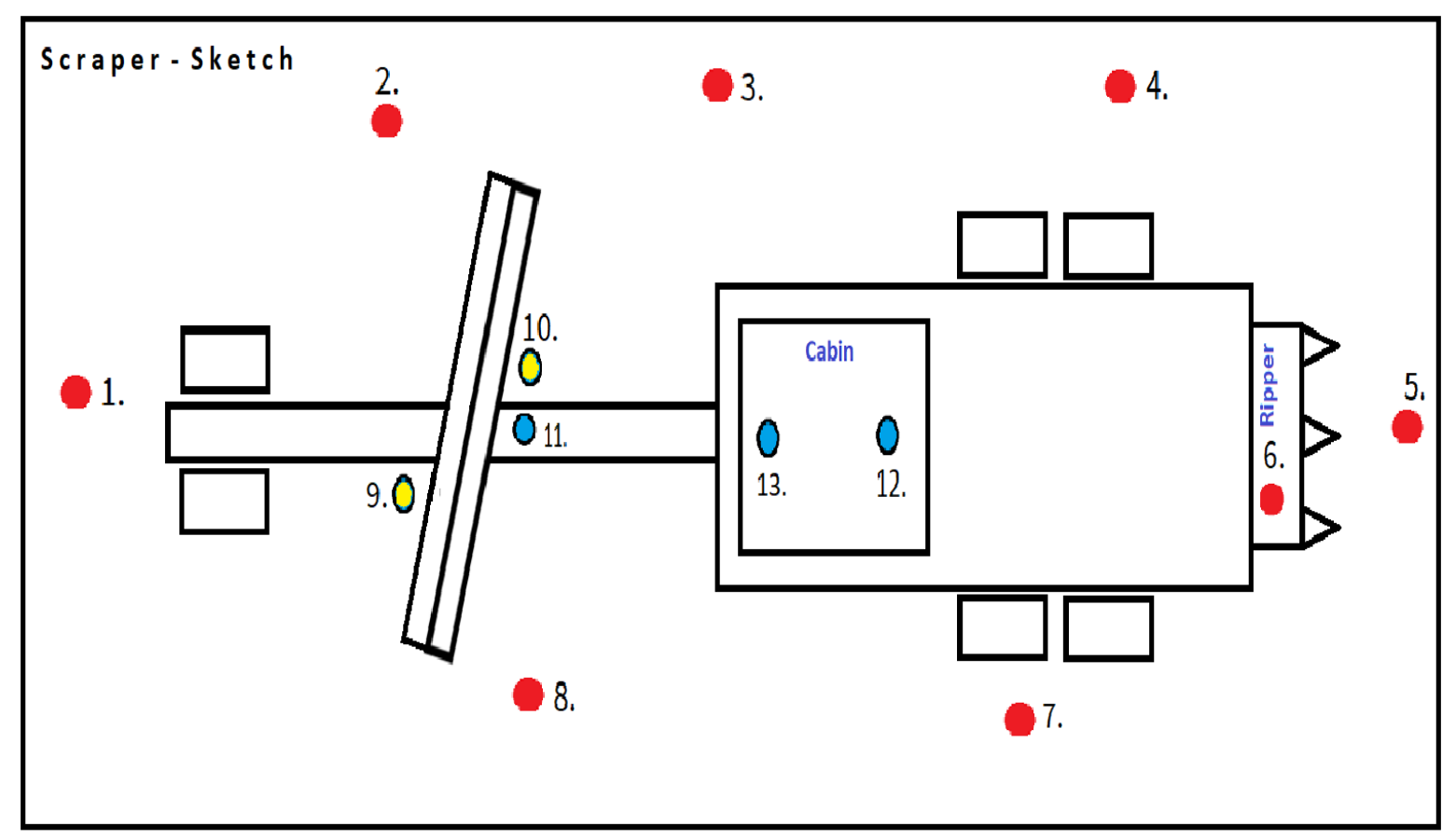

Figure 13 - Camera Positions for a Scraper 
Table 3 gives a brief explanation of camera positions while capturing 360-degree images of the scraper.

Table 3 - Camera positions for Scraper

\begin{tabular}{|c|l|}
\hline Position Number & \multicolumn{1}{|c|}{ Explanation } \\
\hline Position 1 - Red circle & Front side of a scraper. \\
\hline Position $2-$ Red circle & Right side of a scraper, along with the blade. \\
\hline Position $3-$ Red circle & Right side of the machine with the cabin. \\
\hline Position $4-$ Red circle & $\begin{array}{l}\text { Rear right side of the machine with the engine compartment } \\
\text { and ripper. }\end{array}$ \\
\hline Position $5-$ Red circle & Rear side of the machine with the ripper. \\
\hline Position $6-$ Red circle & Ripper platform with different hydraulic hoses. \\
\hline Position $7-$ Red circle & Left side of the machine with the ripper. \\
\hline Position $8-$ Red circle & Left side of the machine with the blade and cabin. \\
\hline Position $9-$ Yellow circle & Left side of the machine close to the blade. \\
\hline Position 10 - Yellow circle & Right side of the machine close to the blade. \\
\hline Position 11 - Blue circle & Circle platform above the blade. \\
\hline Position 12 - Blue circle & Cabin, driver's seat. \\
\hline Position 13- Blue circle & Cabin, floor in front of the seat. \\
\hline
\end{tabular}

As noted from the information in these tables, all machines share some camera positions that are similar to one another-for example, the front and rear sides of the machine, the left and right sides of the machine, and the cabin. However, the number of panoramic (360-degree) images varies based on the type of machine. After capturing the images, GoPro Fusion Studio software was used to process the images. As stated earlier, GoPro Fusion captures two 2D images with one shot (one with the front lens and one with the back lens). Figure 14 presents an example of the two separate images. The camera automatically assigns an image pair with the same image numbers; next, the 
software GoPro Fusion Studio stitched those two images together to produce one 360-degree image.

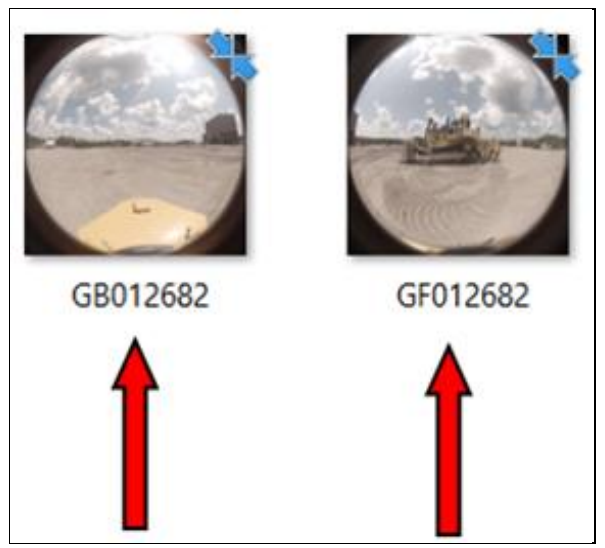

Figure 14 - GoPro Fusion Images

Furthermore, image processing (Figure 15) involved stitching together images, removing the tripod from the scene, and finally compressing those images. Figure 15(a) shows a pair of images to be stitched. Figure 15(b) shows a rendered image, while the Figure 15(c) shows the image after the tripod was removed. The brushing tool from the free online software "PhotoTool" was used to remove the tripod from the image. Though this step was not necessary, it was done so to improve the environment in the image and the sense of immersion for the trainee. Removing the tripod produces a higher-quality image, causes less motion sickness, and creates more immersion into a VR world. 


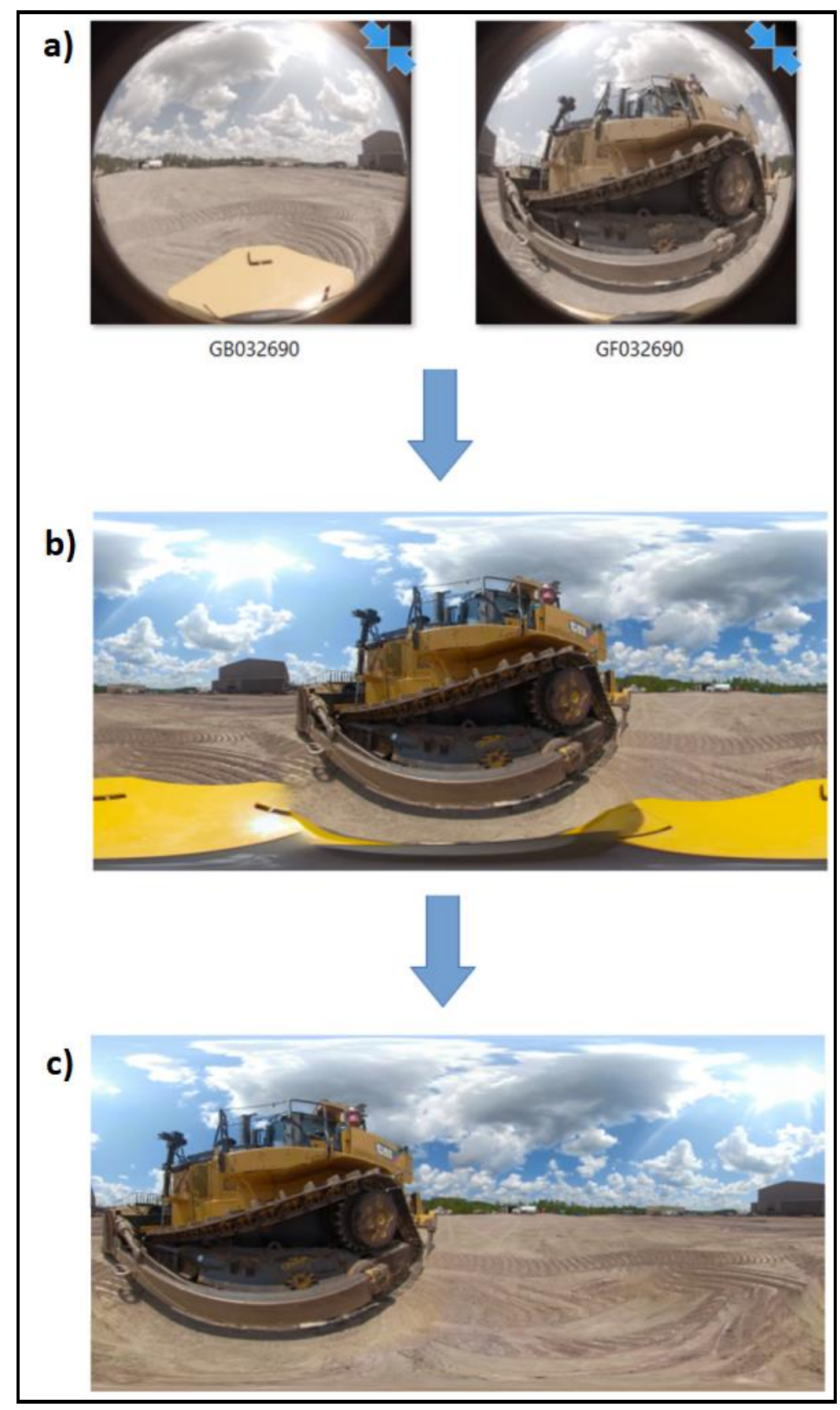

Figure 15 - Image Processing; a) Two images to be stitched; b) 360-degree image; c) Removed tripod 
In addition to taking 360-degree images, regular 2D images were taken with a mobile phone camera to show the details of important machine parts. These 2D images were real images, not computer models, showing parts such as cabin joysticks, buttons, commands, etc. Also, images of actual machine problems (tire issues, leaks, accumulations, etc.) were captured and presented. Such 2D images were included in virtual tours; as such, a trainee can see more minute details of the machine. This will help the trainee to better understand what potentially can be expected (as shown in Figure 16) during pre-shift inspections, as well as while operating the machine.

In addition to images, voice information was included while constructing the virtual tour. The training manual contains explanations for important parts involved in inspections, such as tires, rims, hoses, cylinders, struts, etc. Manuals also provide crucial information about cabin parts, joysticks, and buttons. That written information was optimized and converted into an audio format by using an online text to speech converter. The virtual tour in this study used the online software "Natural Readers" to accomplish this conversion. The audio files, in mp3 format, were then inserted into the CBTT.

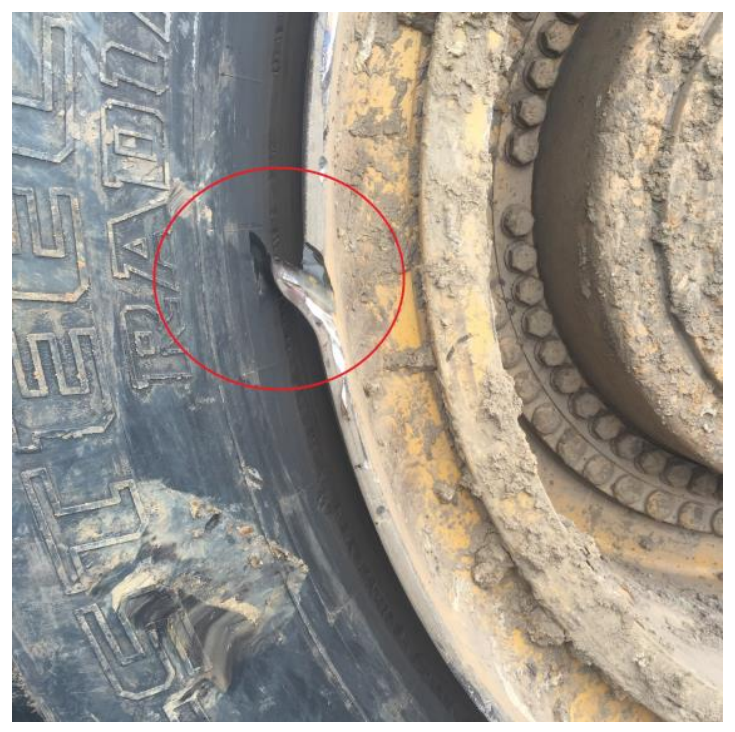

Figure 16 - Tire Problem 


\subsubsection{0-degree Videos}

Technological advancements in cameras have affected the area of film-making and introduced the possibility of recording 360-degree videos to professionals, semi-professionals, and even amateur videographers. Nowadays, platforms such as YouTube and Facebook support 360-degree video formats; it is also possible to watch 360-degree videos on several devices, such as smartphones and tablets. 360-degree video can also be used within VR to attempt to reach new heights of full immersion.

As stated earlier, the camera used in this research project can capture both videos and images. 360degree videos can be either static (placing the camera in a stationary position) or moving (having the camera move while shooting video). Those two types of 360-degree videos, as stated by Van den Broeck et al. (2017), are called moving viewport (MVP) and static viewport (SVP). Broeck et al. also stated that although videos with moving viewports provide an overall better viewing experience and are more engaging, they might have issues when it comes to smooth video transitions. This problem arises especially when using the HMD with full immersion, as scene transitions can often happen unexpectedly and cause physical distress to viewers.

In this research project, both MVP and SVP videos were recorded. Both videos recorded for training purposes were taken with the help of experienced HEOs. For shooting the walk-around inspection videos, the operator was first asked to conduct a pre-shift inspection in the same way they would perform it every day. While the video was recording, the operator was providing explanations of their actions during pre-shift inspections. This video was recorded in one piece (as one video) to mitigate the earlier mentioned obstacle with video transitions. Therefore, no video transitions were included. 
The MVP videos for walk-around inspections were created by mounting the camera on an employee's hard-hat, as shown in Figure 17. The camera was mounted in a way that provided a solid connection between the plastic helmet and the camera. The GoPro Fusion Studio software was then used to edit and render the 360-degree videos. This software offers two types of stabilization options: "Anti Shake" and "Full Stabilization". In the process of creating the MVP videos, the "Anti Shake" option was selected, as this will keep the general direction and movements of the camera while reducing the video's overall shakiness. These videos will allow the trainee to have the same viewpoint as the operators while they were performing pre-shift inspections.
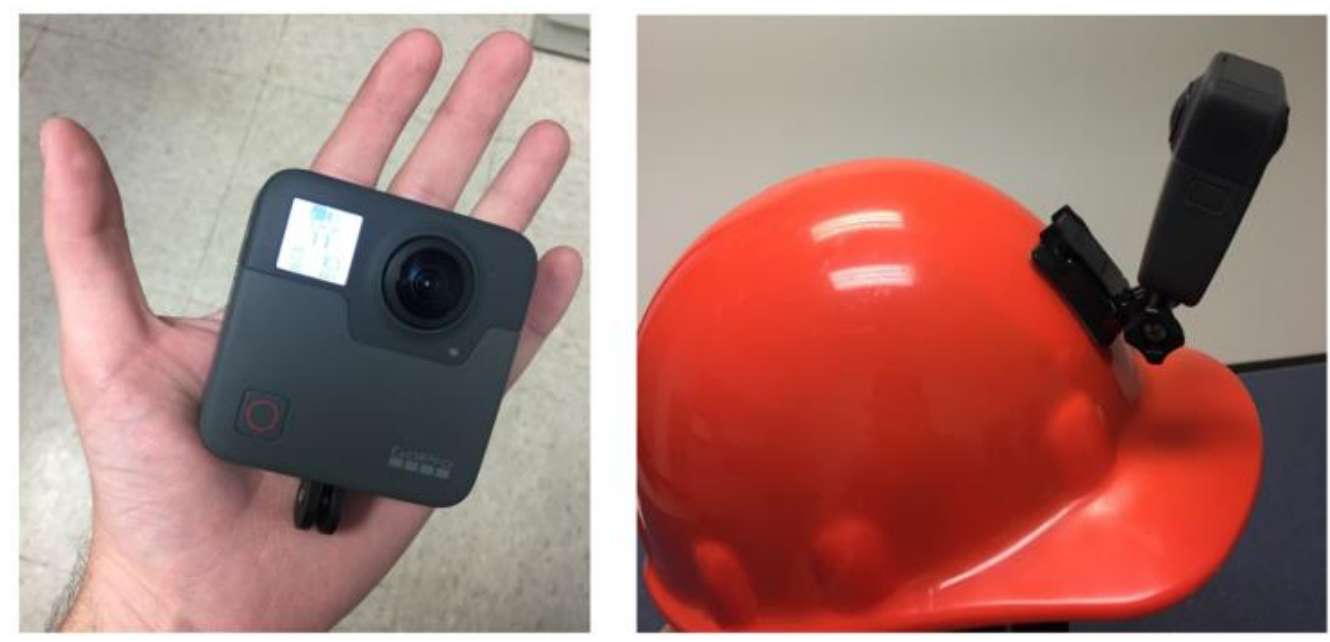

Figure 17 - Camera and Hard-hat

The screenshots of the video inspection for the haul-truck are shown in Figure 18. 

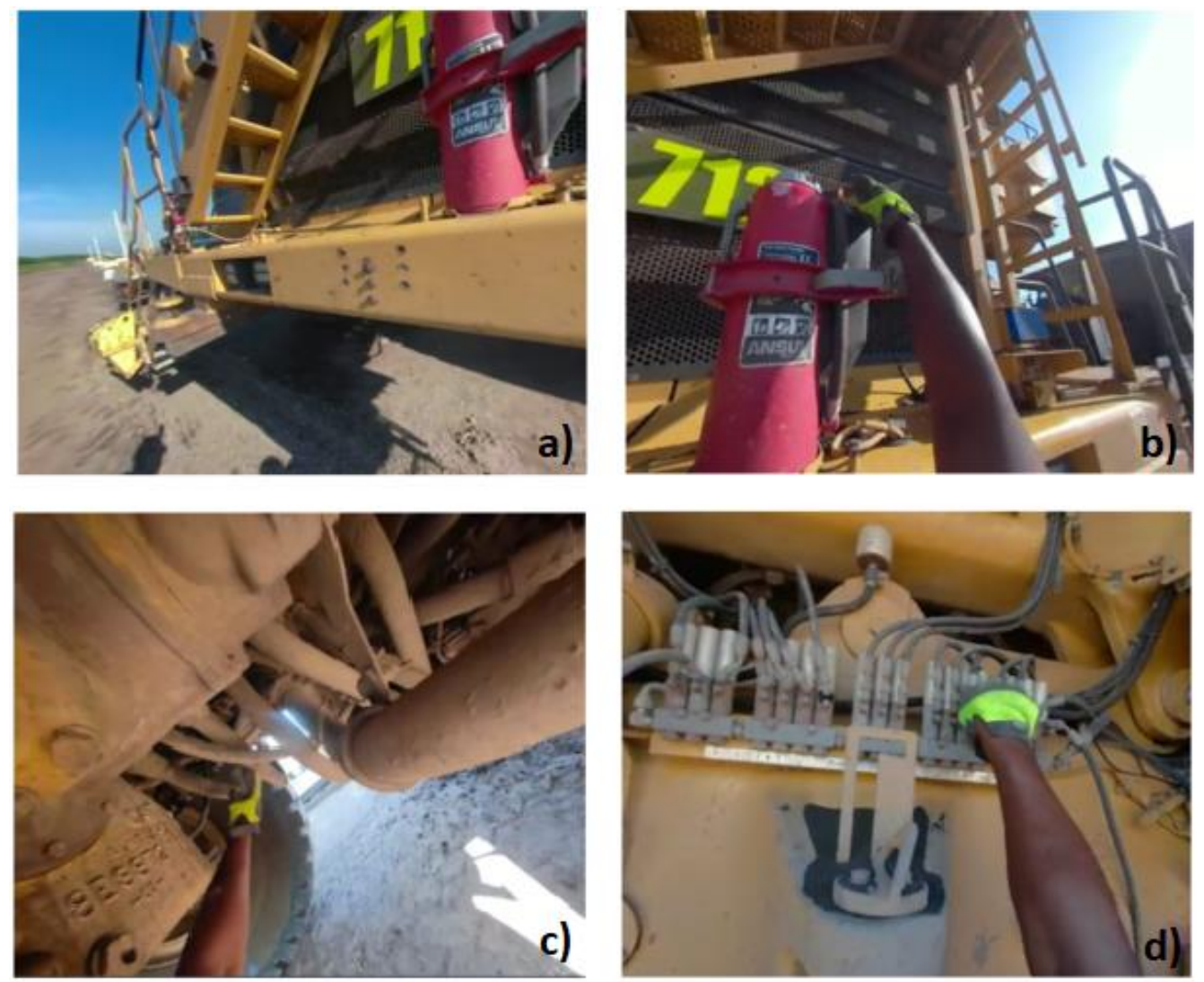

Figure 18 - Video Screenshots. a) Approaching the truck; b) Fire extinguisher check; c) Under the haul-truck; d) Rear side of the Haul-truck

The static viewport videos were created inside the cabin of the machine. The primary goal of the SVP videos was to record the operation of that particular machine. This video will also be helpful for the future operators, as it will provide an inside perspective on the operation of the machine. The camera was placed on the right window (for haul-trucks and scrapers) and on the rear glass (for dozers), as presented in Figures 19 and 20. As stated before, the second stabilization method offered by the GoPro is "Full Stabilization". This method will lock the orientation of the camera and remove all movements; as such, this option was used for rendering SVP videos, where no movement of the camera was necessary. Voice information was added into these static 360-degree videos, explaining what tasks the operator was performing while operating a machine; the voice 
clips were incorporated by using the earlier mentioned software, "Natural Readers" and "OpenShot". For example, in one of the videos for the truck, the processes of loading, dumping, and driving a haul-truck are explained by the voiceover.
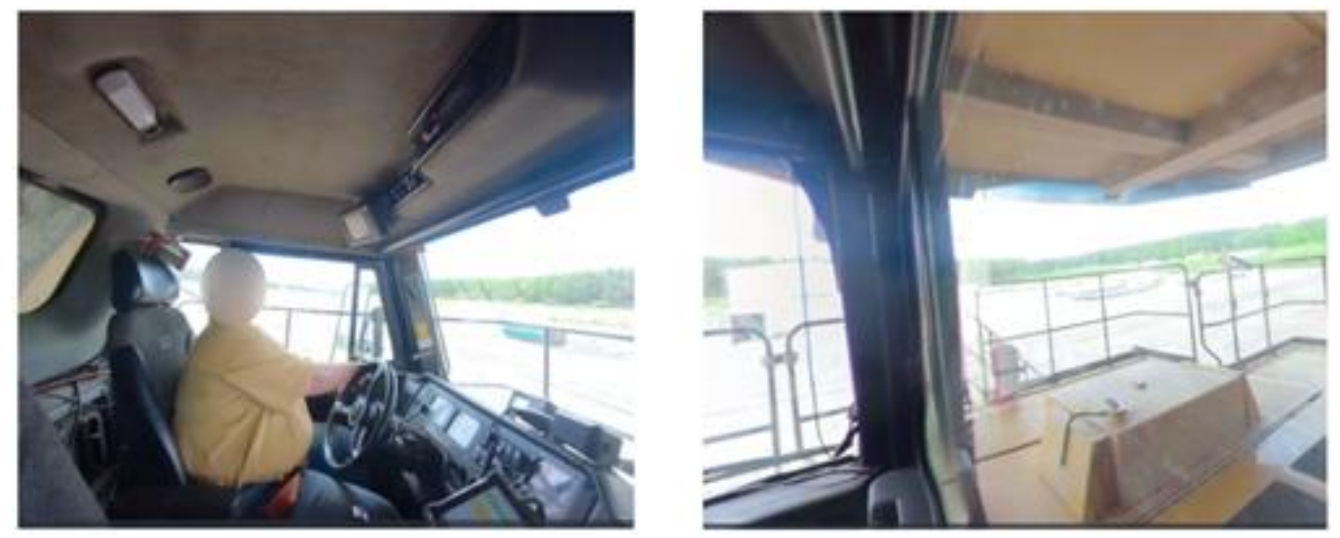

Figure 19 - Camera Position for SVP Videos for Haul-trucks
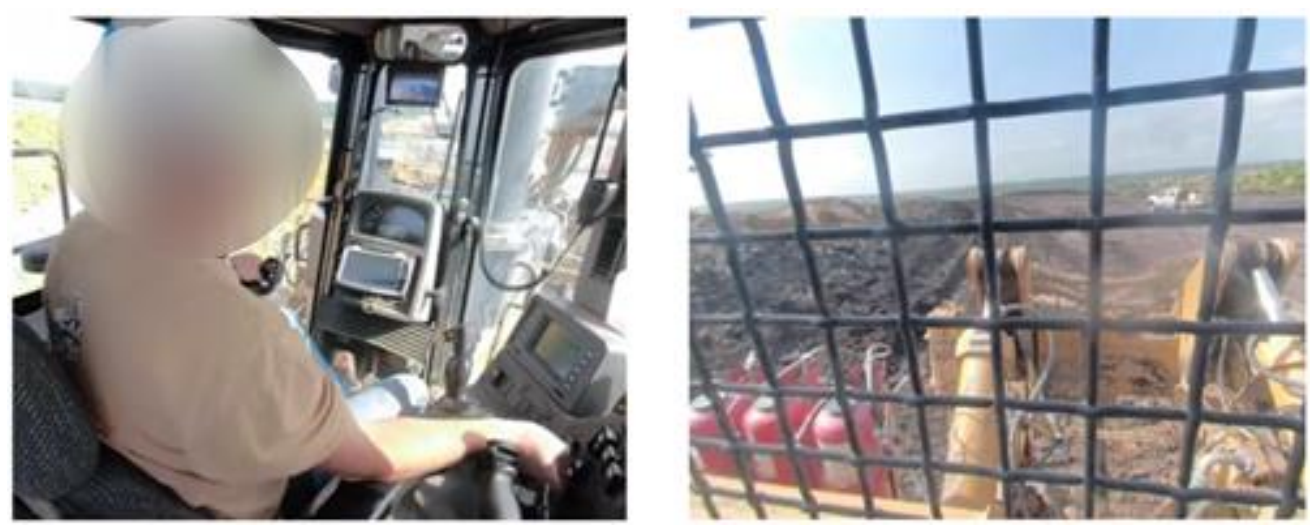

Figure 20 - Camera Position for SVP Videos for Dozers

In summary, gathering materials was the first phase in the process of developing CBTT. The 360degree images and videos, 2D images, and sounds were created first. Those images were then edited and included in the Computer-Based Task-Training program. 
Material gathered during Phase 1 has been used in order to develop the software in both Phase 2 and Phase 3. Since the purpose of the project was to consider both Computer-Based Task-Training and Virtual Reality application, these two separate products were developed simultaneously while gathering the materials. Computer-Based Task-Training software, developed with WordPress, is an online non-immersive training tool. On the other hand, the Virtual Reality application can be both a fully immersive VR environment and a desktop non-immersive application.

In the next chapters, both of these developments will be explained separately, as they were built using different tools and processes; consequently, this means that both can be used independently from each other.

\subsection{Phase 2 - Computer-Based Task-Training (CBTT)}

Computer-Based Task-Training was developed using the open-source and free content management system (CMS) WordPress ${ }^{\mathrm{TM}}$, as explained earlier in chapter 2.5.

The new Computer-Based Task-Training consists of three main training parts, which are also the main training objectives:

- Proper walk-around inspection;

- Proper pre-operational cabin inspection; and

- Proper start, shut down, and emergency procedures.

A trainee should demonstrate their understanding of those main objectives at the end of the training to ensure that they are properly trained in these tasks prior to going out in the field. 
The first objective of training concerns walk-around inspection, one of the most important responsibilities of all heavy equipment operators. This inspection, during which the HEO should inspect various machine parts, will help maintain not only the safety of the operator but also the safety of other people who work at the mine site. Some machine parts to be inspected during this process are tires, fire suppression system, fire extinguishers, leaks, mechanical defects, etc.

The second objective of training involves pre-operational cabin inspection, which is a part of preshift inspection and will serve to secure a safe cabin environment. For instance, during cabin inspection, an operator should check the functionality of the cabin's seatbelt, horn, steering, brakes, glass, and other cabin parts to maintain safe operation of the machine.

The third main objective addresses the procedures for proper start and shut down, as well as for emergency events to be followed in specific cases. For example, operators must be aware that when certain machine parts are not functioning (such as the horn or seatbelt), they must stop operating the machine entirely.

Such problems noticed during pre-shift machine inspections require fast response. Figure 21 illustrates the safety checklist that should be filled out by an operator before every shift starts. As shown in the figure, there are several problems which require immediate shutdown or attention. For instance, if the seat belt, back-up alarm, horn, fire extinguisher, or park and service brake are not operational, an immediate shutdown of the machine is required. 


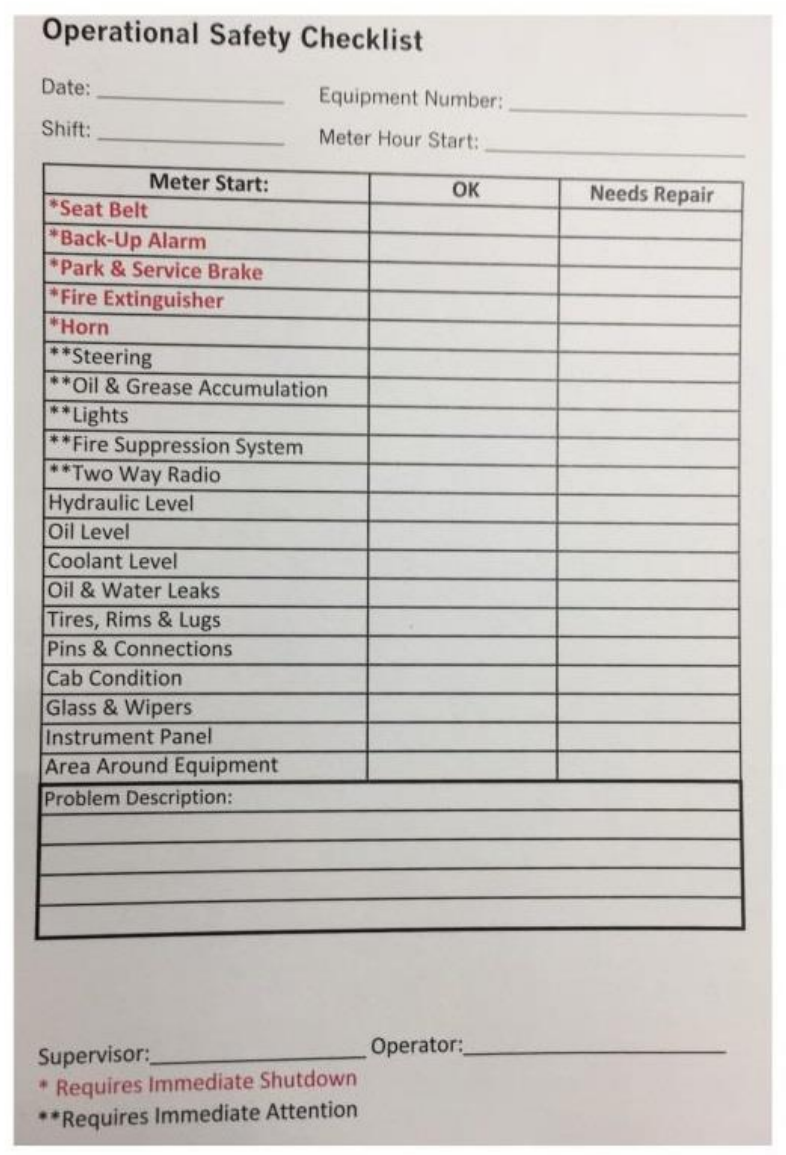

Figure 21 - Safety Checklist

\subsubsection{Training Flowchart and Objectives}

Before beginning the development of the Computer-Based Task-Training application, it was important to create a draft of the overall concept of the CBTT. Figure 22 shows the flowchart describing the various components of the Computer-Based Task-Training. After running the software, a trainee will first choose a mine location, then the training course for the particular machine. The option for choosing the mine location is useful if there are multiple mine sites within the same company which work independently but share the same types of machines. Each training course has three separate sets of instruction: (1) Walk-around Inspection; (2) Pre-operational Cabin Inspection; and (3) Proper start, shutdown and emergency procedures. These three sets of 
instruction address different topics of the pre-shift inspection and contain further, more detailed steps, all of which a trainee should complete in order to meet the three main learning objectives (Instructions 1, 2, and 3).

Each set of instruction consists of four steps, each of which describes the aforementioned instructions in closer detail. The first three steps are presented in a combination of textual and voice information, as well as $2 \mathrm{D}$ images. The fourth step in each set of instructions is the 360 degree non-immersive virtual tour and 360-degree non-immersive video. During the 360-degree virtual tour, a trainee is able to control the interactive virtual environment developed with 360 degree images, and they can investigate the machine by navigating through the scenes with the mouse and keyboard. Similarly, with the 360-degree video, a trainee is able to watch an experienced operator of heavy equipment performing a pre-shift inspection and equipment operation, controlling the video with the mouse and keyboard. Each main instruction consists of four parts, as given in Table 4 . 


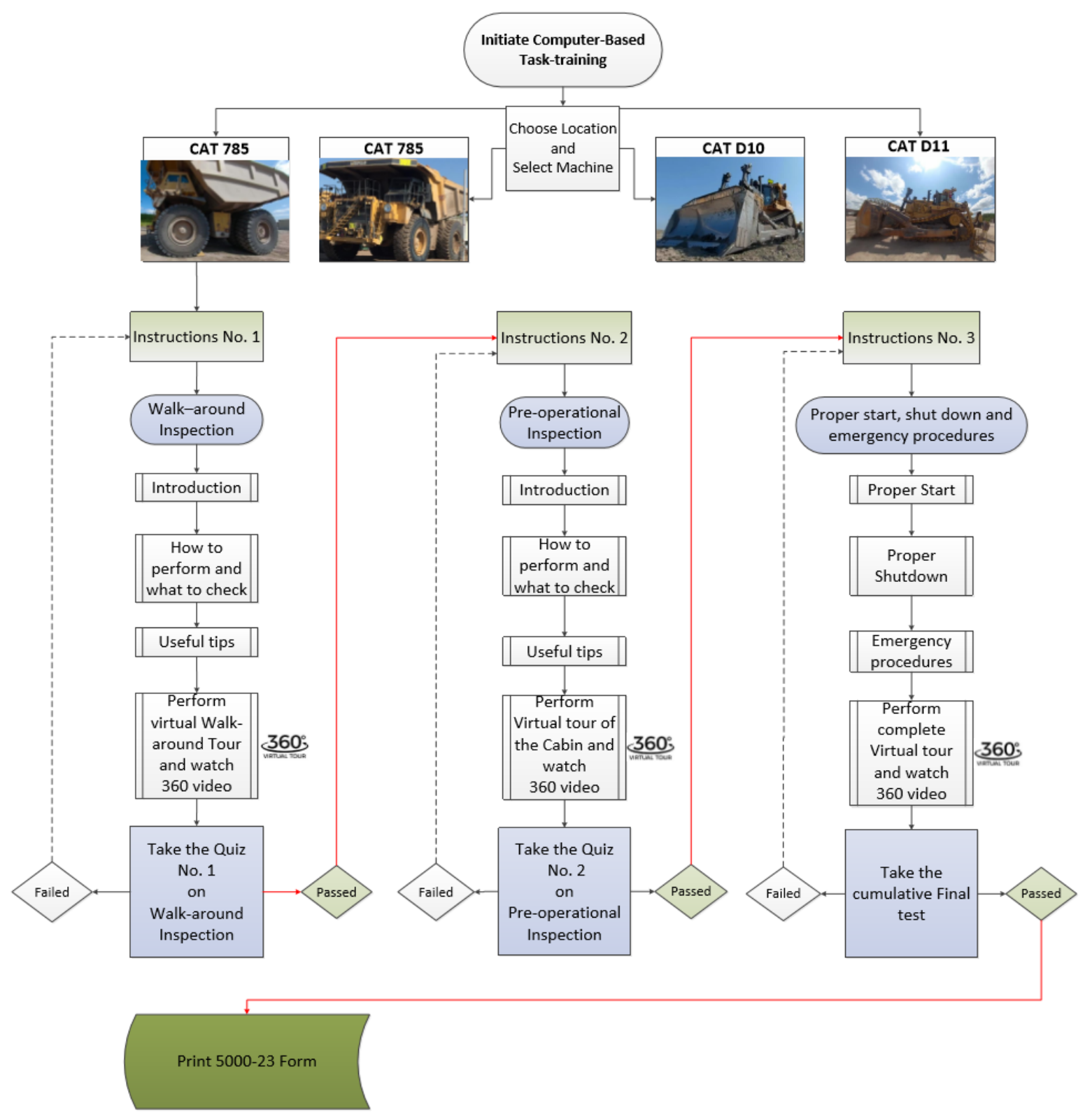

Figure 22 - Computer-Based Task-Training 
Table 4 - Main Training Objectives

\begin{tabular}{|c|c|c|c|}
\hline $\begin{array}{c}\text { Main } \\
\text { objectives }\end{array}$ & $\begin{array}{c}\text { Proper walk-around } \\
\text { inspection }\end{array}$ & $\begin{array}{c}\text { Proper pre- } \\
\text { operational cabin } \\
\text { inspection }\end{array}$ & $\begin{array}{c}\text { Proper start, shut down, } \\
\text { and emergency } \\
\text { procedures }\end{array}$ \\
\hline Part 1 & Introduction & Introduction & Proper start \\
\hline Part 2 & $\begin{array}{c}\text { How to perform and } \\
\text { what to check }\end{array}$ & $\begin{array}{c}\text { How to perform and } \\
\text { what to check }\end{array}$ & Proper shutdown \\
\hline Part 3 & Useful tips & Useful tips & Emergency procedures \\
\hline Part 4 & $\begin{array}{c}360 \text {-degree virtual } \\
\text { walk-around tour and }\end{array}$ & 360-degree virtual & 360-degree complete \\
& 360-degree video & degree video & virtual tour and 360-degree \\
& & & videos \\
\hline
\end{tabular}

At the end of each of the three sets of instruction (main objectives), trainees take a knowledge assessment quiz in order to assess their understanding of the information covered during that set of instruction. The number of questions for each quiz are derived from the training manual and from consultations with the mine personnel. Each of the quizzes that relate to Instruction No. 1 and Instruction No. 2 consist of four multiple choice questions. The final test, which is given at the end of Instruction No. 3, consists of eight questions. To pass each quiz, a trainee has to answer all questions correctly. If a trainee does not pass a quiz, they must go through the set of instructions related to that quiz again, retaking the quiz upon completion. After passing a quiz, the trainee is able to move on to further instruction; for example, after a trainee has successfully completed the knowledge assessment quiz about the first set of instructions (proper walk-around inspection), they 
can proceed to the second set of instructions (proper pre-operational cabin inspection). The same applies for proceeding from the second set of instruction to the third. Although trainees may take each quiz as many times as they need to, a maximum number of allowed attempts may be set.

\subsubsection{Permission Levels and User Roles}

Permission levels and user roles can be customized based on the needs of the Computer-Based Task-Training software and software users. A software can have one or more registered users. If the application is to be managed by multiple people, not every user should be authorized for full application control. As such, it is important to assign the users with certain roles so that every user knows their rights and permissions, as well as what changes to the application they can or cannot make. WordPress offers the ability to assign several levels of authorization to each user, increasing the overall security of the web application.

One of WordPress's most important features is the permission and current user Application Programming Interfaces (API). These features are a set of functions which verify the user's permissions to prevent unauthorized users from accessing the application. In addition, it prevents the execution of tasks beyond a user's permitted duties.

The three permission levels for users and their roles, which have been proposed in the ComputerBased Task-Training web application, are as follows:

- Administrator role;

- Editor role; and

- Trainee role.

The administrator role has the highest level of authority among all users. The administrator, who regulates the CBTT, can monitor the complete dashboard and fully control both back-end and 
front-end content. Thus, an administrator can make core changes related to coding, install new plugins, or delete existing ones. The administrator is also able to assign or change user's roles. Figure 23 illustrates the administrator's dashboard within WordPress.

The editor role is second to the administrator in authority, with a partial permission level. The editor can insert new content, create new training courses from the template, and modify an existing course. However, an editor cannot make essential application changes, such as coding. Figure 24 illustrates the editor's dashboard within WordPress.

Of all three user roles, a trainee has the lowest permission level. Thus, a trainee is only a visitor, lacking any authority to make changes to the content of the web application, courses, plugins, and code. A trainee is also not allowed to create a new course; they can only take an existing one. Figure 25 illustrates the trainee's dashboard within WordPress.

There is a noticeable difference in a dashboard screen depending on the user role to which it is linked. The "richest" dashboard is for administrators, then for editors, and finally for trainees. In the next chapters, the training template and the process of creating the new training course will be explained from the editor's perspective (Figure 24). 


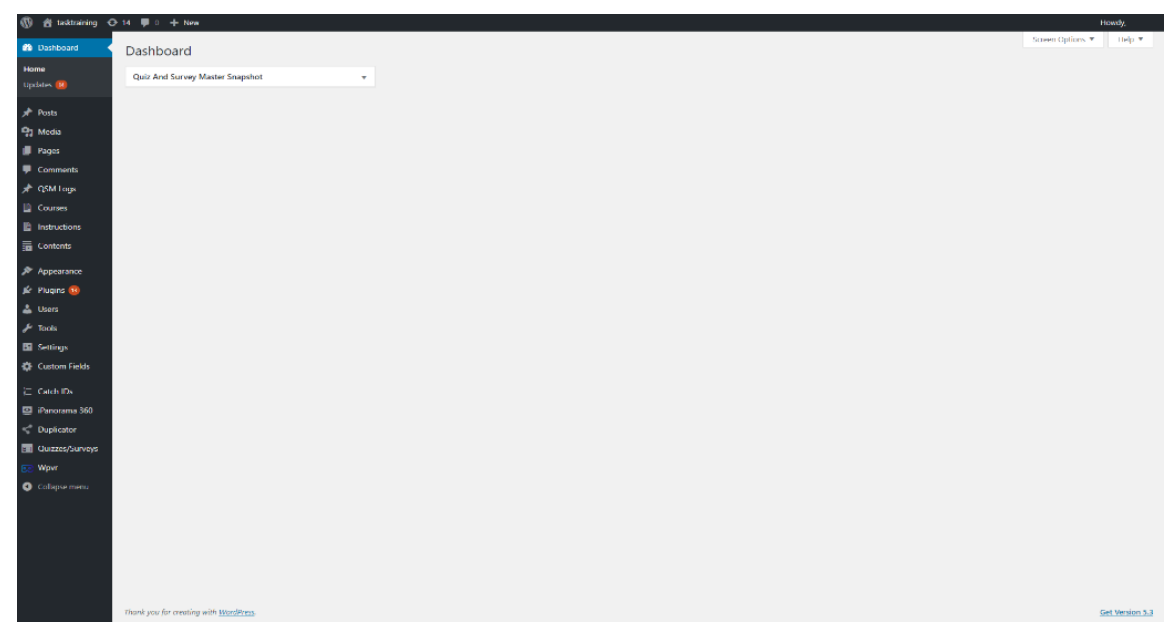

Figure 23 - Administrator Dashboard

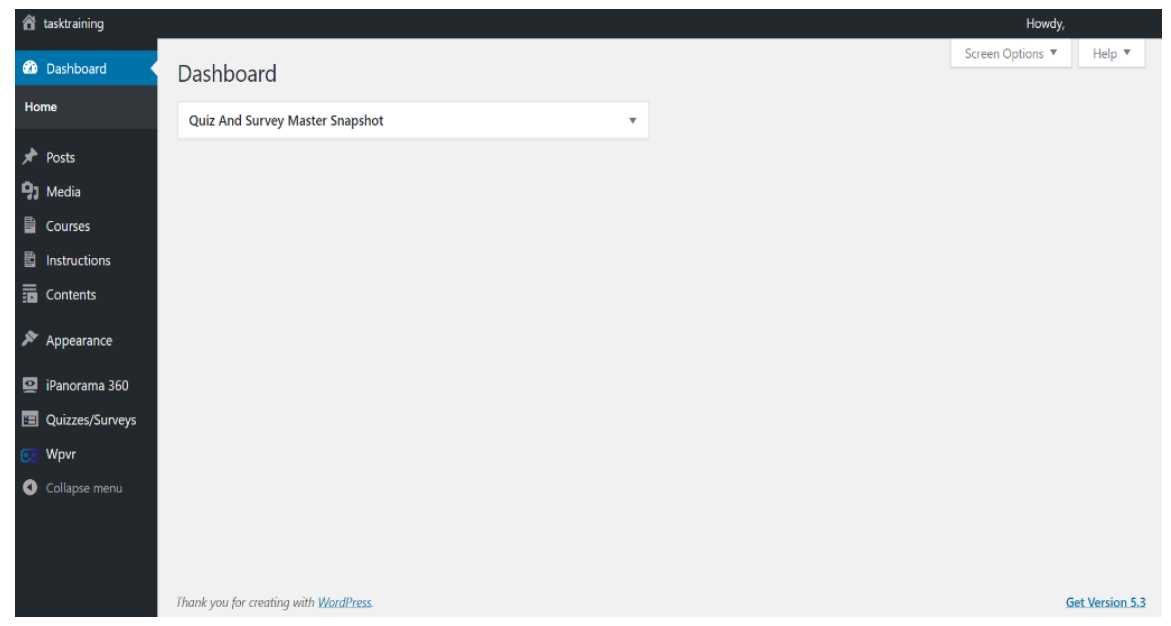

Figure 24 - Editor Dashboard

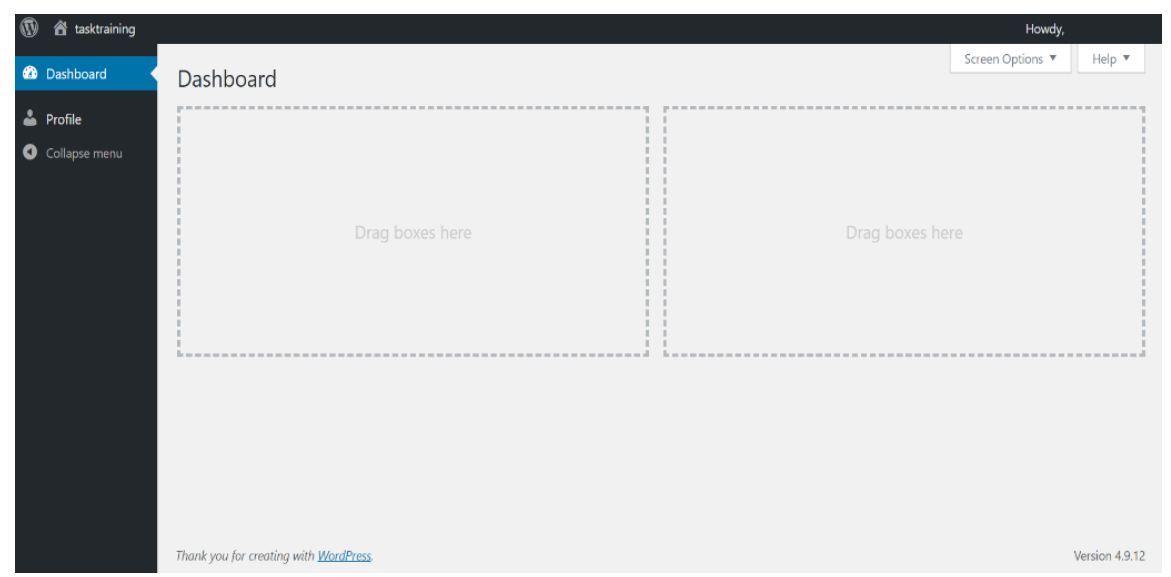

Figure 25 - Trainee Dashboard 


\subsubsection{Development}

During the process of developing the template for the Computer-Based Task-Training and creating the training courses for different machines, several design options were considered. As stated earlier, WordPress offers thousands of different plugins that can be installed and used for different purposes on the web-based application. Among those, several plugins that fit the project purposes were identified and selected as suitable tools for the development of the new CBTT. Other menu options were developed manually. As a result, the main menu of the editor's dashboard consists of nine options, which are given in Figure 26. All of these nine menu options are used in the process of creating a new training course for desired mining machines.

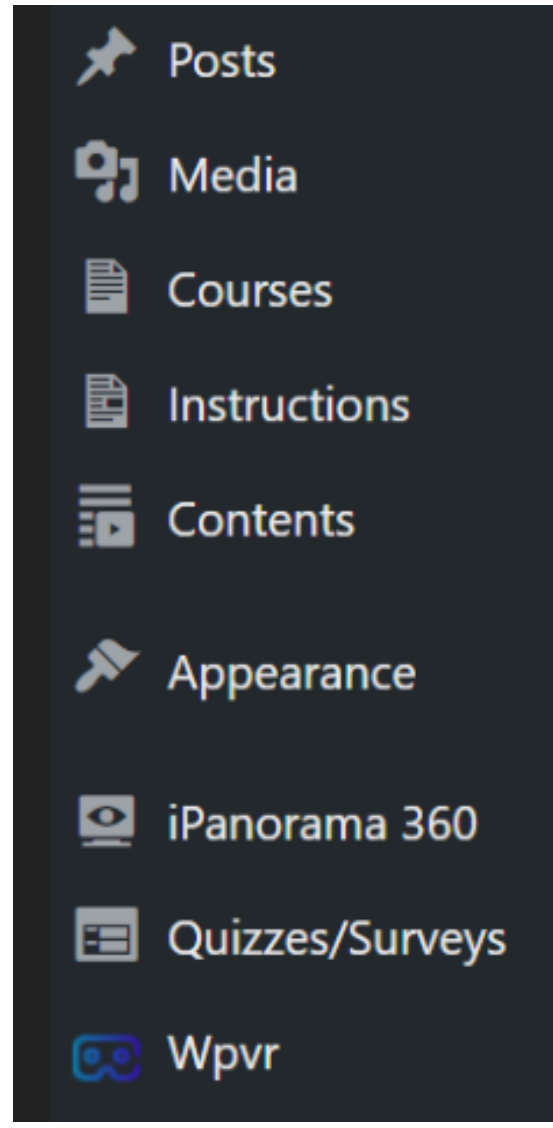

Figure 26 - CBTT - Main Menu Options 


\subsubsection{Implemented Plugins}

The three major plugins used for creating the training courses with the earlier gathered images and videos, as well as for creating the knowledge assessment quizzes, are listed and explained below:

- “iPanorama 360";

- "Quizzes/Surveys Master"; and

- "Wpvr".

Plugin iPanorama 360 (Figure 27) is the virtual tour creator that is relatively easy to use without high-level programming knowledge. Aside from building the 360-degrees virtual tours, the plugin allows for additional coding improvements, such as a simple tracking system that allows the user to be aware of what positions were visited while performing a virtual tour. Another improvement of this plugin was made by allowing voice information to be inserted and played while executing the virtual tour of the machine. In addition, a new theme for Virtual Tours was created to improve the user's experience.

\section{으 iPanorama 360}

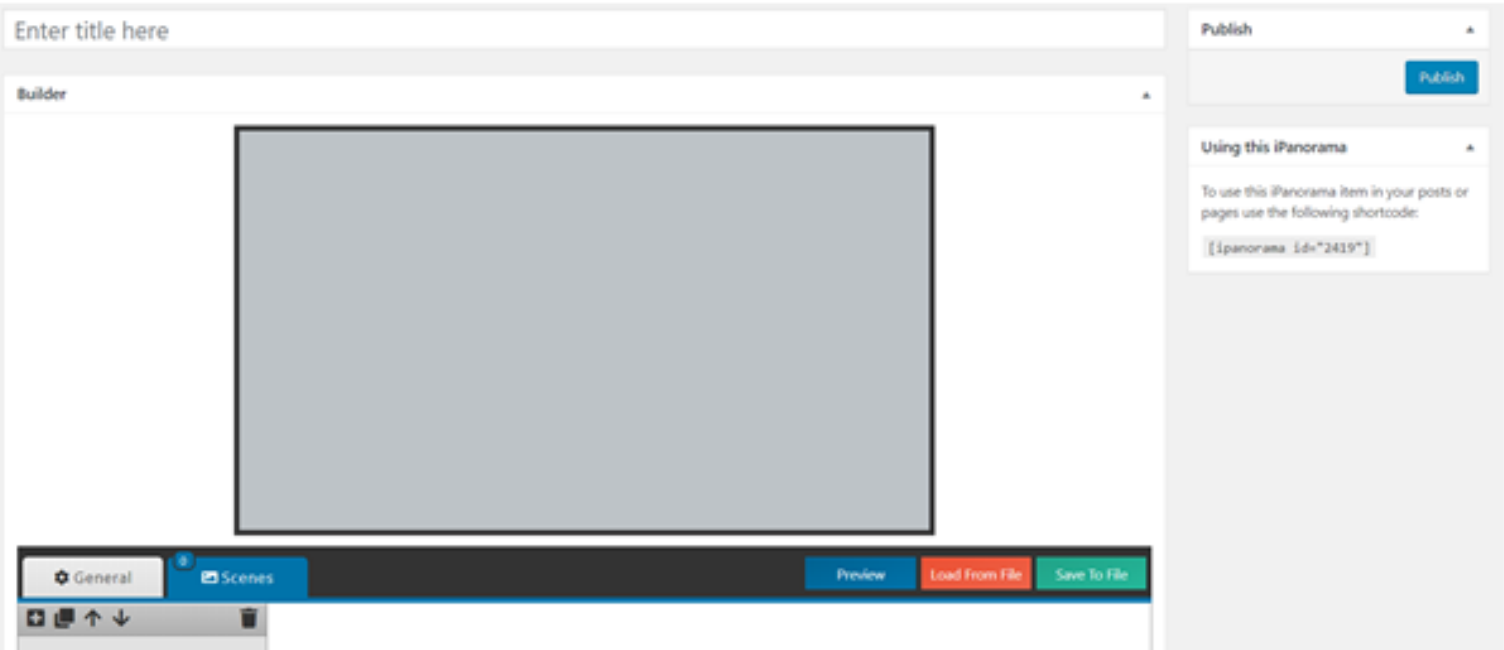

Figure 27 - Plugin for Creating Virtual Tours - iPanorama 360 
The key functionality of a Virtual Tour is the navigation of 360-degree images by clicking on special buttons, allowing the user to change their position by transferring from one scene to another. Several scene "types" can be used with spherical or 2D images; in this project, two scene types, Sphere for 360-degree images and Cube for 2D images, were used to develop Virtual Tours. In the sphere scene type, a 360-degree image is wrapped all around the inner side of the sphere, while the Cube type has six sides where maximum of six different 2D images could be inserted. While 360-degree image is presented in a sphere, the scene type cube was used to show characteristic details such as joysticks, commands, and possible machine problems.

Additional features of the iPanorama 360 plugin are mouse wheel zoom, thumbnails for desired scenes, auto play or auto rotate, etc. (iPanorama 360, 2018).

The Quizzes and Surveys Master (QSM) plugin was used for assessing trainee knowledge and comprehension during a training course (Figure 28). This plugin allows for the simple creation of quizzes with different types of questions. Question types that were used in these quizzes include multiple choice, true or false, and multiple response questions. The plugin also allows text customization and inserting images that can accompany text questions. The number of questions in each quiz can also be changed at any time by an editor or administrator. 


\section{E Quizzes/Surveys}

\section{Create New Quiz Or Survey}

Name

Figure 28 - Plugin for Creating a New Quiz

The QSM plugin can also directly send quiz results by email to notify the trainer about a trainee's performance. The quizzes were graded by the trainer on a points-based system. All questions and quiz results were stored within the QSM database (Quiz Master, 2018).

Like the 360-degree images, which were used for creating virtual tours, 360-degree videos were also inserted into the CBTT. The Wpvr plugin was used to play these 360-degree videos. The Wpvr plugin allows for the simple insertion and publishing of a video in a developed web-based application, presented in Figure 29.

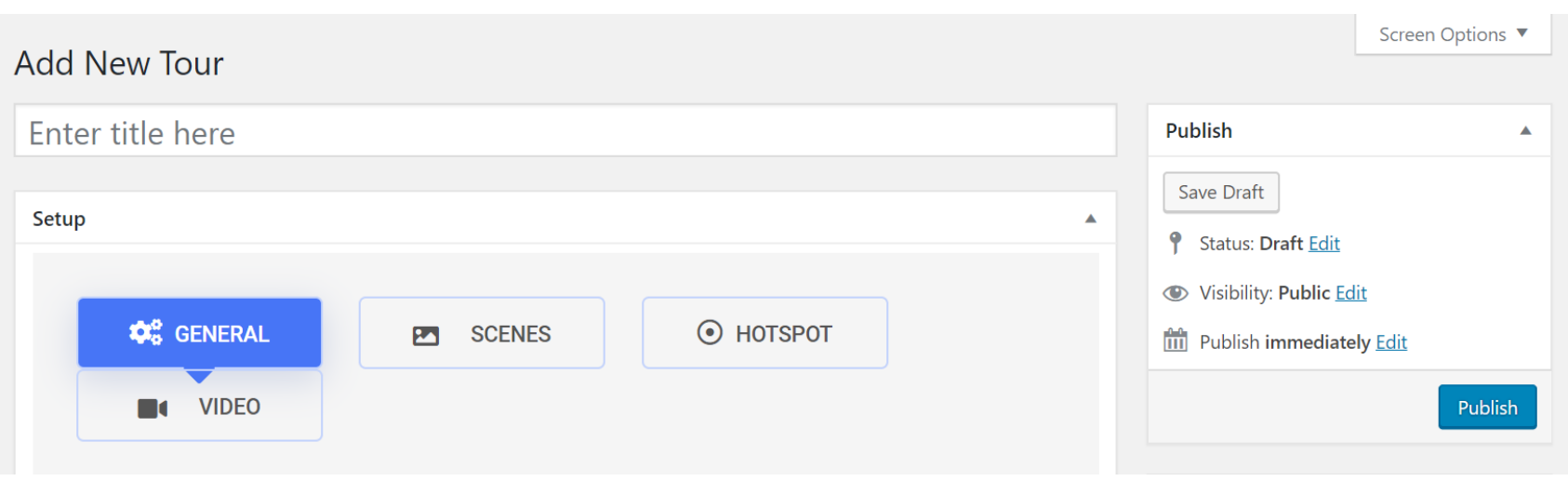

Figure 29 - Plugin for Inserting 360-degree Videos - Wpvr 
Aside from the three above-mentioned plugins, a few additional plugins were added to improve user's experience. Those plugins were Catch ID's, Duplicate Post, and Regenerate Thumbnails.

The Catch ID's plugin was used to show the ID number of media files, allowing for easier insertion and presentation of media files; as such, in the process of developing the new training, it was easier to find a media file ID number through the use of this plugin. Figure 30 shows the settings of the Catch ID's plugin and the menu options on which this plugin can be applied.

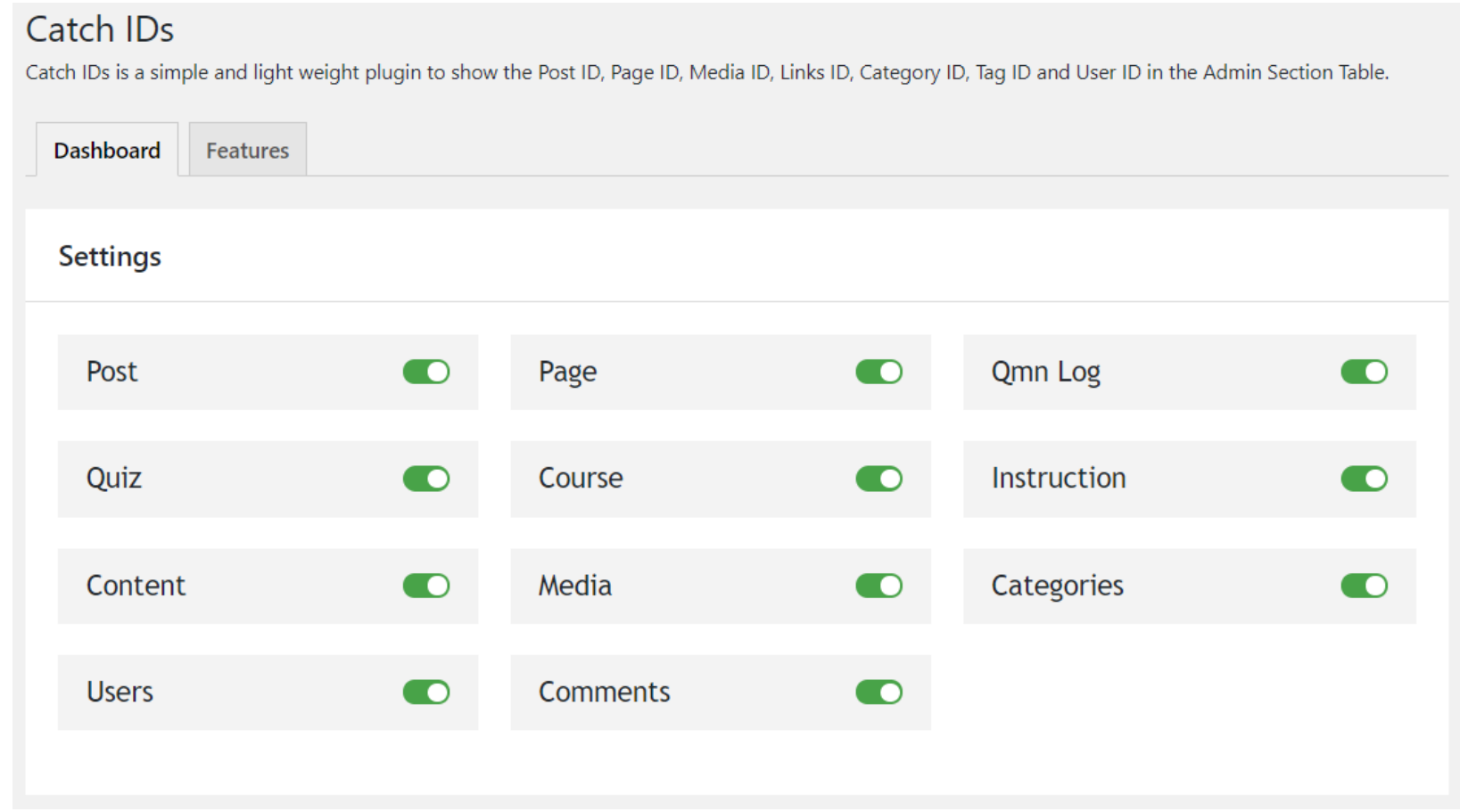

Figure 30 - Catch IDs

The Duplicate Post plugin was used to clone posts. The ability to duplicate posts using this plugin allowed the creation of new posts to be much easier, as content that would be shared between old and new posts could be instantly duplicated rather than copied manually. In other words, by 
applying this plugin to already created posts, the process of creating a new post was made more efficient.

The Regenerate Thumbnails plugin adjusts image sizes that have been uploaded to the Media Library to improve the overall application performance, such as the speed of CBTT.

These additional plugins are not necessary to the functionality of the CBTT; however, they improve the general user experience and the quality of user performance.

\subsubsection{Other Menu Options}

The menu option Media serves as a database for the media files of the CBTT. Media files that can be added to the Media Library are images, videos, sounds, and text documents.

The menu options Courses, Instruction, and Contents are custom post types, specially developed for this project. They are not a default part of the WordPress CMS, but were created and inserted manually for the purpose of creating specific parts of the new training course. Custom post types are menu options which can also be created using a separate plugin called Custom Post Type UI.

The menu option Appearance was used to create a "navigation menu" once the training had been fully developed.

\subsection{Phase 3 - Virtual Reality Application}

The Virtual Reality application was developed in Unity3D, a free game engine software (explained earlier in the Chapter 2.4.2). The same images and videos used in the Computer-Based TaskTraining were used to create virtual tours with Unity3D. 
Virtual tours for each machine were developed separately, creating the total of seven different virtual tour applications. Developing the virtual tours independently from each other was necessary, as images that used for VR applications were not compressed and were too large in memory size. As explained earlier, images and videos were compressed to be used in the Computer-Based Task-Training software because this software can be run on the network and mobile devices and, therefore, can require a faster Internet speed. On one hand, such large memory files noticeably slow down the speed of interaction with the CBTT. On the other hand, in the VR application, images and videos which were not compressed establish a better user experience when using the application with VR headsets. At the same time, the speed of such VR applications can depend on computer characteristics (such as the processor). Therefore, each of the seven separate virtual tours runs faster independently.

\subsubsection{Implemented Plugins}

The major plugins used for creating and running the VR applications with the earlier gathered images and videos are as follows:

- “Mobile VR Tour 360”; and

- “Oculus Integration”.

The Mobile VR Tour 360 (Unity, 2018) plugin serves for creating the virtual tours and can be improved using additional options. The added options made it possible to insert both sound and video files that were gathered previously; the sound player and other interface options were created to improve the user's interaction with application.

The Oculus Integration asset enables use of the Oculus Rift CV 1 headsets with the aforementioned plugin. The asset includes several advanced features, such as an audio manager. This asset was set 
up so that a user can interact with the HMD and its joysticks while still being immersed in the VR world.

\subsubsection{Creating VR Application}

In the process of creating the VR applications, the concept of a sphere was applied as the base format of the VR environment. All gathered materials for the specific machine of each virtual tour were first stored in Unity3D database, shown in Figure 31.

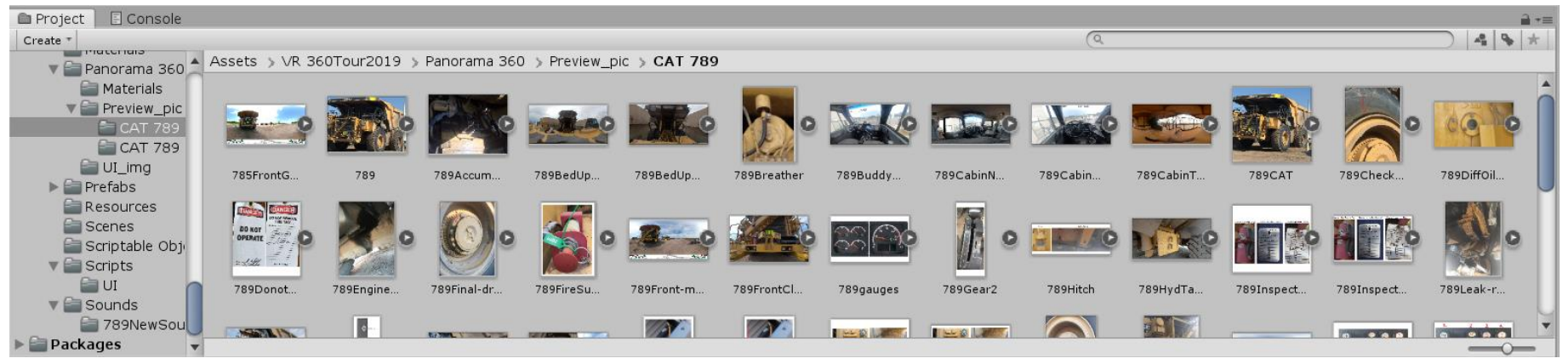

Figure 31 - Unity Database

The concept of sphere means that the collected 360-degree images and videos were placed in spheres within the system. In other words, each 360-degree image was inserted into one sphere (Figure 32), as were the 360-degree videos.

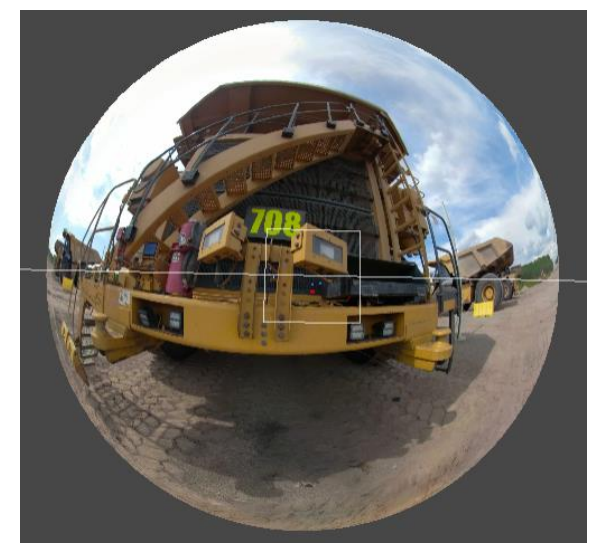

Figure 32 - One Sphere - One Image 
These spheres were then connected together to create a Virtual Tour. For example, in the virtual tour for haul-trucks, there were sixteen 360-degree images and two 360-degree videos taken by the camera setup. Therefore, the total number of spheres in the virtual tour was eighteen. Each sphere presents a separate field in which buttons, sounds, and 2D images can be inserted and designed for the tour (Figure 33). For example, the inserted buttons can easily be setup to allow interaction and movement between spheres. No coding skills are necessary to use this virtual tour creator. Additionally, the knowledge assessment quizzes were not developed in this VR application.

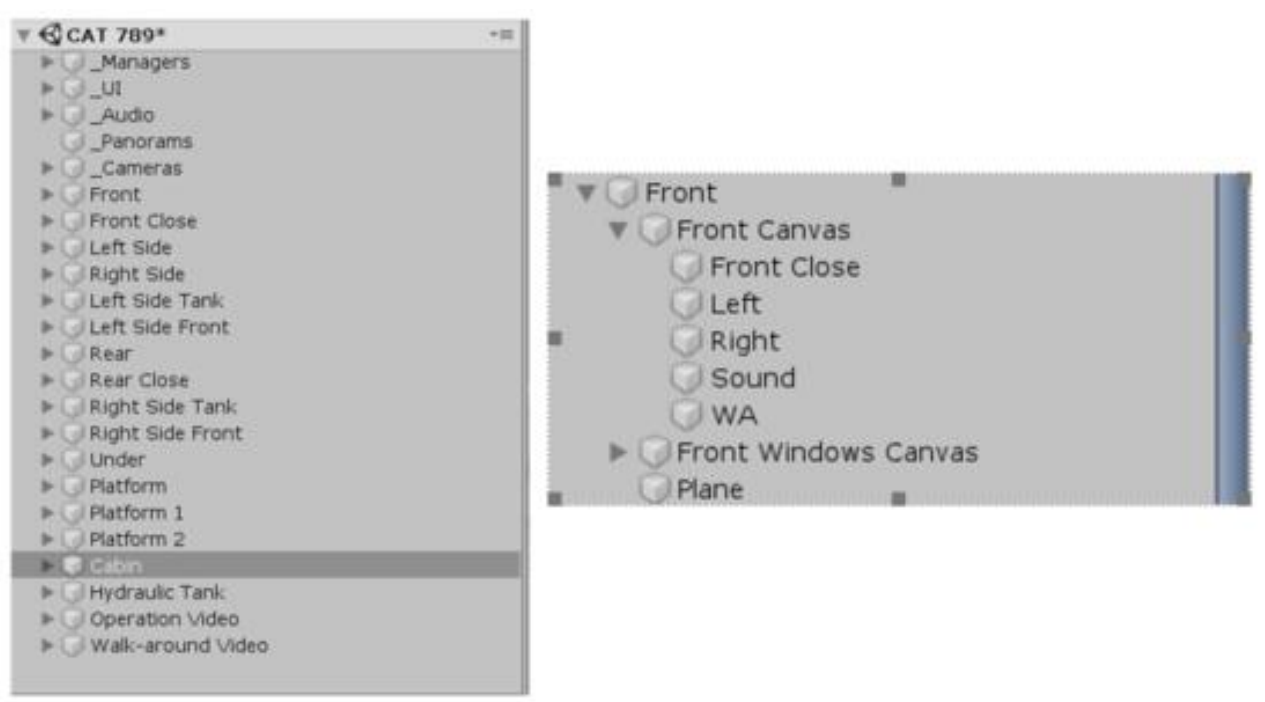

Figure 33 - Scene Hierarchy

Figure 34 shows the window in which one can create a new virtual tour. 


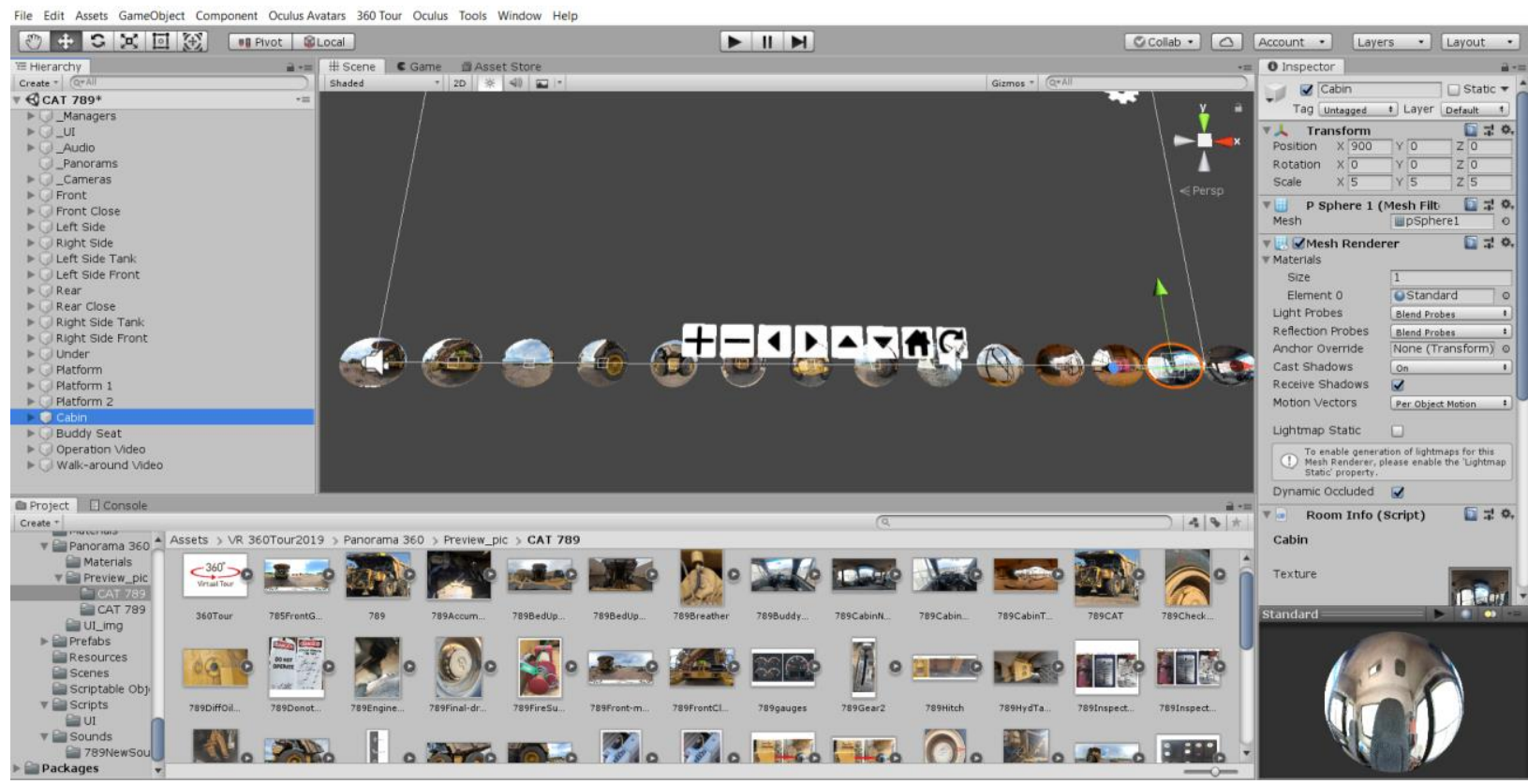

Figure 34 - Creating New Virtual Tour 


\section{Chapter 3}

\section{Results and Discussion}

\subsection{Mine Description}

This research project was conducted at a surface coal mine located in Mississippi in the United States. The mine is a subsidiary of one of the largest coal producers in North America, with more than 2 billion tons of coal reserves.

At the coal mine, a truck and shovel fleet is responsible for topsoil stockpiling and overburden removal. Material (coal and overburden) is transported with Caterpillar 789 and 785 off-highway haul trucks. Interburden material is pushed into the excavated area with the Caterpillar D11 dozerpush fleet. Finally, dragline operations are used for re-handling of the overburden. Coal seams are mined by a highly efficient surface miner (SM). Lignite is loaded into a haul-truck and hauled to an on-site hopper. Finally, coal is crushed and transported to silos.

The machines for which training courses were developed in the Computer-Based Task-Training software and in the virtual reality application were haul-trucks, dozers, scrapers, and the surface miner.

\subsection{Images and Videos}

After the previously described process of gathering 360-degree images, 2D images, and 360degree-videos, these materials were inserted into the Computer-Based Task-Training program and VR application. These materials represent a crucial piece of a trainee's ability to interact with the training process. However, videos and images that are captured with the 360 -degree camera can also be used separately and independently from the developed software. For example, such 360degree images and videos can be run in any player that is compatible with this type of content. 
One of the Media Players that supports 360-degree content is the GoPro VR Player. Additionally, 360-degree content can be seen by using the Oculus Rift HMD, without inserting such materials into the VR application. However, the process of using images one-by-one can be noticeably slower, as a person will have to manually change the image or video and insert new ones. On the contrary, in the VR application or CBTT, videos or images that were already inserted into the software and set at the right place can be seen and interacted with inside the virtual tours, without needing to leave and re-enter the application.

It is also possible to see the collected materials on any computer, not just within the developed software. Another advantage of the materials gathered by the camera is easy revision. If the produced materials are not satisfactory, it is easy to capture a new video or image. Normally, as the videographer becomes more experienced and knowledgeable about using the 360-degree camera, they can produce, stich, and edit the images and videos at a faster pace.

\subsubsection{Images for Virtual Tours}

After gathering the 360-degree images, compressing them, and removing the tripod, the images

were then stored in the database. Table 5 presents the 360-degree images for the haul-truck Caterpillar 789 and their positions.

A similar concept was followed for all other machines for which the virtual tours were created. The biggest difference between the virtual tours of different machines is in the actual number and position of the 360-degree images. 
Table 5 - 360-degree Images for the Haul-truck

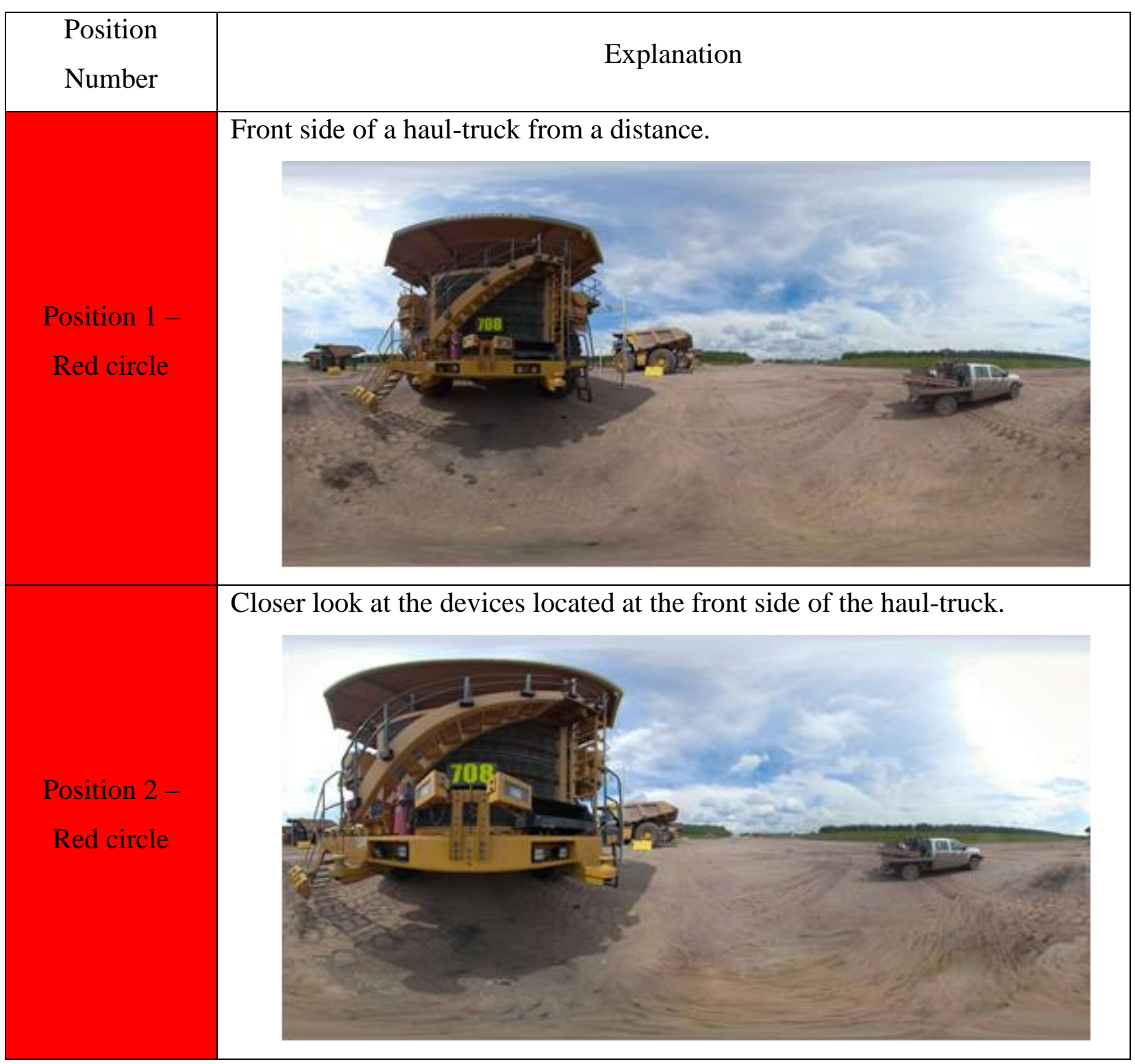




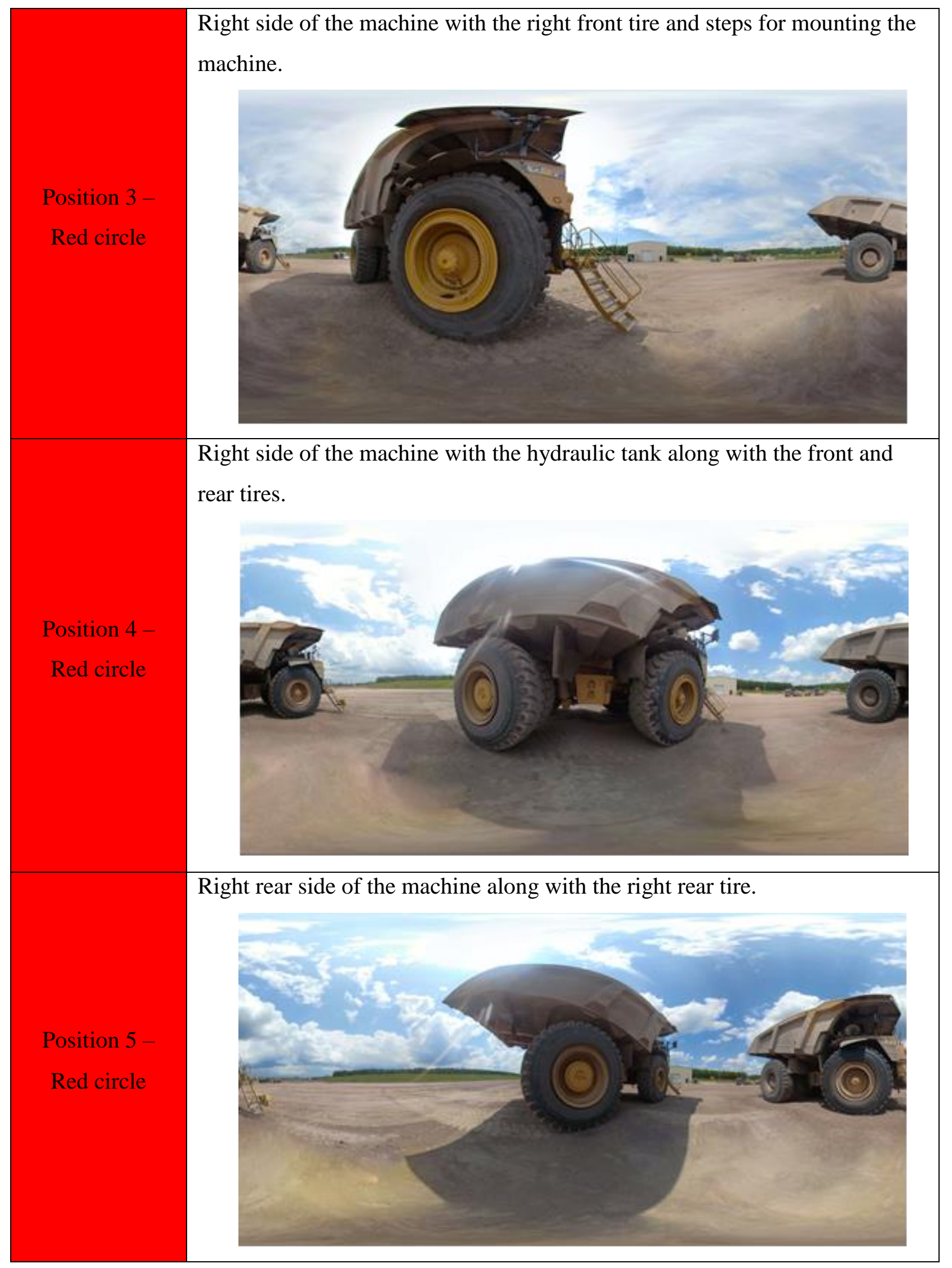




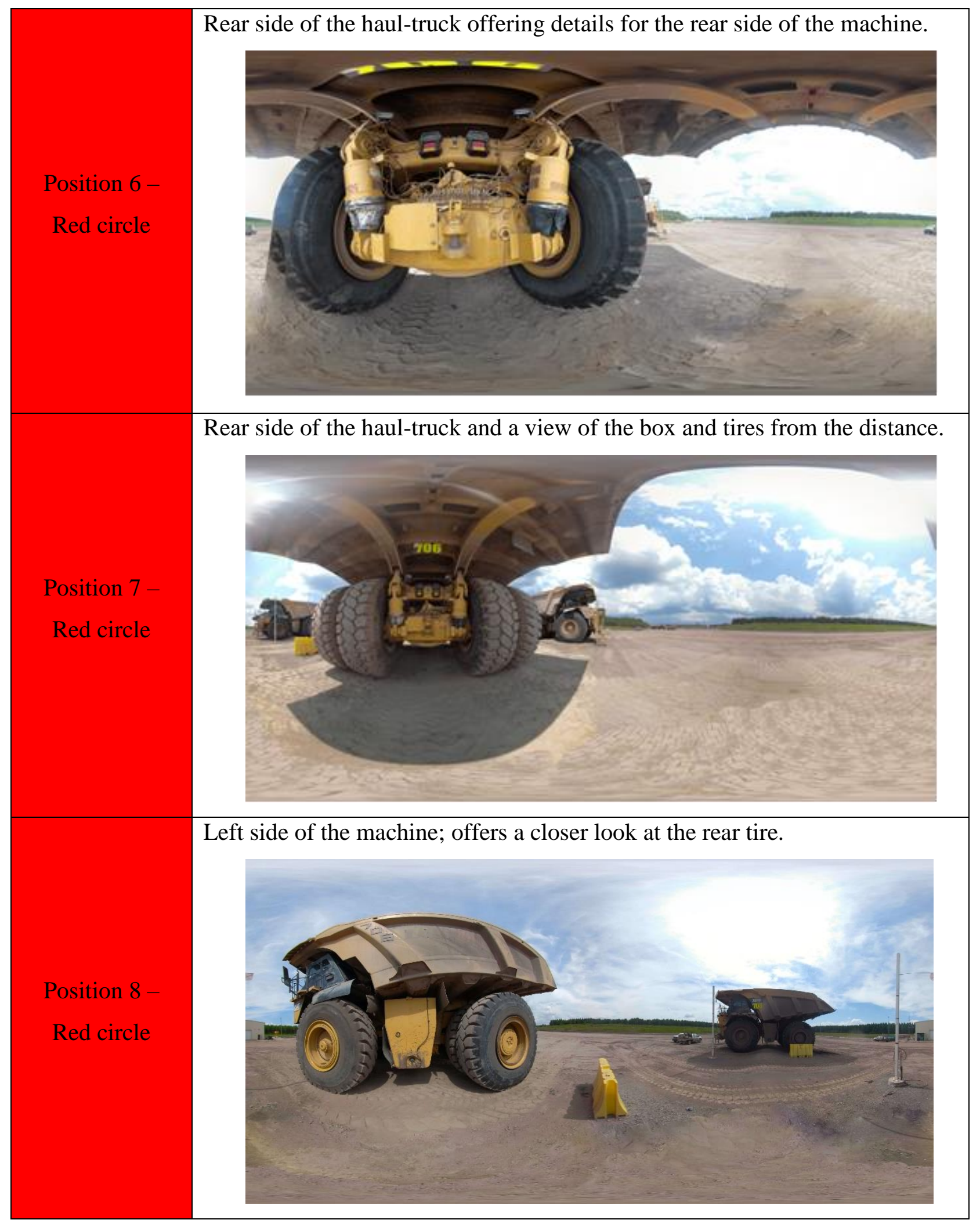




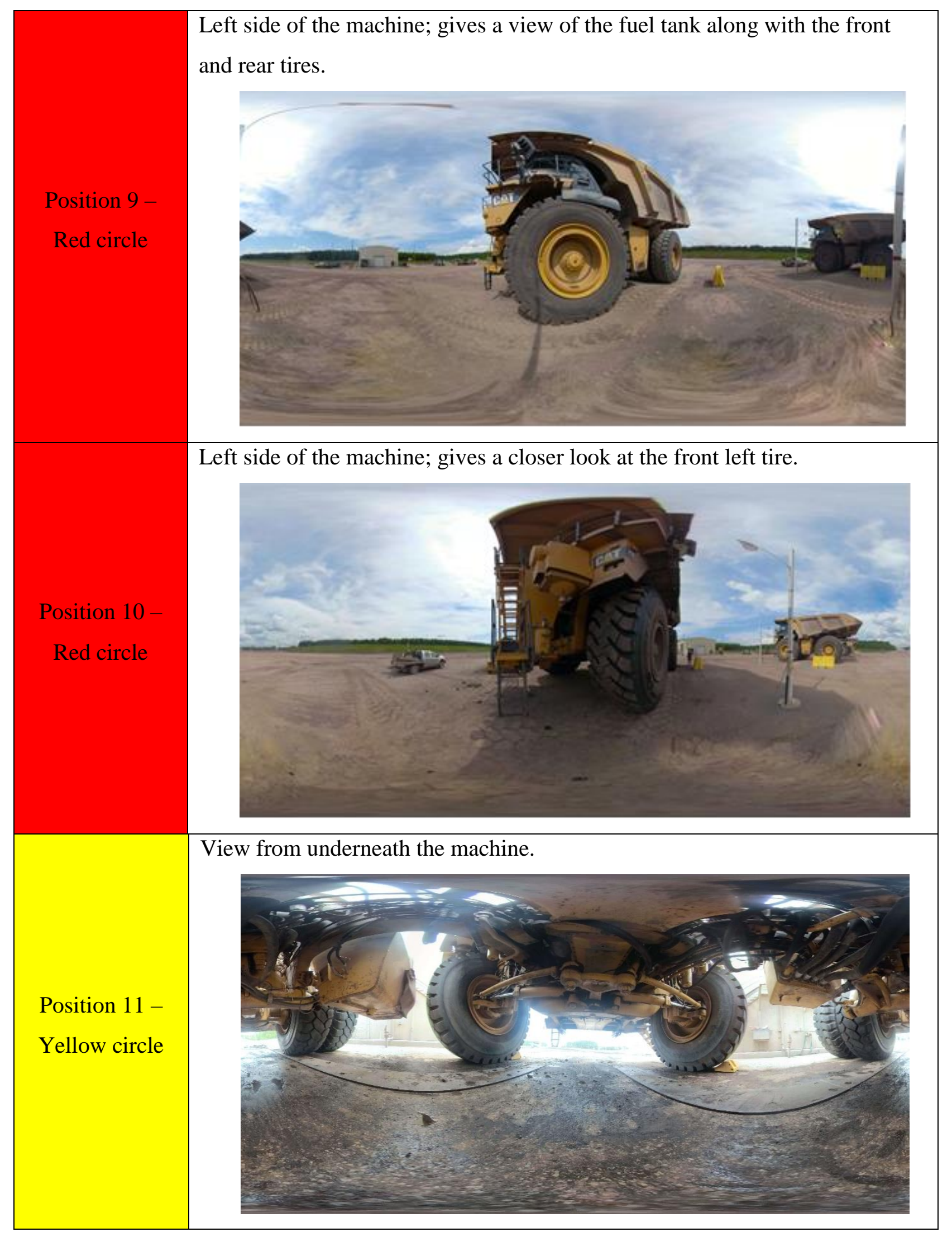




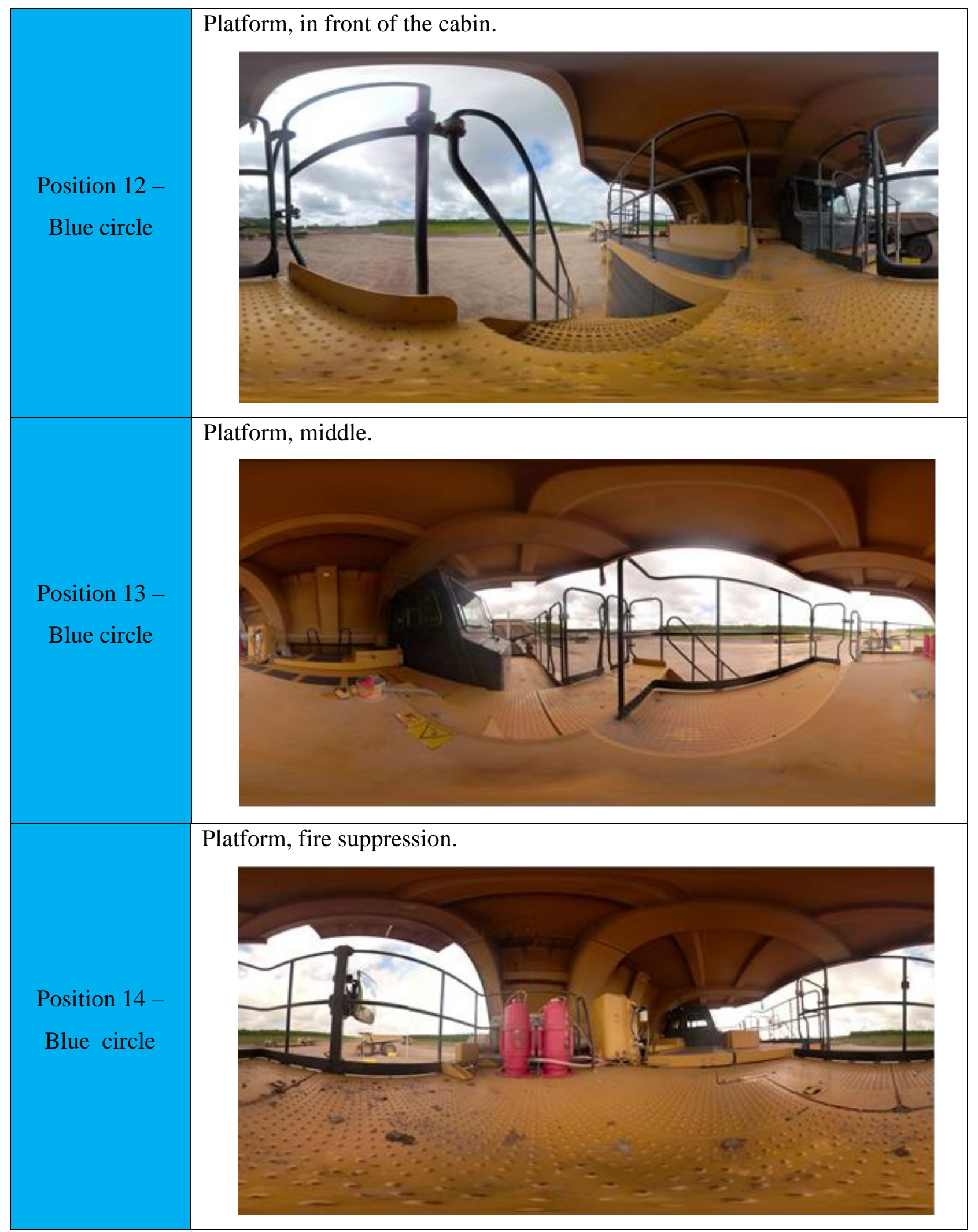




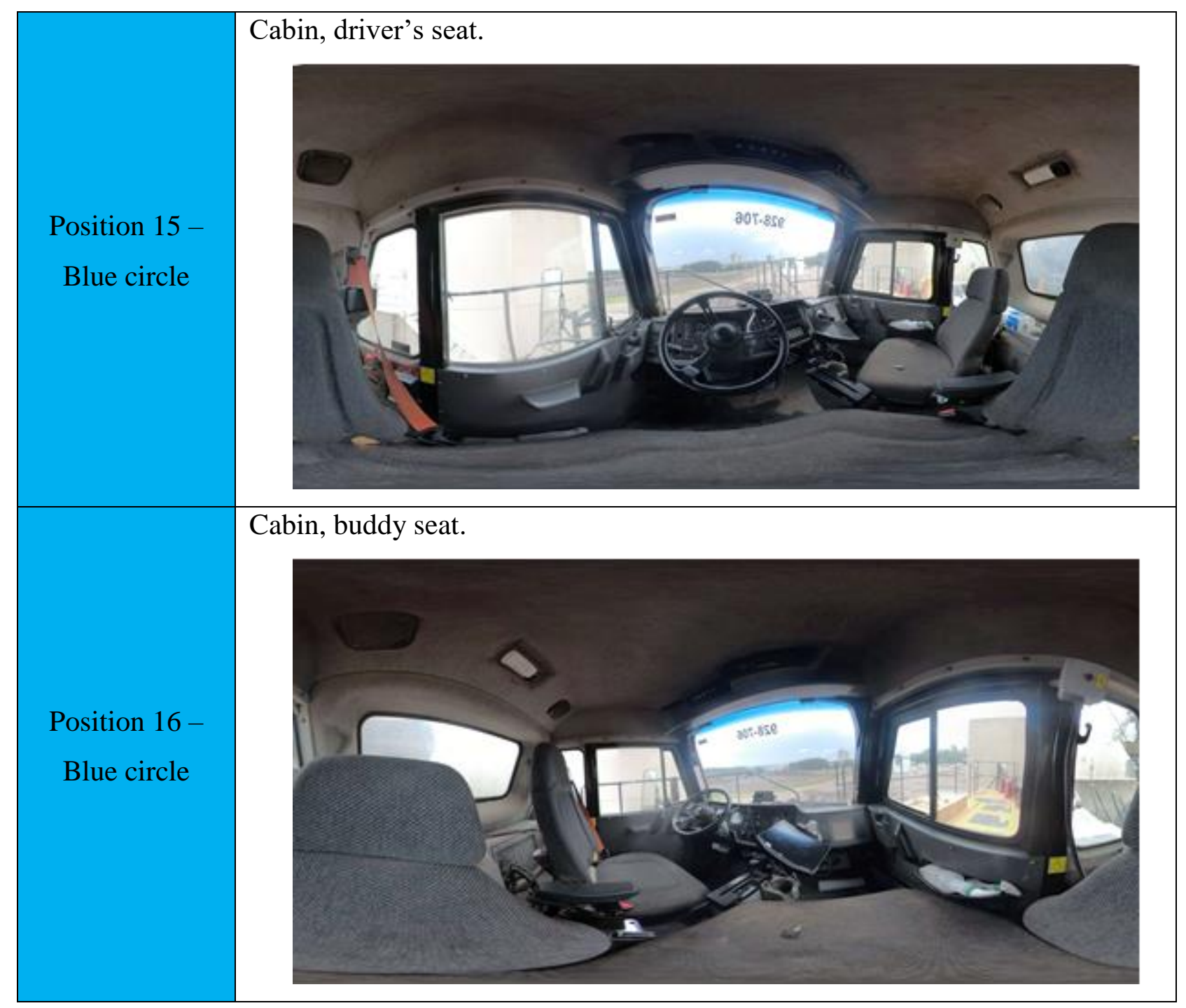




\subsubsection{Videos for Virtual Tours}

In addition to the images, videos were also recorded by the process of gathering video materials previously explained in chapter 2.6. Screenshots from the 360-degree video of the inspection of the haul-truck are shown in the following pages in Figures 35, 36, 37, and 38.

Videos were edited with GoPro Fusion Studio software, compressed, and inserted into both Computer-Based Task-Training and VR application. Two videos were created for each machine. One video showed the HEO performing the pre-shift inspection, and the other showed the HEO operating the machine.

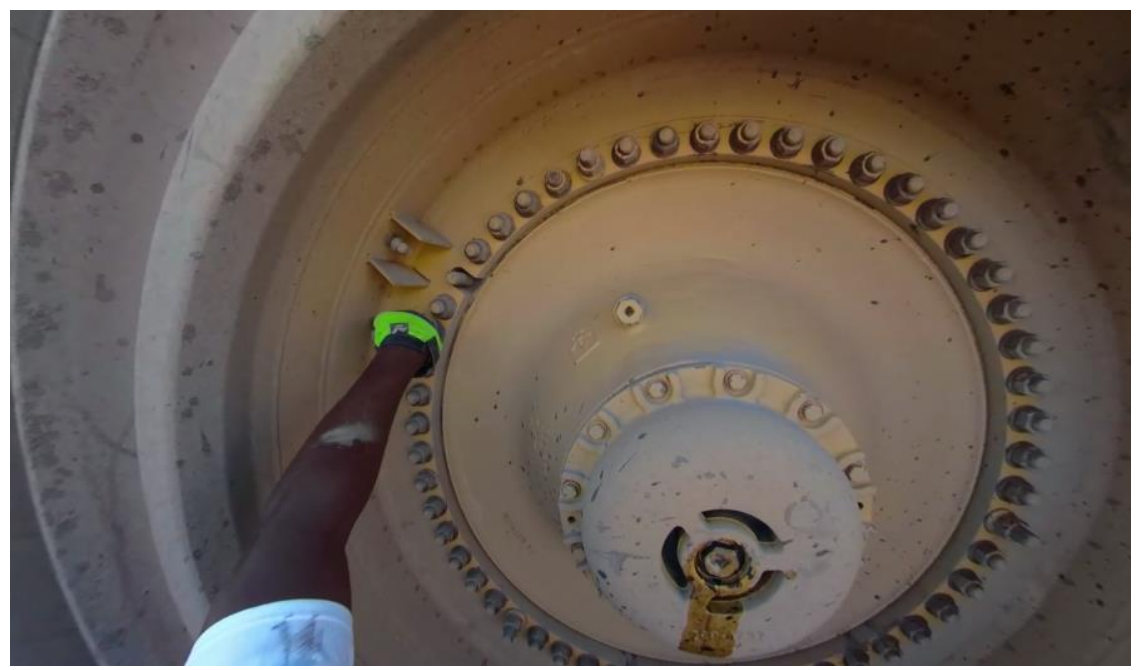

Figure 35 - 360-degree Video - Tire Inspection 


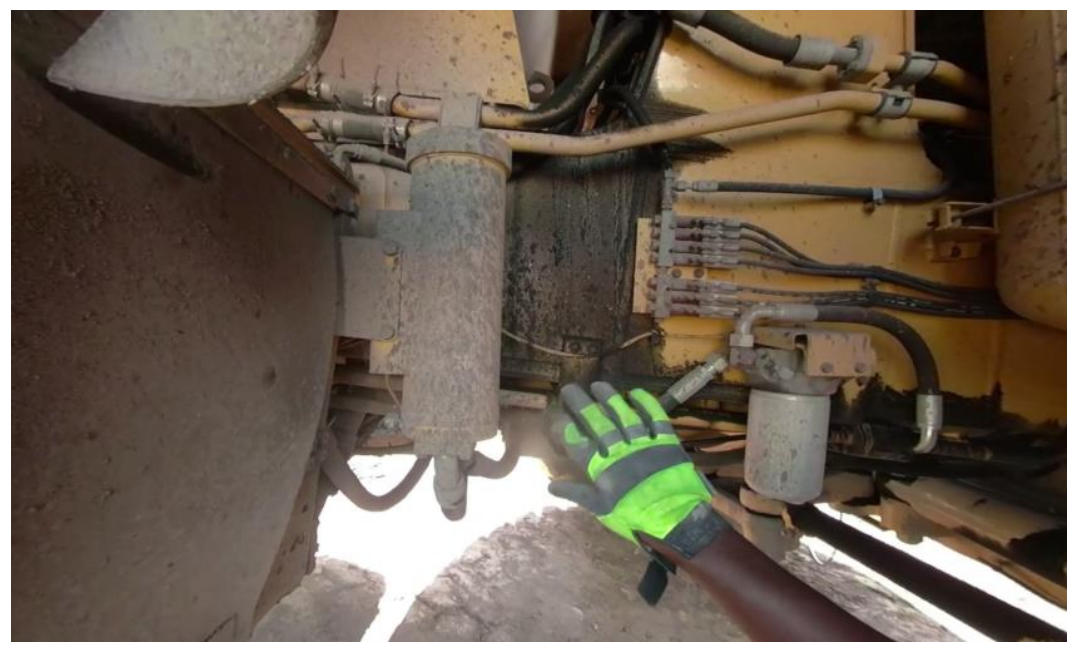

Figure 36 - 360-degree Video - Inspection of Hoses

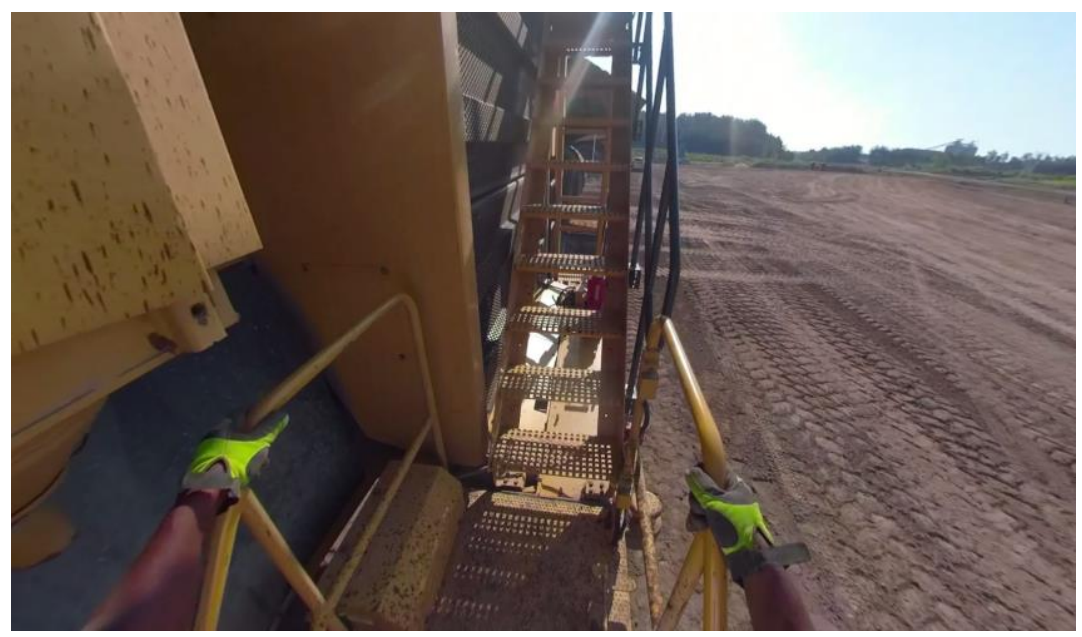

Figure 37 - 360-degree Video - Three Points of Contact

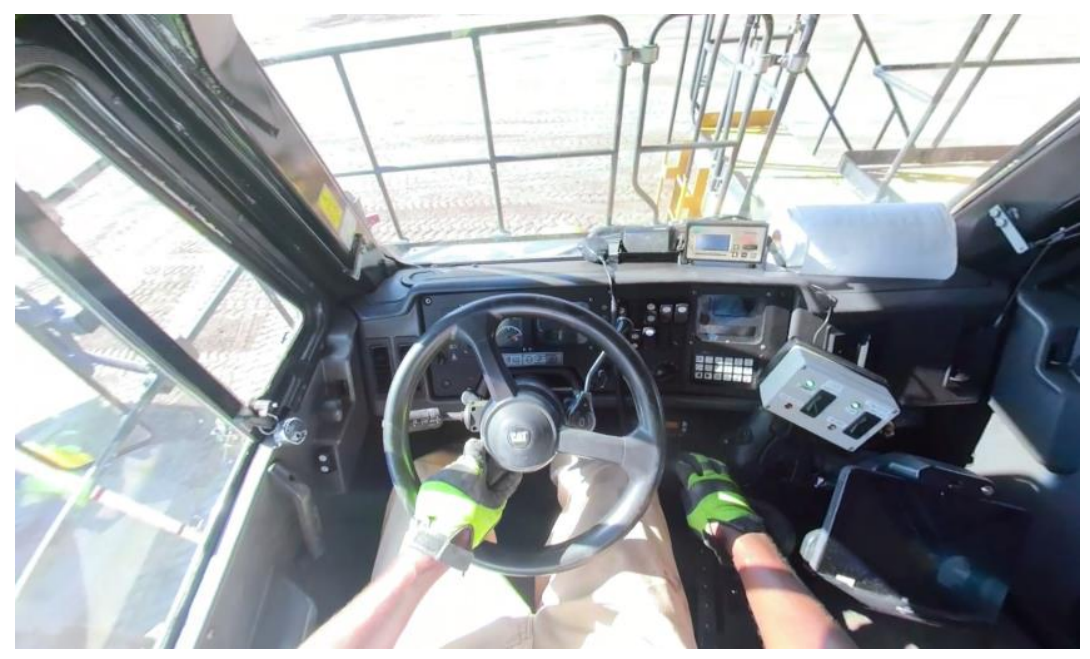

Figure 38 - 360-degree Video - Cabin Inspection 


\subsection{Computer-Based Task-Training (CBTT)}

Training courses were developed for seven machines which were widely used in the surface mine.

Table 6 presents the list of the machines (courses).

Table 6 - List of Developed Courses

\begin{tabular}{|c|c|}
\hline & Machine Name \\
\hline 1. & Haul Truck - CAT 789 \\
\hline 2. & Haul Truck - CAT 785 \\
\hline 3. & Dozer - CAT D10 \\
\hline 4. & Dozer - CAT D11 \\
\hline 5. & Scraper - CAT 16M \\
\hline 6. & Scraper - CAT 24M \\
\hline 7. & Surface Miner - Wirtgen 4200 \\
\hline
\end{tabular}




\subsubsection{Creating the New Computer-Based Task-Training}

The training template, developed as the major feature of the CBTT, allowed for the creation of a new training course for a specific machine. Whether a user wants to take an existing training course or create an entirely new course, the first step will be navigating the login screen. A user should register with user name or email address and login to access the software. The login page (Figure 39) consists of only two fields (Username and Password) and two buttons for login or registration. As stated earlier, the administrator will assign a role to the new user, determining whether that new user will be an administrator, editor, or trainee.

Only administrators and editors are allowed to edit the existing training course and to create a new course.

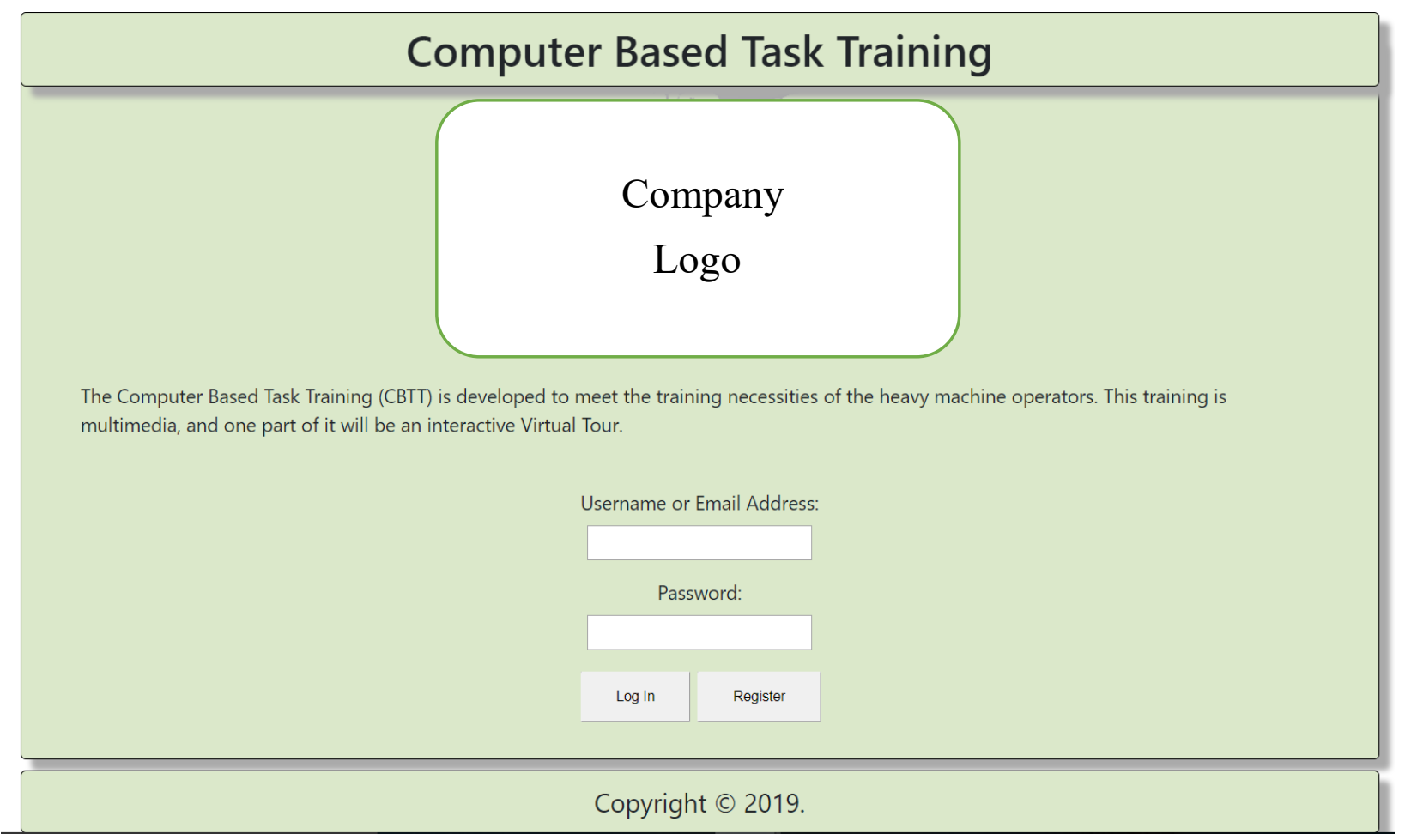

Figure 39 - Login Page 
After a user logs in as an administrator or editor, they will be transferred to the dashboard page. Both an editor and an administrator can add a course, change an existing course, add or remove media files, and create Virtual Tours and knowledge assessment quizzes.

The editor should first insert any relevant media files (Figure 40). The editor can add a media file by using the "Media" option from the left side menu. They can click "Add New" (a) and either drag and drop the file or browse their computer for media files (b), as indicated in the figure.

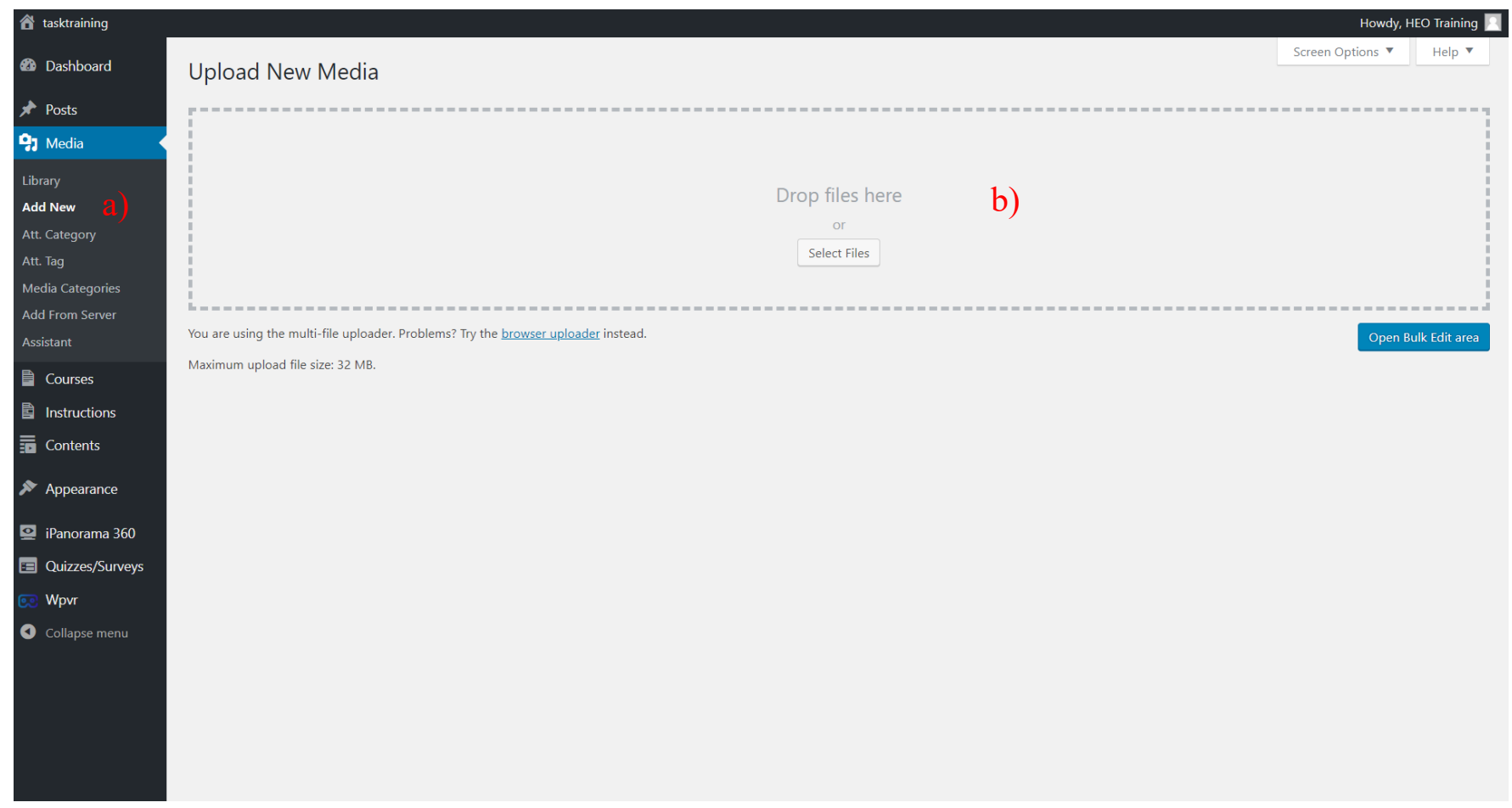

Figure 40 - Insert Media Files

After inserting media files, the new training course can be created through the following eight steps.

\section{Step 1. Create a Course}

Menu option "Courses" is the first step in the process of creating a new course (Figure 41). A course creator should first enter the course title (a) and course name (b). Central square field (c) is 
a place for the course image, which should be a 2D photo of a machine from the media gallery.

Finally, a mine location should be selected (d), and the new course should then be published (e).

Refer to Figure 42 for a more detailed look at this option.

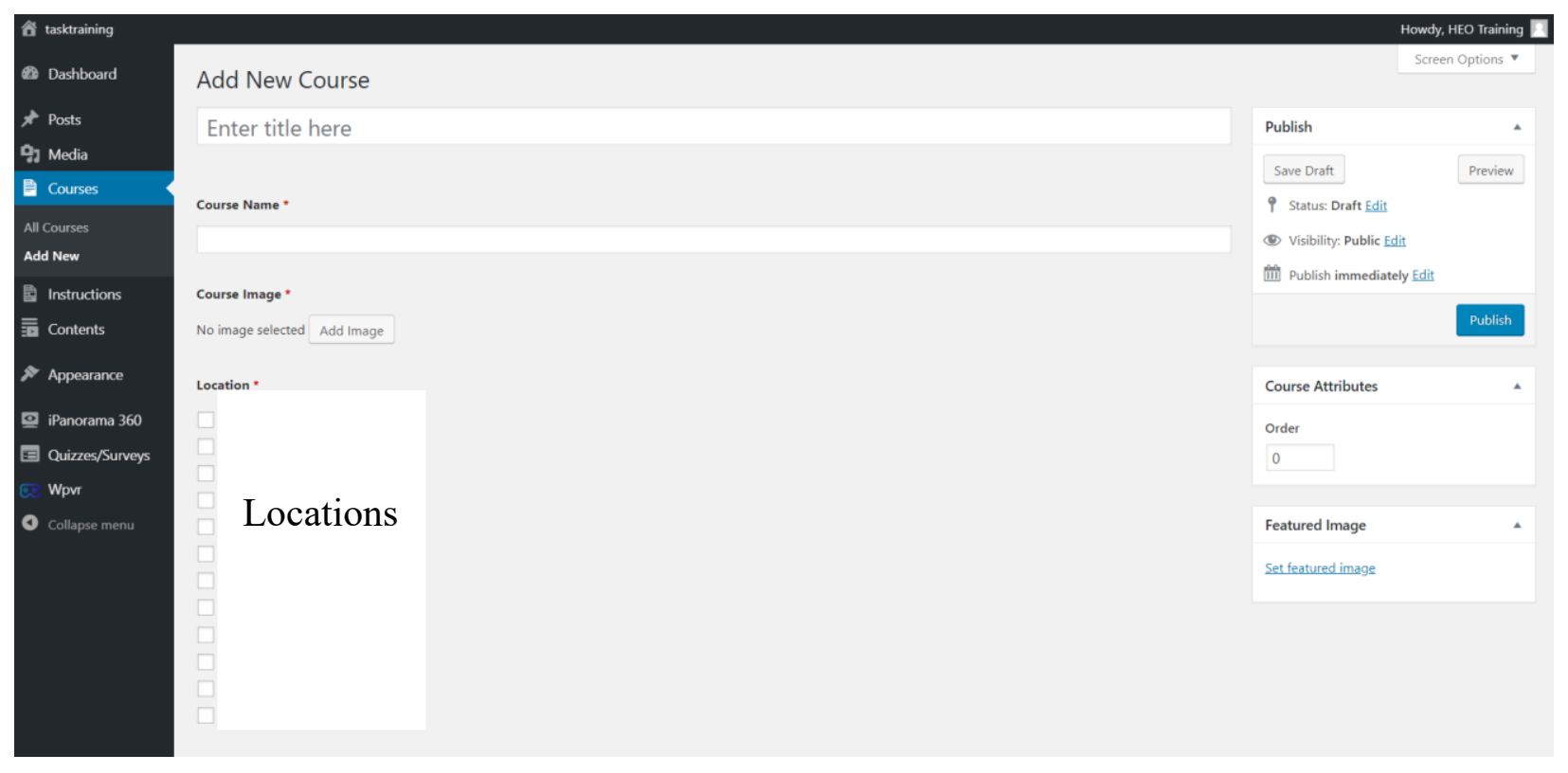

Figure 41 - Mепи Option Courses 


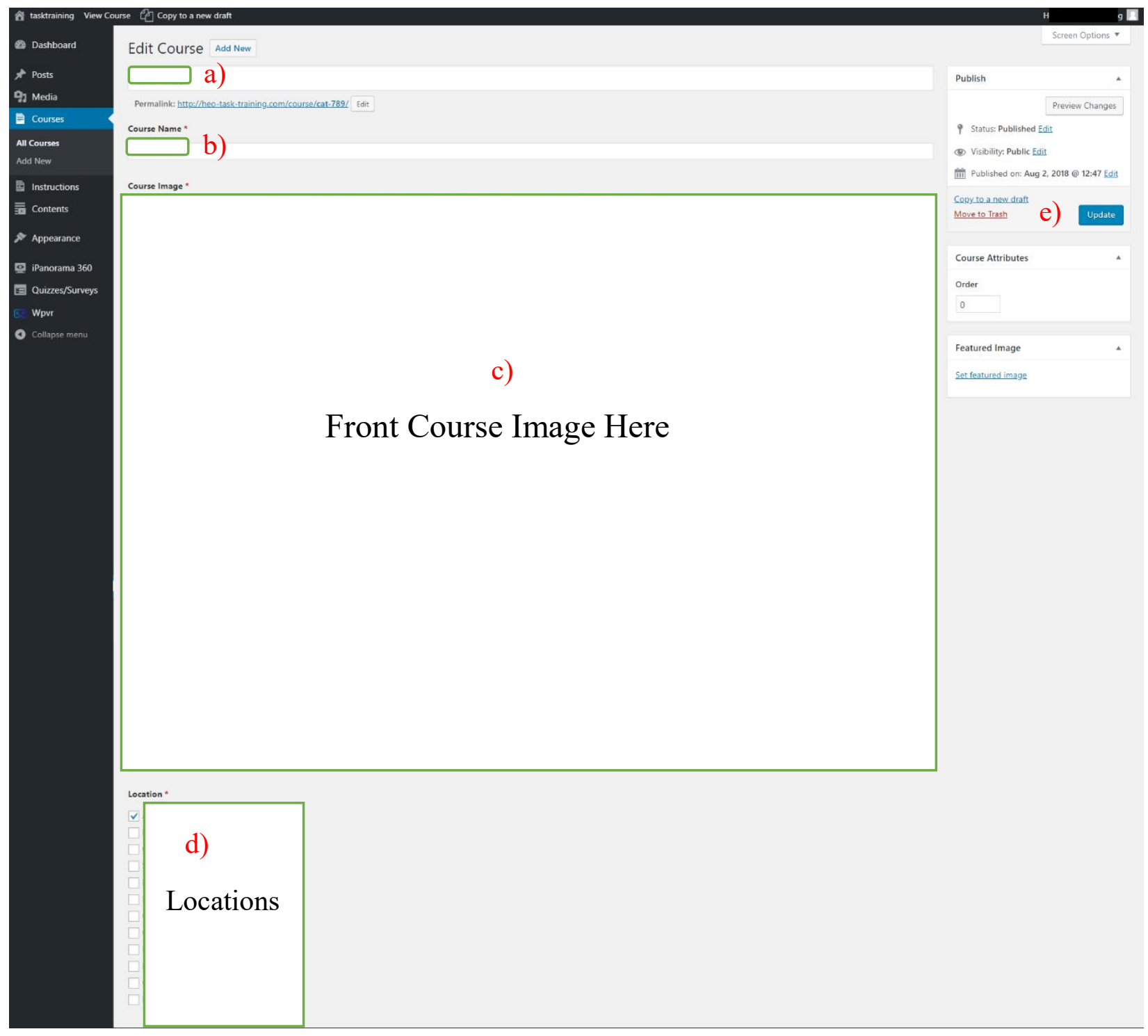

Figure 42 - Step 1 - Create New Course

\section{Step 2. Create the Virtual Tours}

This step is achieved by using the "iPanorama 360" plugin and menu option. Virtual tours are created by combining 360-degree images, 2D images, and voice information.

\section{Step 3. Create Posts}

The "Posts" option is the first menu option in the left side menu (Figure 43). After a user creates a Virtual Tour, it is necessary for them to create a post for the same tour. This option (post) is used 
to connect a virtual tour developed with earlier mentioned plugin with the specific course (machine). The title of the new post should now be added (a). In the label (b), a shortcode of the created virtual tour should be inserted. Every virtual tour has a unique shortcode that is generated automatically after creating a virtual tour. The shortcode is given in the following format: [iPanorama id="554"]. Figure 45 shows the empty Post.

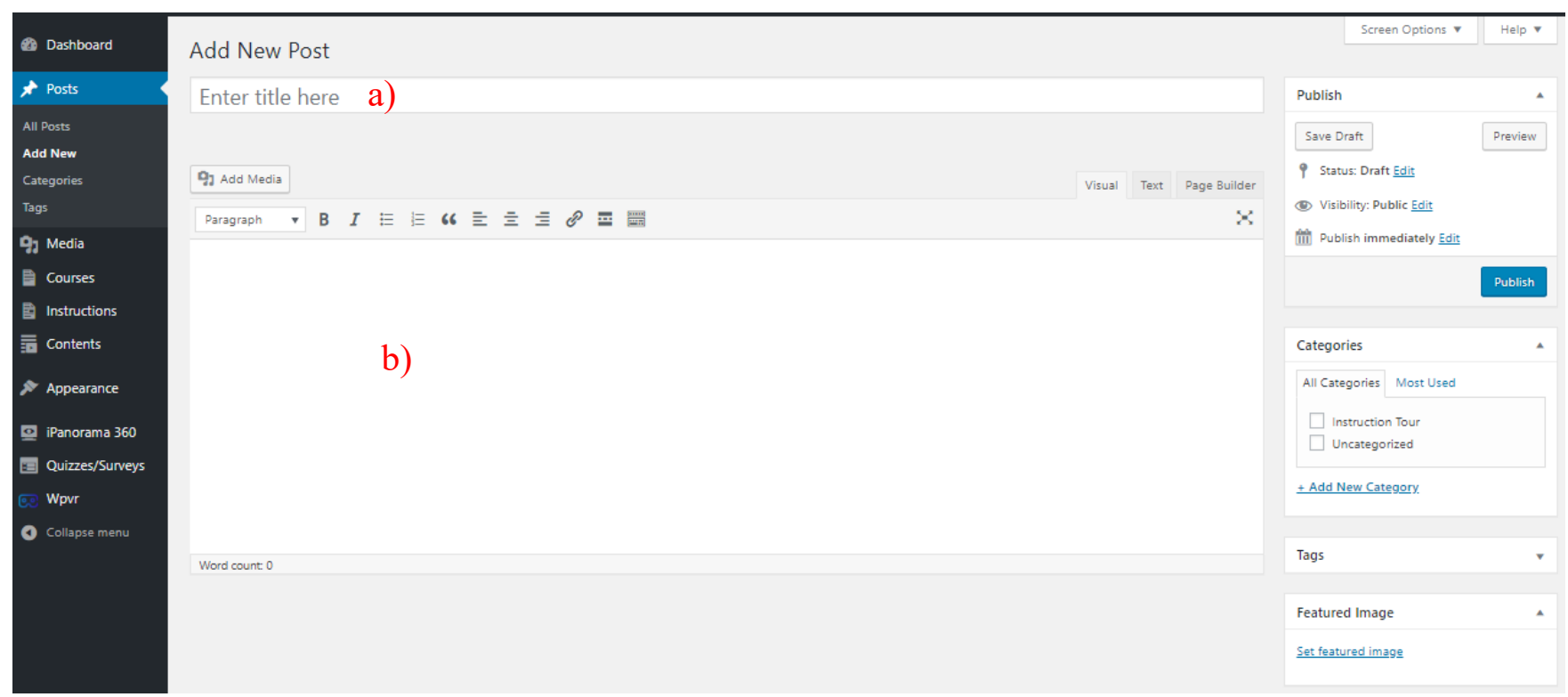

Figure 43 - Step 3 - Create New Post

\section{Step 4. Create Knowledge Assessment Quizzes}

Quizzes are created with the "Quizzes/Surveys Master" plugin. Questions and answers can easily be added, removed, and edited by using the form shown in Figure 44. 
Edit Question

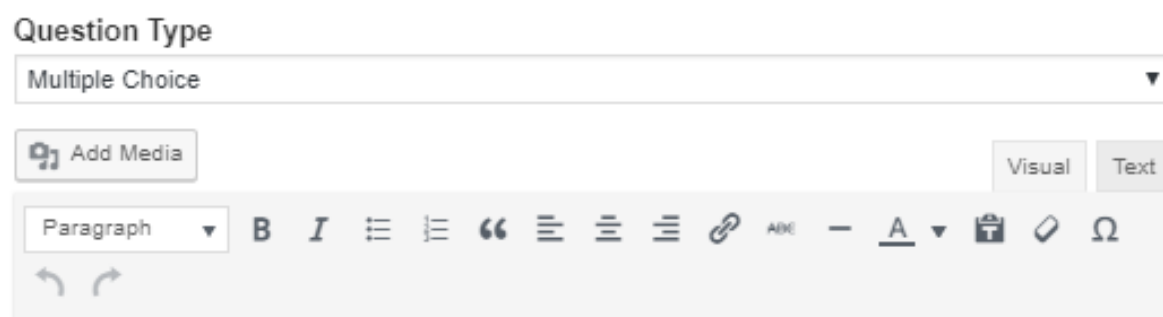

Your new question!

\section{Answers}

Add New Answer!

Correct

Correct Answer Info

Hint

Comment Field

None

Required?

No

Category

New:

Save Question Cancel

Figure 44 - Create Quiz 


\section{Step 5. Show 360-degree Videos}

The "Wpvr" menu option contains the video player that is used to show the 360-degree training videos in this Computer-Based Task-Training. Insert title (a) and upload the video (b) which was previously uploaded to the media library. Refer to Figure 45.

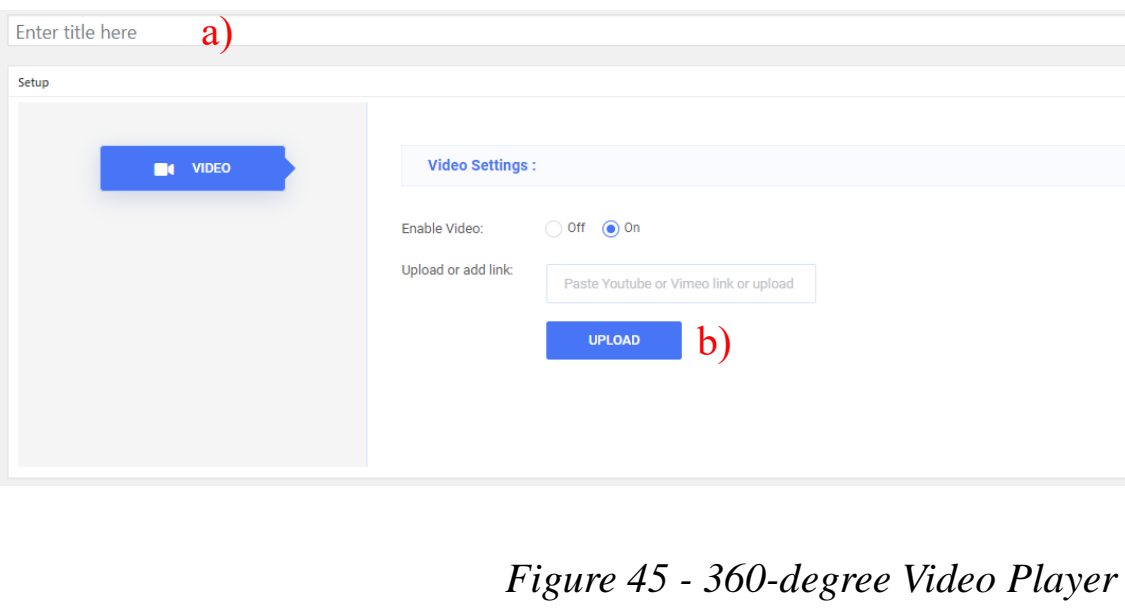

\section{Step 6. Create Instructions}

As explained earlier in Chapter 2.7.1, each training course is divided into three sets of instructions:

\section{Walk-around Inspection}

Example: CAT 789 Instruction \#1 - Walk-around Inspection

\section{Pre-operational (Cabin) Inspection}

Example: CAT 789 Instruction \#2 - Pre-operational Inspection

\section{Proper Start, Shutdown and Emergency procedures}

Example: CAT 789 Instruction \#3 - Proper start, shutdown and emergency procedures

The "Instructions" menu option is used to create an instruction. The title (a) and instruction name (b) should be inserted. These two fields are the same. The instruction should be then connected 
with its associated course name (c), associated quiz (d), and associated virtual tour (e). All three of these factors were previously created in earlier steps. The number of pages should then be inserted (f). Usually, each instruction has between 5 to 8 content pages, depending on the amount of material the editor wants to present. At the end, the "publish" button (g) should be clicked. Figure 46 shows a filled-out form for the walk-around inspection instruction for haul-truck CAT 789.

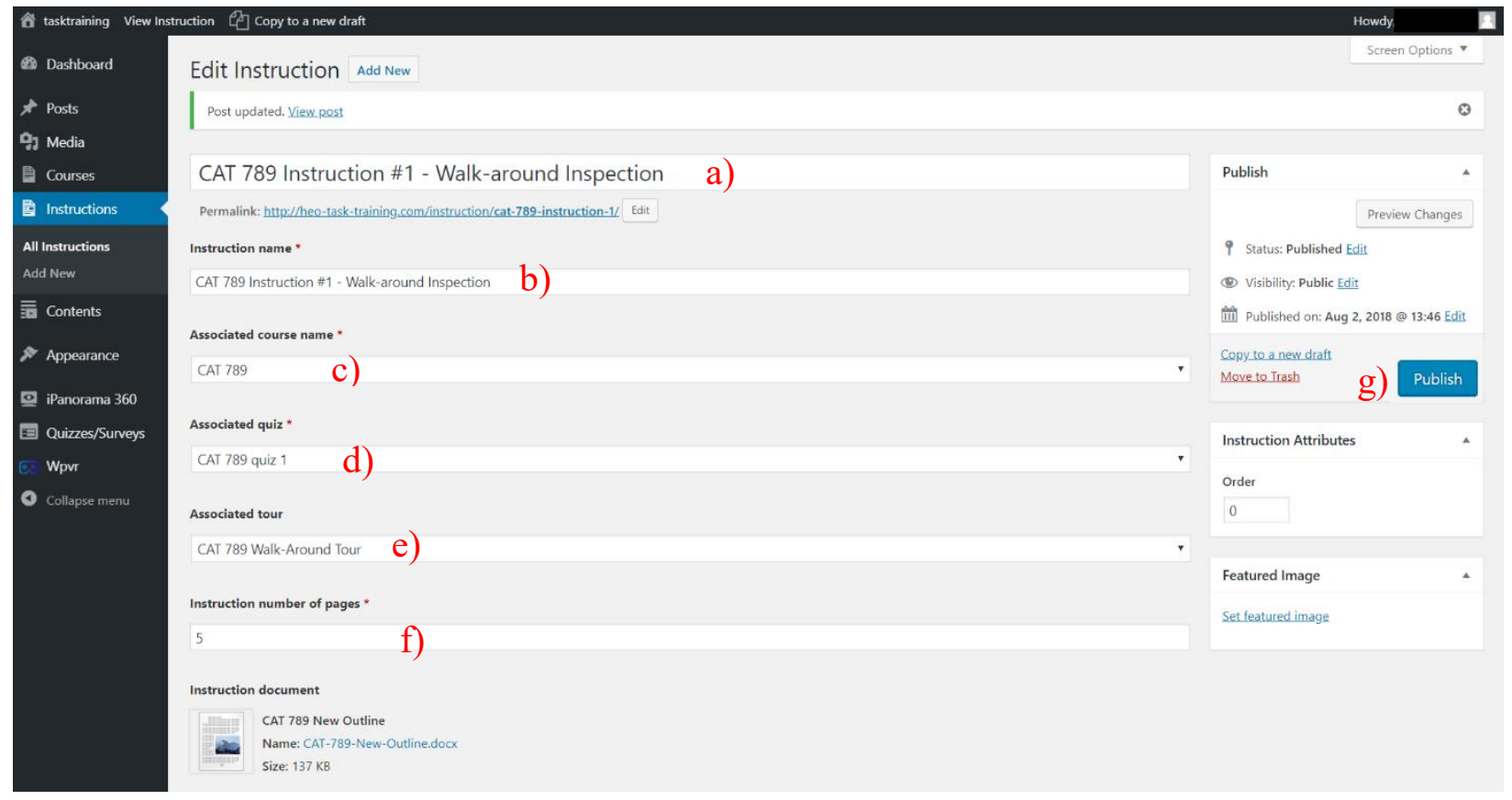

Figure 46 - Create New Instruction

\section{Step 7. Create Contents}

Each of the three sets of instructions consists of several pages filled with "Contents". In other words, the "Contents" menu option breaks each "Instruction" into several pages. As mentioned before, the number of content pages is chosen by the person creating a training course. The title (a) and the content page number (b) should be inserted. The associated course name should be chosen from the dropdown menu (c). Finally, the text of training content should be inserted. This 
field is used to enter the content of the page, including written explanations of the particular instruction and 2D images. The image tour ID field is not required to be filled, because the course and virtual tour were connected in the previous step (Step 6). Finally, the publish button (d) should be clicked. Figure 47 shows the form for creating the new content page.

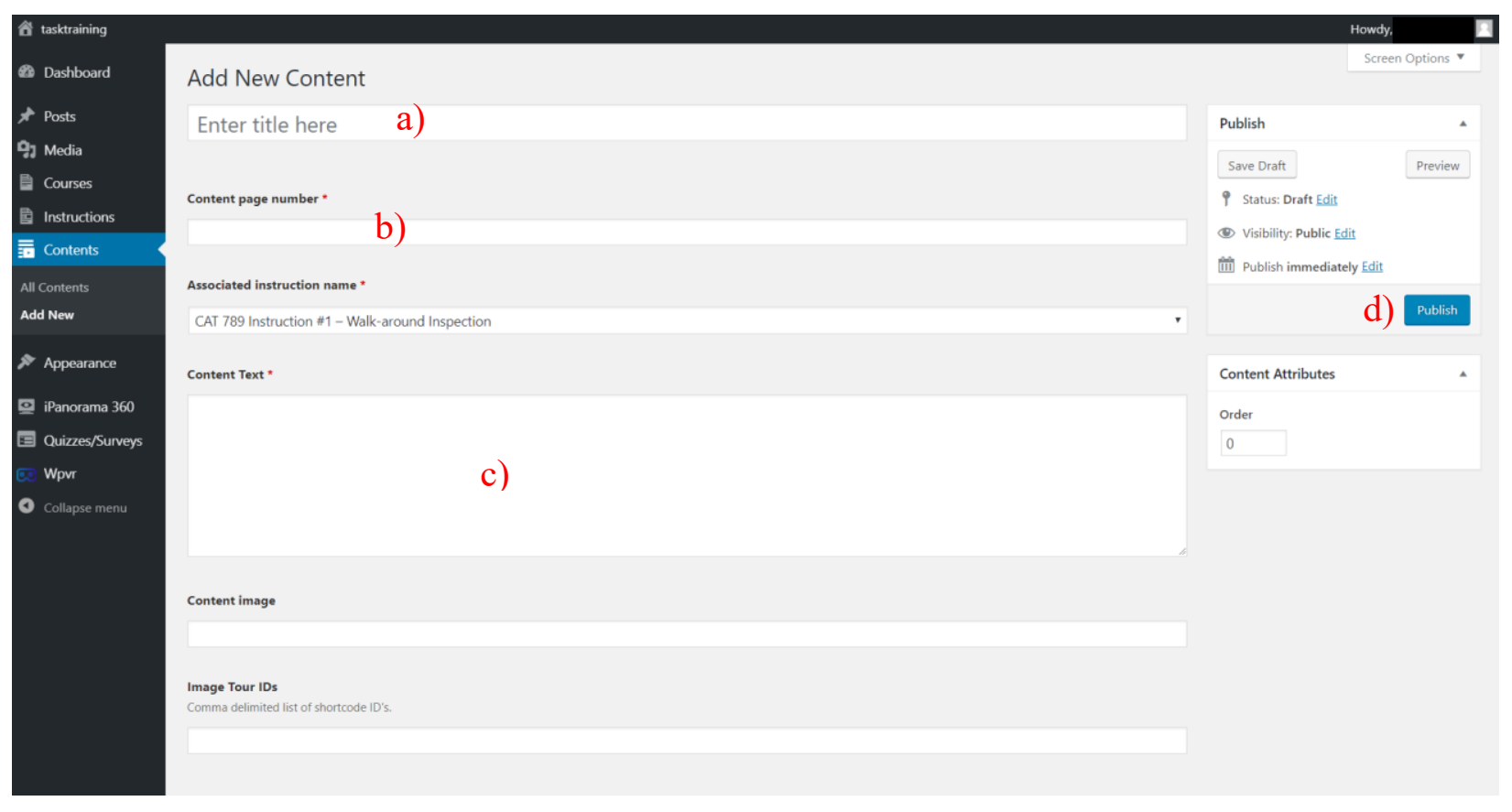

Figure 47 - Create Content Page

\section{Step 8. Create Navigation Menu}

The "Appearance" menu option serves to create a "navigation menu" for each set of instructions. This menu should be created after every other component of the training has been developed. The use of this menu feature is optional.

\subsubsection{Select Location and Machine}

After a user logs in with correct credentials, they can begin taking one of the developed courses. The first step is to select a mine location and machine to be task-trained. Figure 48 shows the form for choosing a mine location. 


\section{Computer Based Task Training}

-- Choose location --

Home

Figure 48 - Select Location

Figure 49 shows the screen where the user can select one of the seven developed training courses.

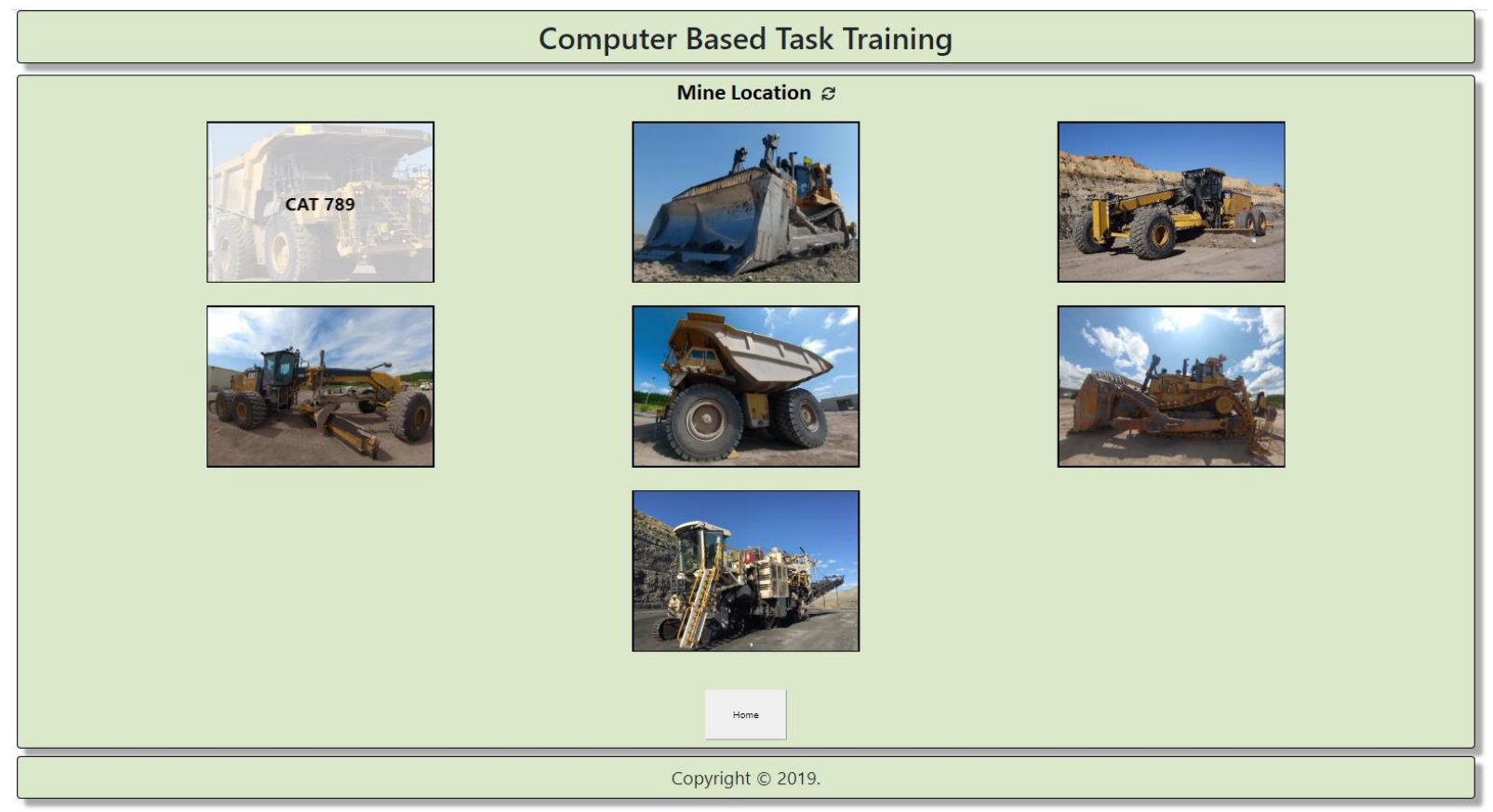

Figure 49 - Select Machine

After selecting the training course, a trainee can navigate through the selected course by using arrows (a) or the navigation menu (b). A trainee is able to read, listen, and watch training materials related to the selected training course. Figure 50 presents a page sample of a training course. 


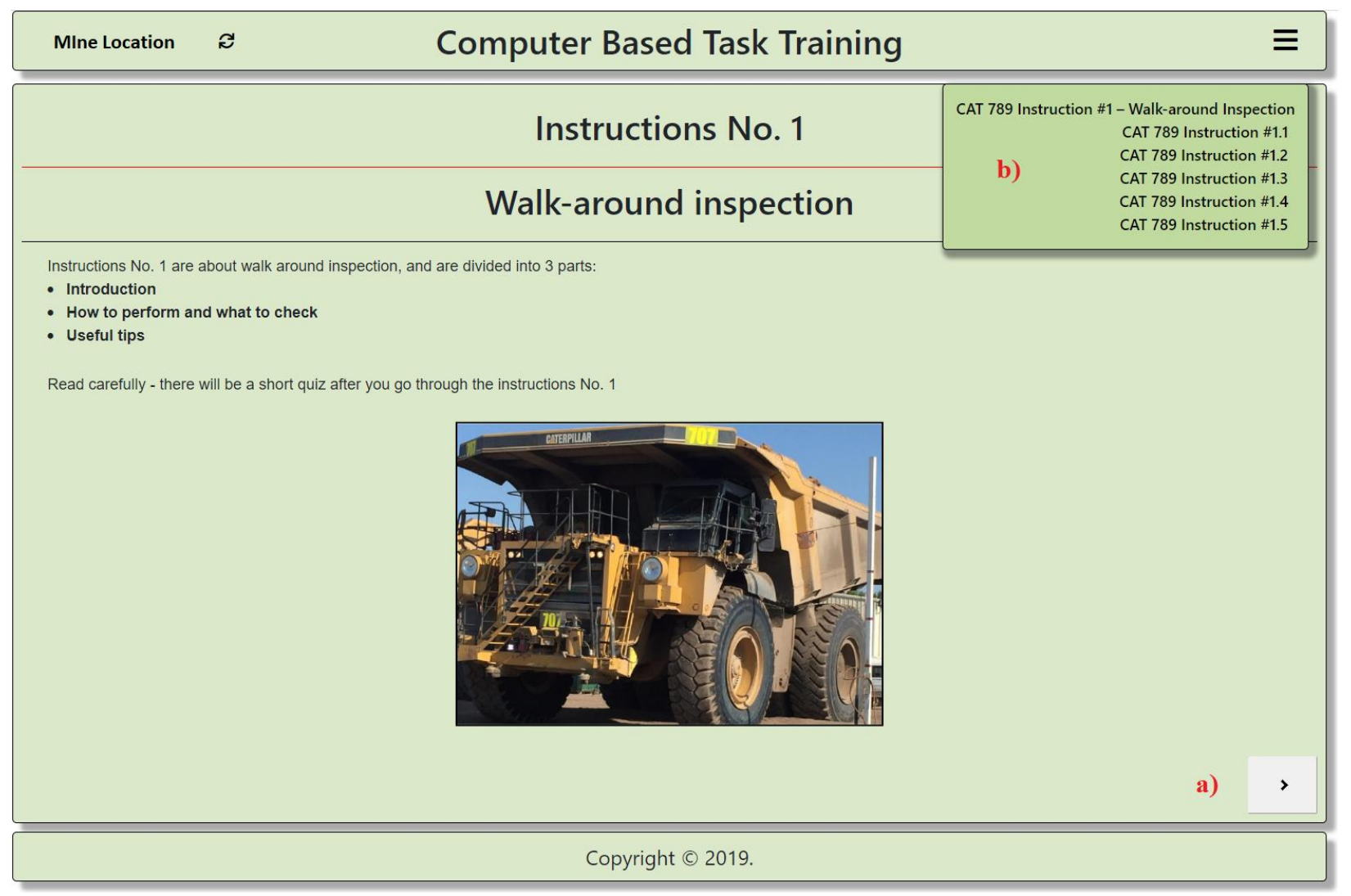

Figure 50 - Instructions No. 1

\subsubsection{Virtual Tours and Videos}

Figure 51 shows the last content page for virtual tours and 360-degree videos. The last content page in each of the three sets of instruction has videos and a virtual tour related to its particular machine. A person can run the virtual tour by clicking on button (a). A 360-degree video can be run with the play button (b). The "Begin Quiz" button (c) allows a user to start the knowledge assessment quiz on the current set of instructions (i.e. walk-around inspection). 


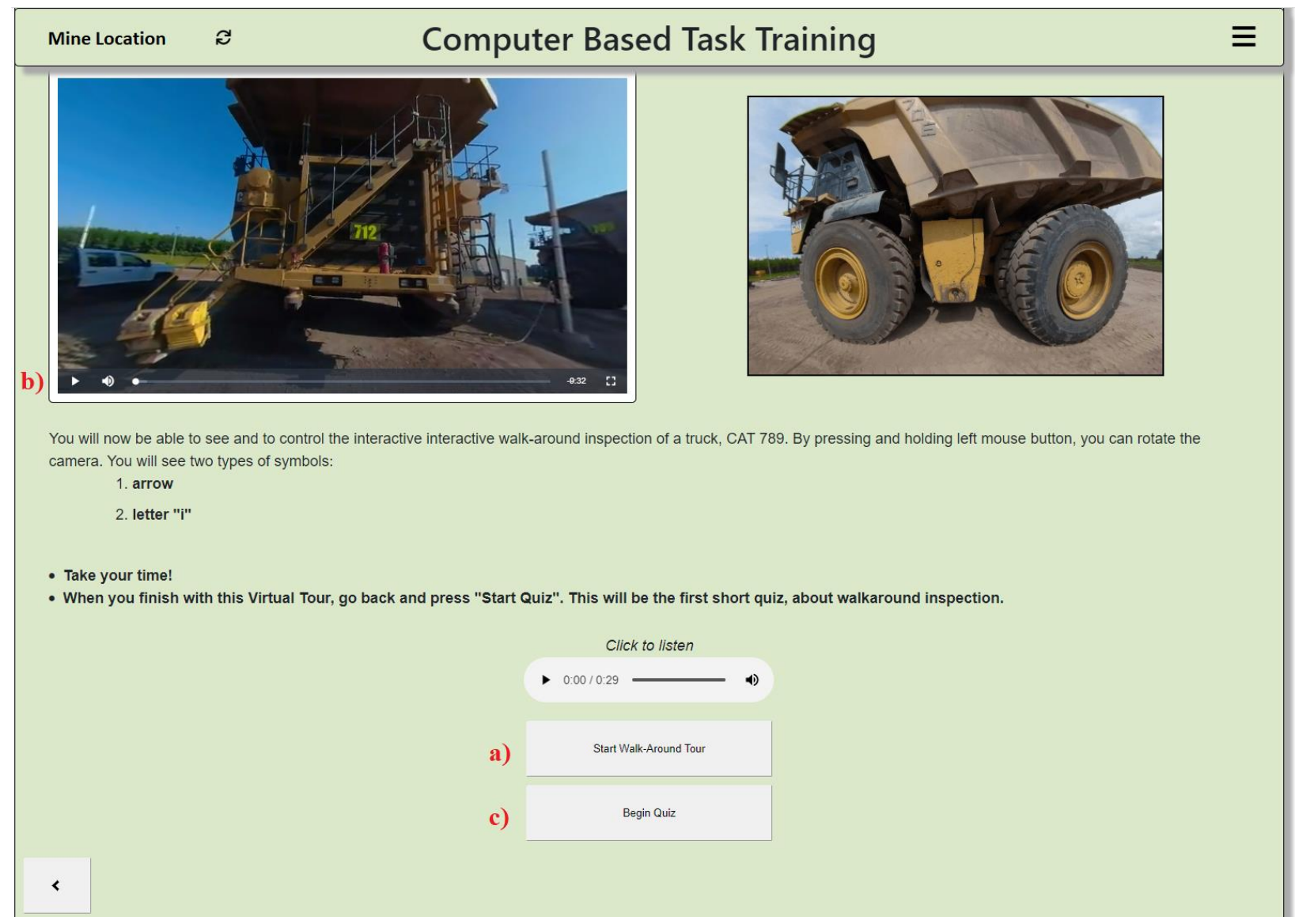

Figure 51 - Last Content Page

Figure 52 shows an example of a virtual tour. After running the virtual tour, a user can navigate between scenes (360-degree images) by using hotspots (a). By changing scenes, a trainee can observe different machine parts. The system tracks what images are visited during a virtual tour. When a blue square (b) appears, it indicates that this location has been visited. Therefore, the user knows what areas of the tour are still left to be checked. A trainee can go into a full-screen mode (c) and use an image thumbnails slider (d) as a second option for navigating between scenes. These concepts have been applied to all virtual tours created for the chosen machines. 


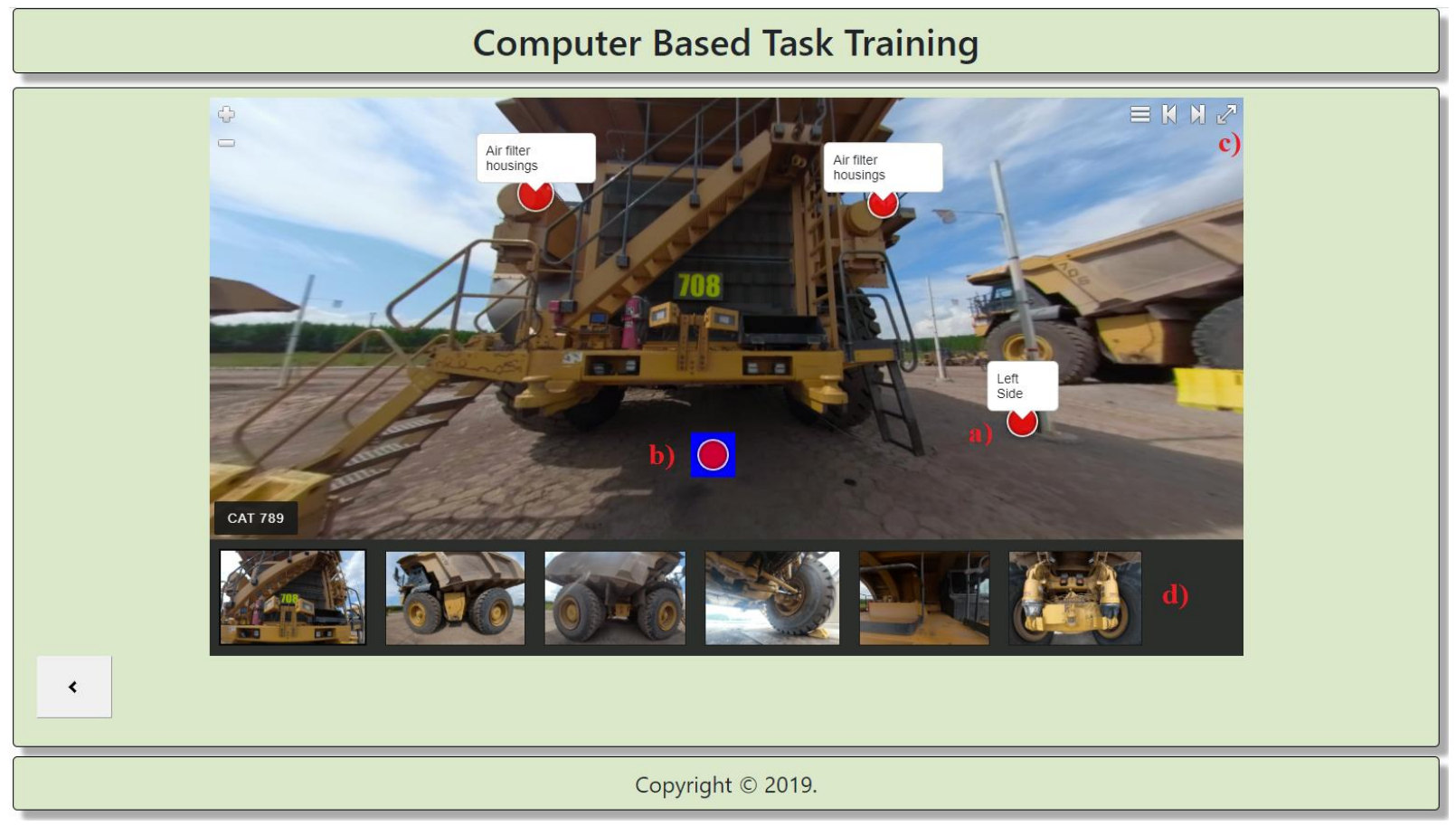

Figure 52 - Virtual Tour

Figures 55 and 56 give examples of 360-degree images inserted into a virtual tour.

\subsubsection{Quiz}

A trainee should take the quiz at the end of one set of instruction before proceeding to the next set.

Figure 53 shows a sample quiz. A trainee should first enter their name and then take the quiz.

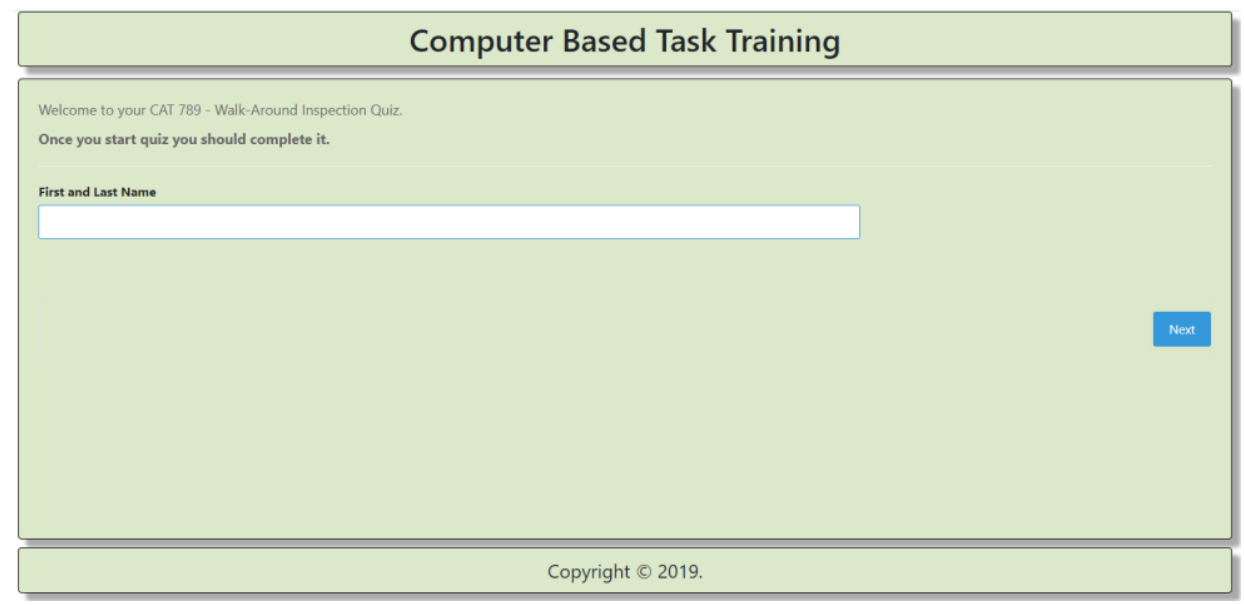

Figure 53 - Begin Quiz 
Quiz results are sent to an administrator or an editor by email directly after a trainee submits their quiz responses. This email (see Figure 54) includes a trainee's name, a test score, the time taken to finish a quiz, and the quiz questions paired with the trainee's responses.

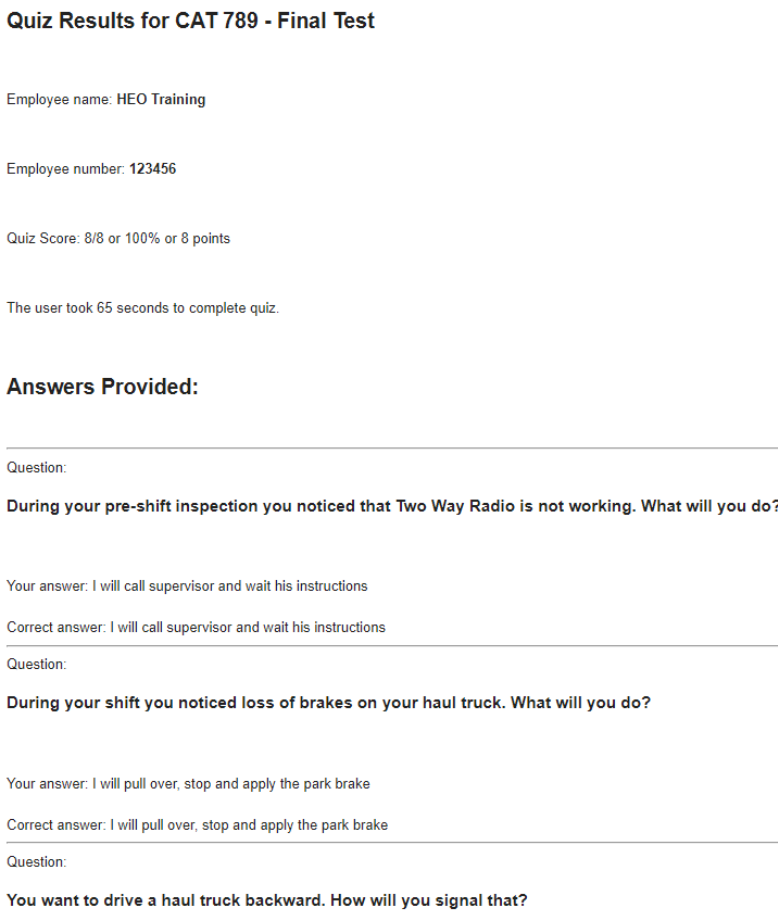

Figure 54 - Quiz Results 


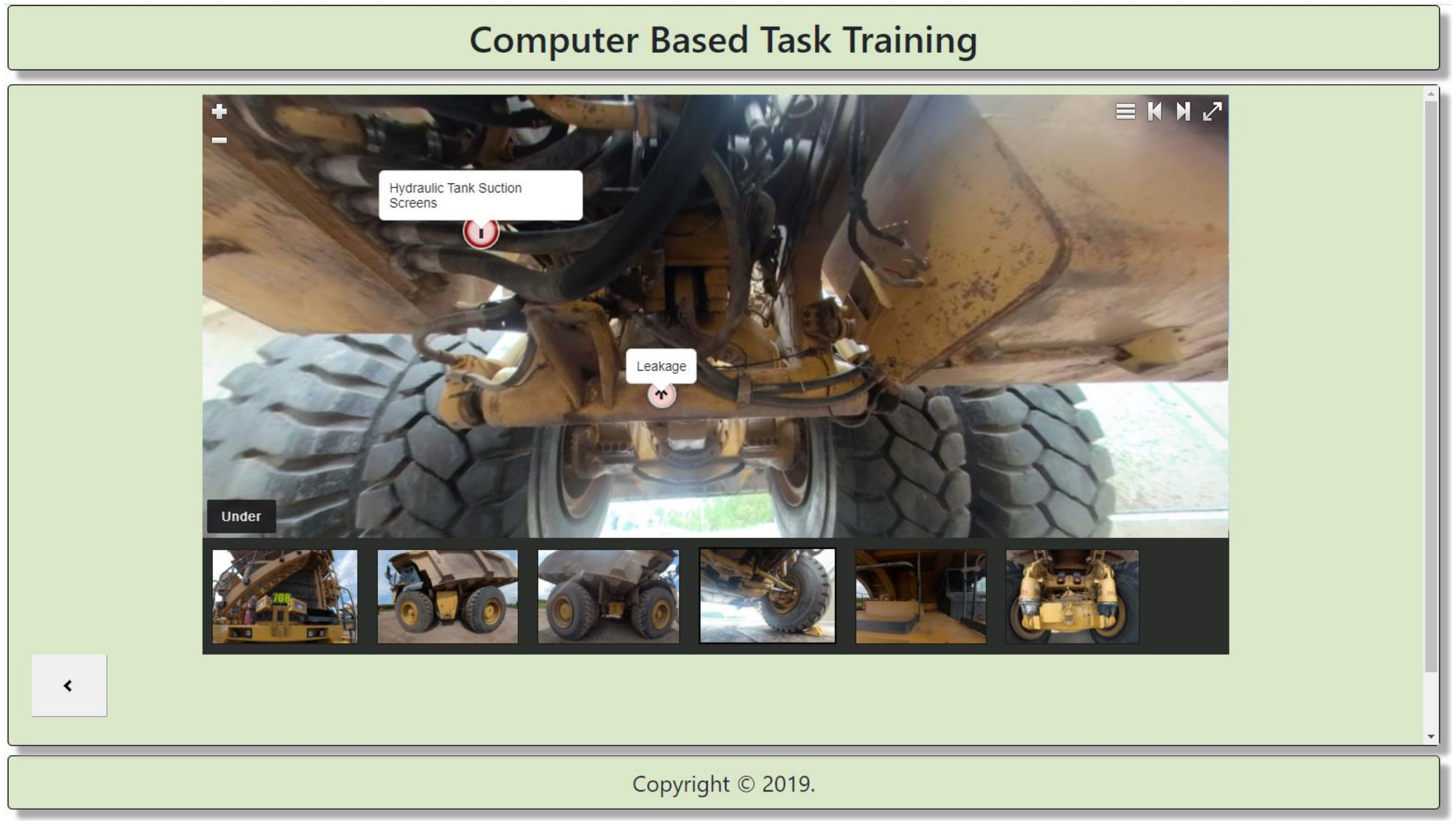

Figure 55 - Underneath Haul-truck 


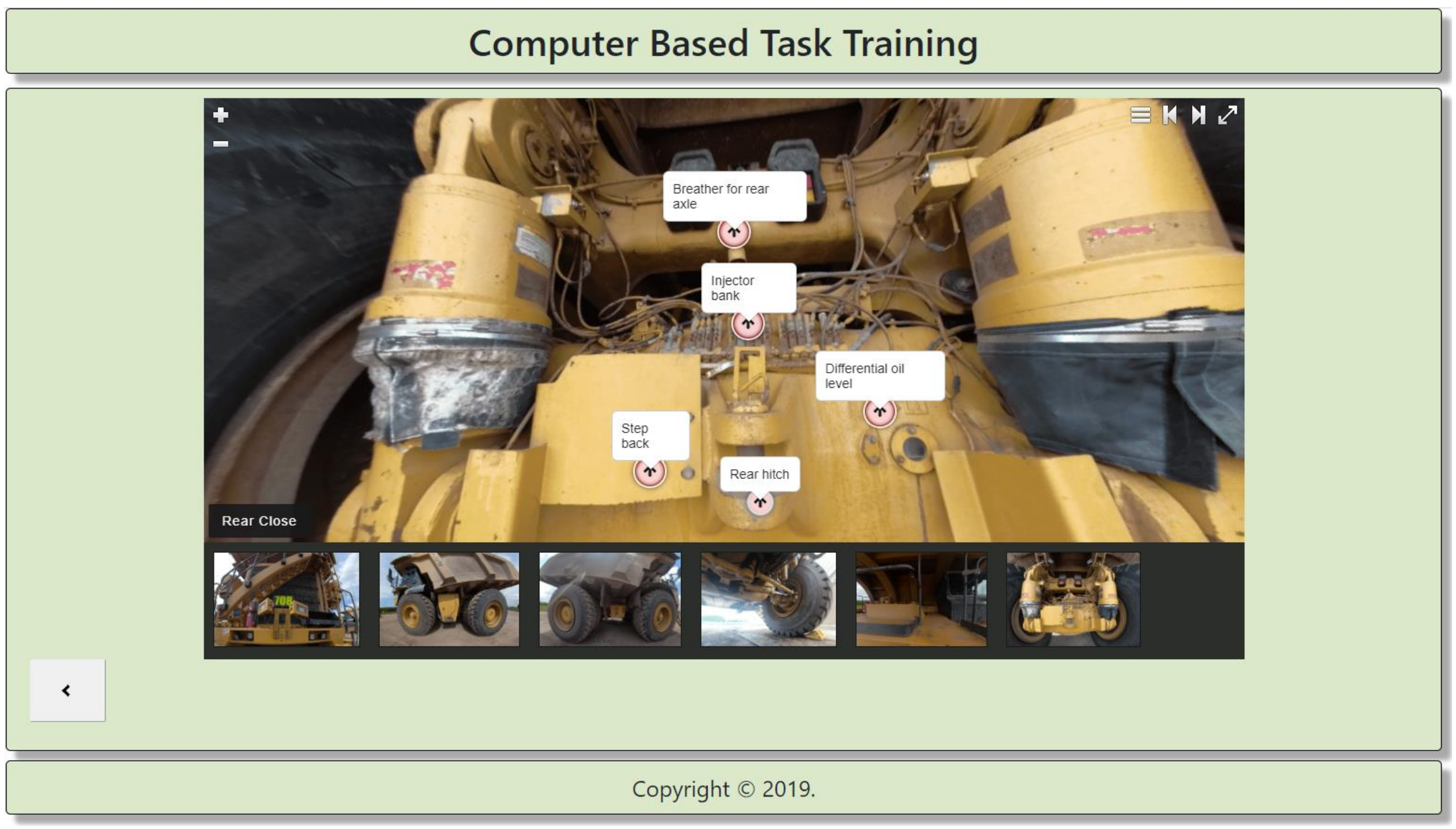

Figure 56 - Rear Side of Haul-truck 


\subsubsection{Mobile phone view}

Computer-Based Task-Training is optimized for use on mobile devices. The only prerequisite for accessing CBTT on a mobile device is to establish a solid Internet connection. All features which are available in a desktop version of CBTT are also available on mobile devices (see Figures 57, 58, and 59). For example, a user can create a new course, modify an existing course, or take an entire training course. This feature makes it possible to use CBTT outside of an office environment.

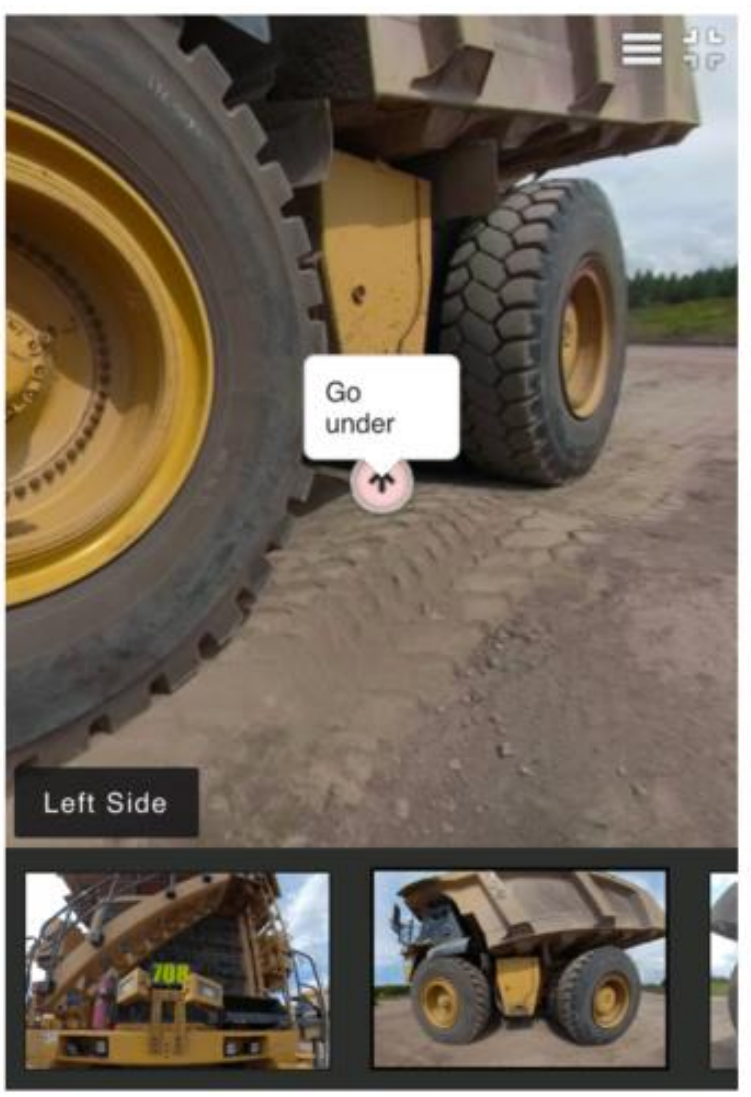

\section{Computer Based Task Training}

Which of the following is enough reason not to start the truck?

Mud on front tires

- Low tire

Mud on back tires

Dirty cabin

Figure 57 - View on Mobile Devices 


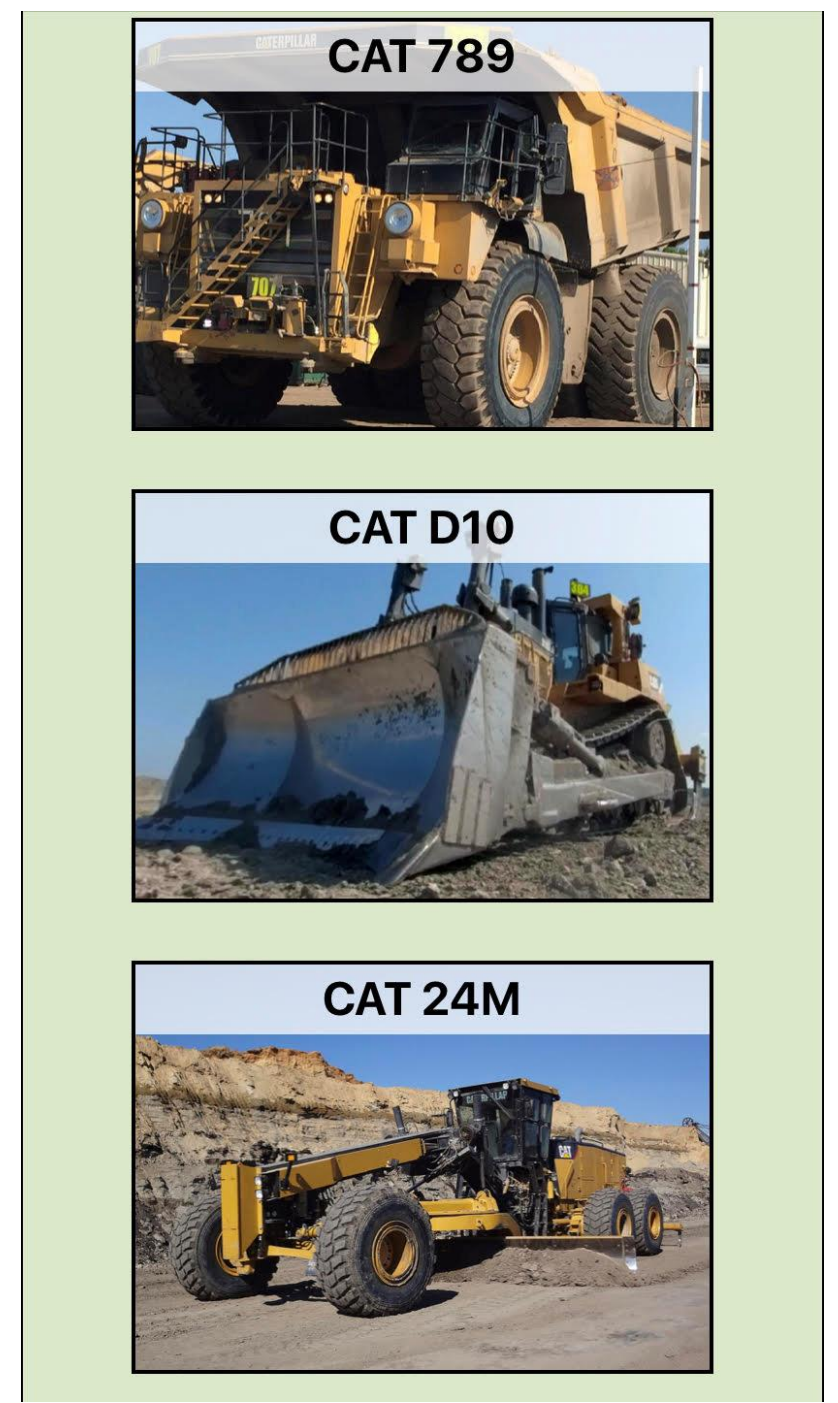

Figure 58-Mobile View - Select a Course

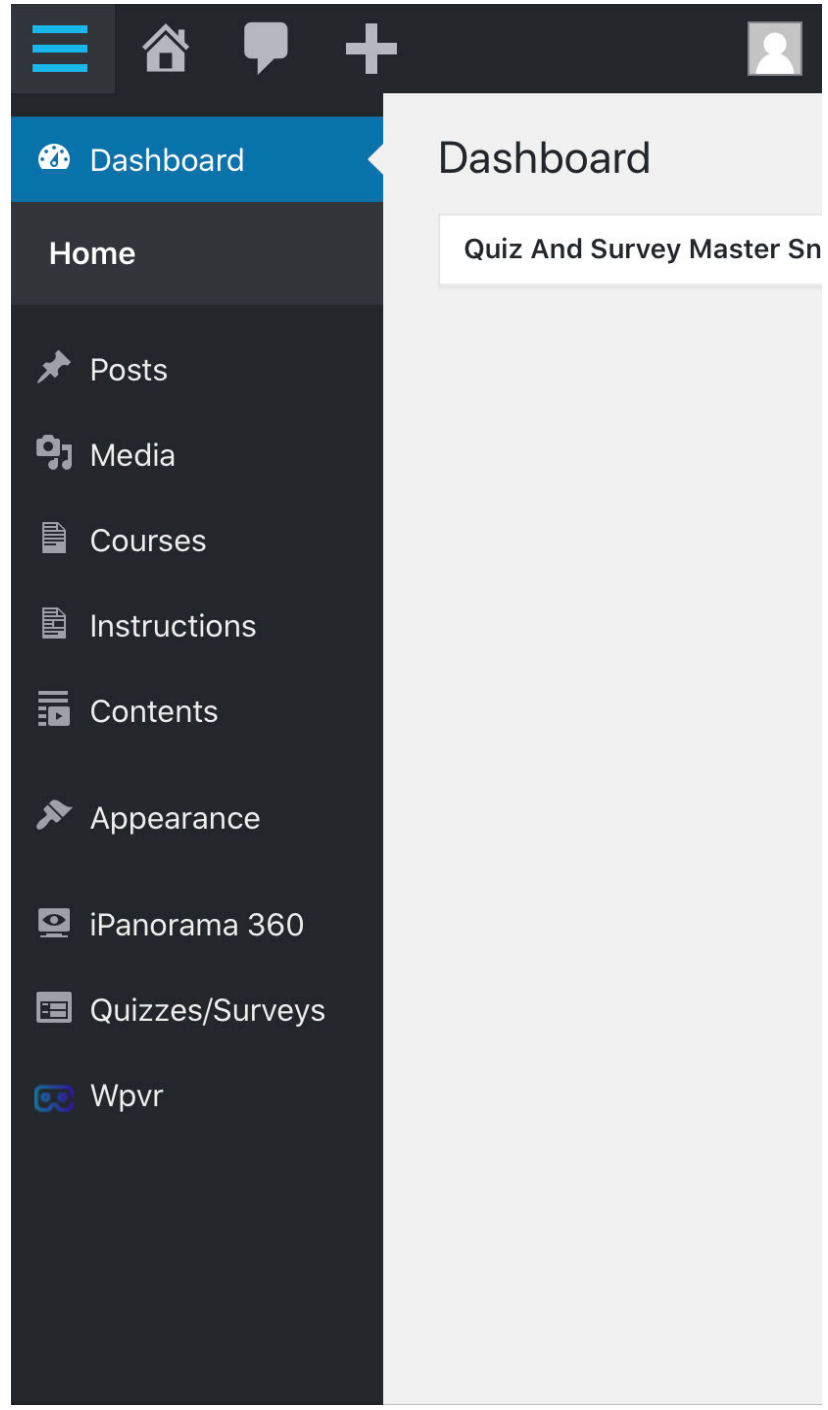

Figure 59 - Mobile View - Editor's Mode 


\subsection{Virtual Reality Application}

The Virtual Reality application was developed to improve the training of Heavy-Equipment operators by fully immersing them into a VR world; in this way, the trainee can use the HeadMounted Display (HMD) Oculus Rift and interact with the VR world while performing the virtual tour of a selected machine. Through VR, a trainee also has the opportunity to observe how an experienced operator performs the pre-shift inspection. As stated earlier, the VR application was developed with Unity3D software.

Besides the use of the VR application with Oculus Rift, virtual tours in the VR application can also be performed on desktop PCs. If used without HMD, this application becomes non-immersive in nature. Therefore, the same virtual tours can be used as both fully-immersive virtual tours or nonimmersive desktop virtual tours. Figure 60 shows the application icons for seven developed virtual tours.

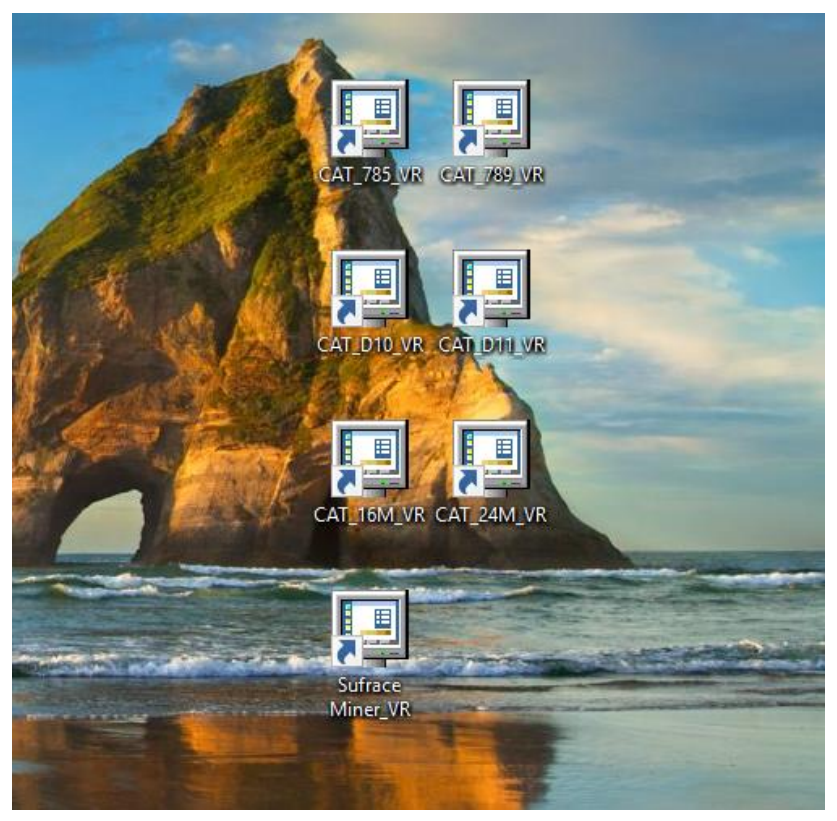

Figure 60 - VR applications 


\subsubsection{Oculus Rift Setup}

Connection between an "oculus ready" laptop and the Head-Mounted Display is established after installation of the Oculus Integration asset, which allows the use of Oculus Rift CV1 HMD. Oculus Rift VR headsets, two sensors, and two joysticks are used to achieve user's interaction with the VR world. Figures 61 and 62 show the user's interaction with the VR application run with Oculus Rift CV1. Sensors and joysticks are marked with (a) and (b), respectively. The person immersed in the VR world sees what is presented on the computer screen.

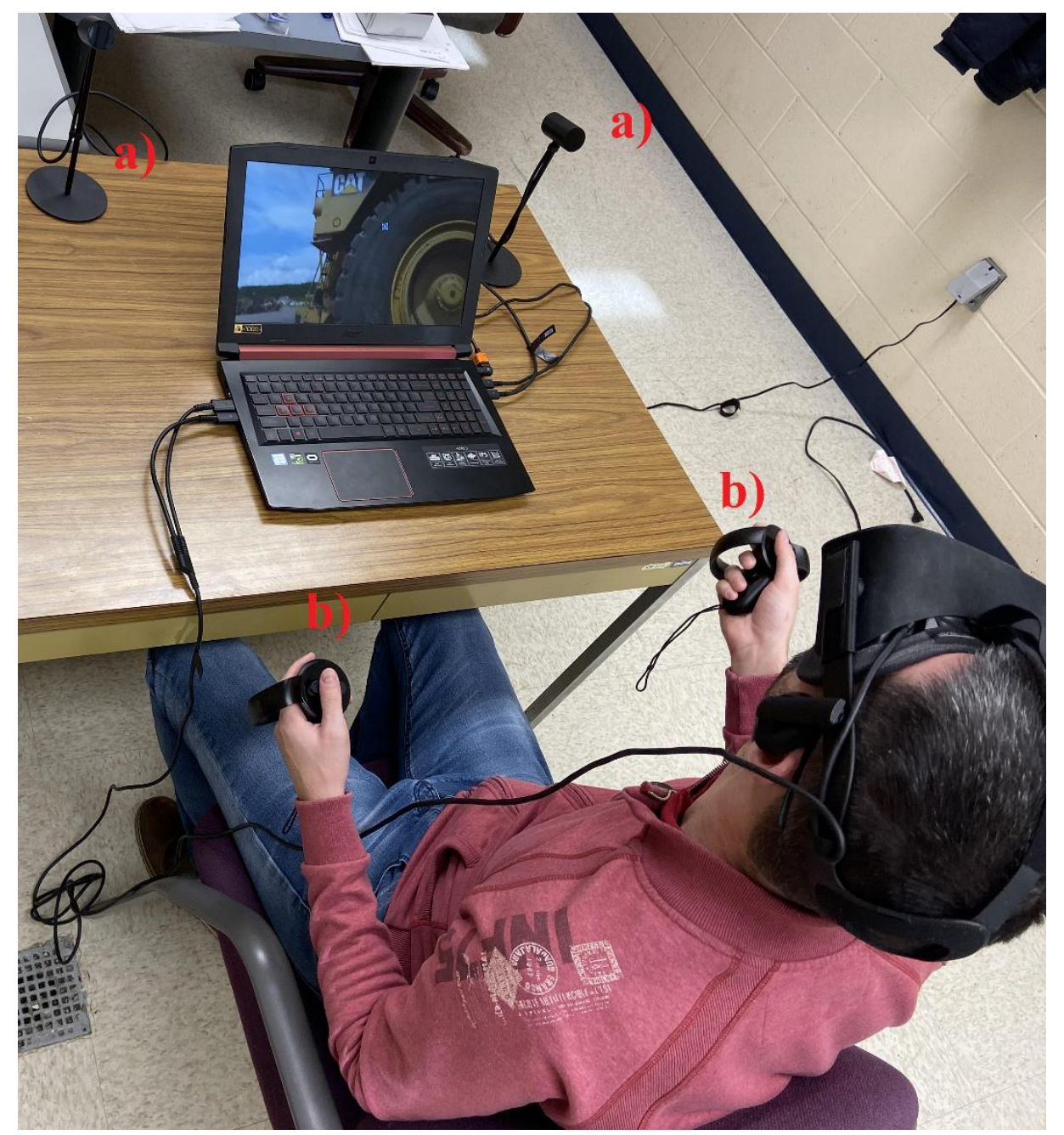

Figure 61 - VR application with Oculus Rift CV1 


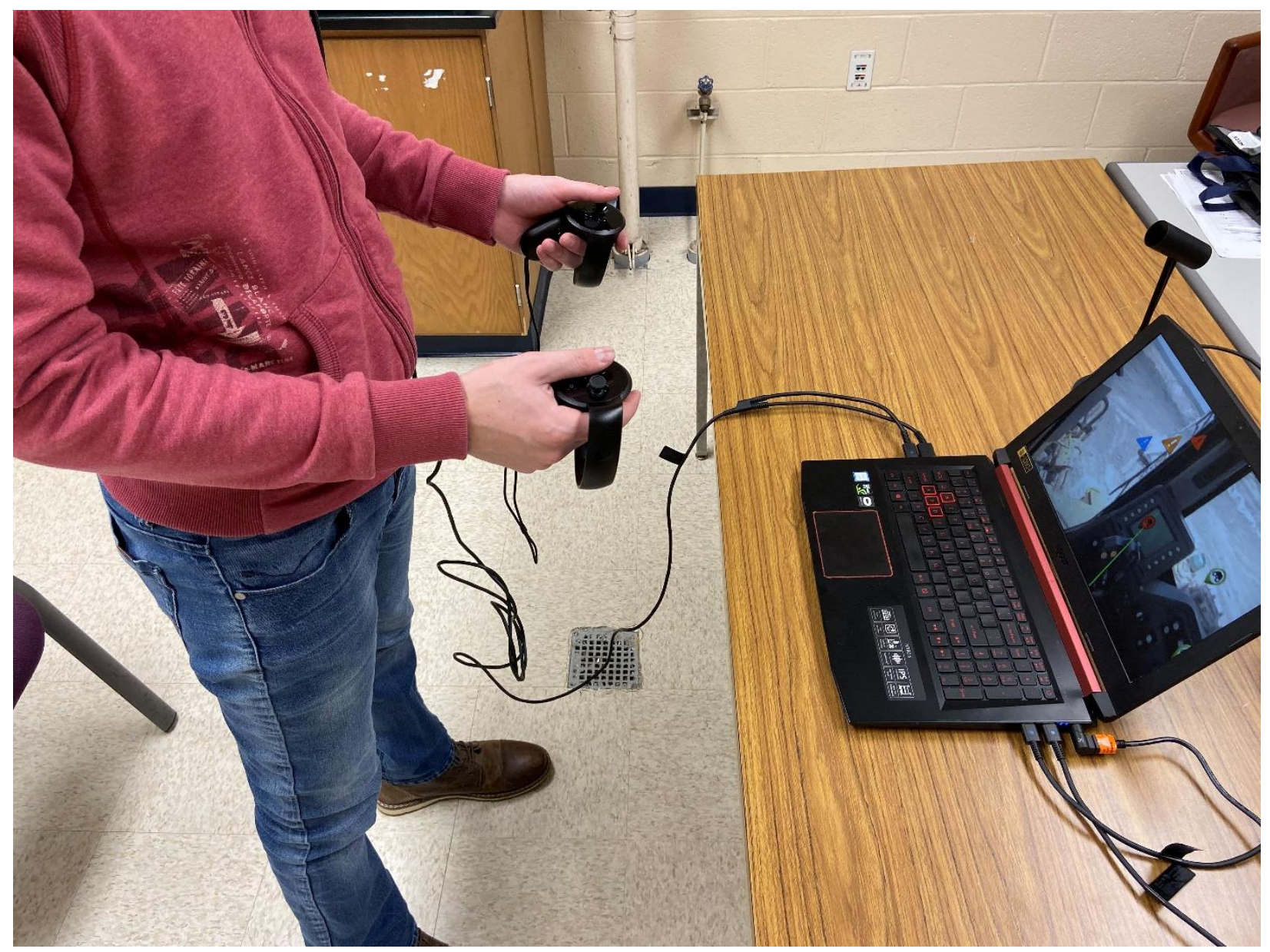

Figure 62 - User Interaction

\subsubsection{Non-Immersive Desktop Version}

As stated before, another option for running this VR application is the non-immersive mode. This mode involves using the application on a desktop PC and performing a virtual tour by using a mouse and keyboard. Figures 63 and 64 show screenshots of such an application. 


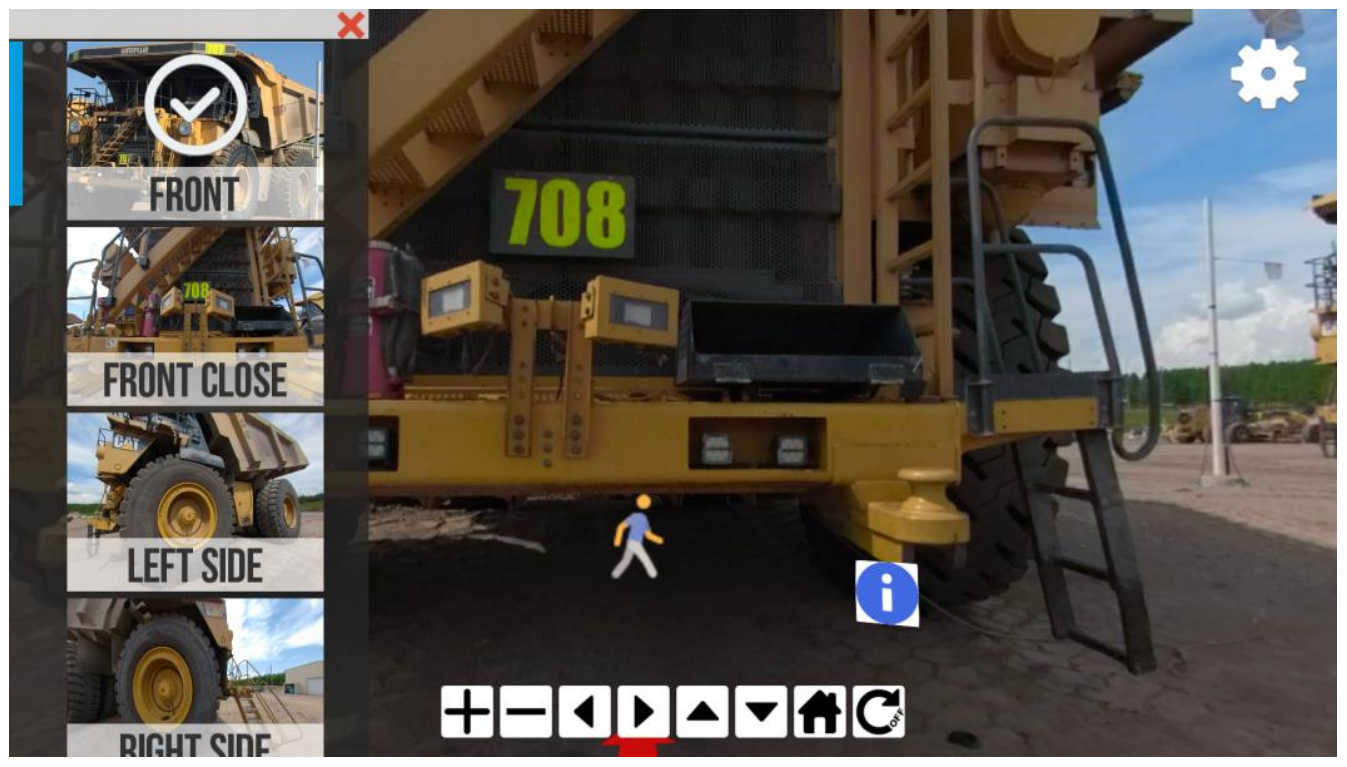

Figure 63 - Non-immersive Mode

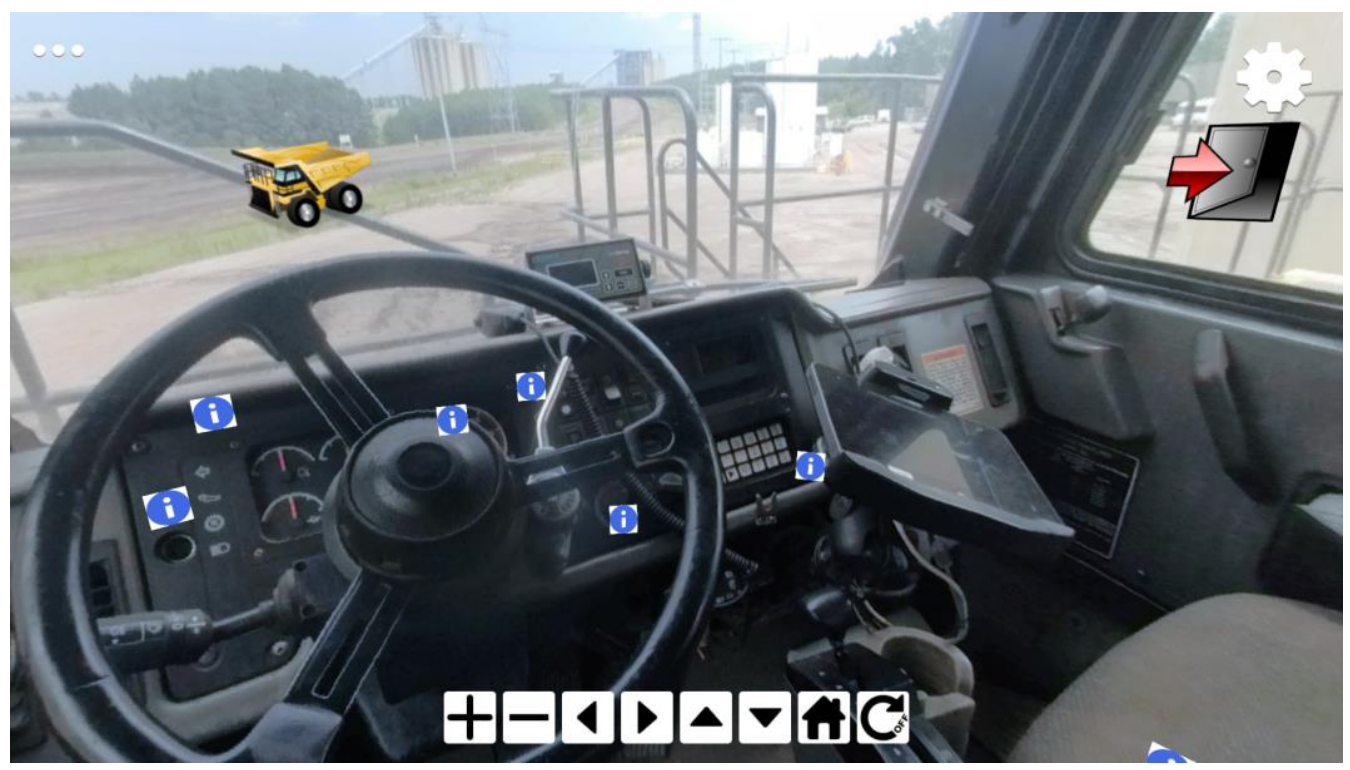

Figure 64 - Non-immersive Mode-Cabin

The blue icons (iButtons) show 2D images of the machine parts (Figure 65), as well as problems that a trainee can potentially expect during a pre-shift inspection of the machine (Figure 66). These are also followed by voice information that explains particular parts of the machine. 


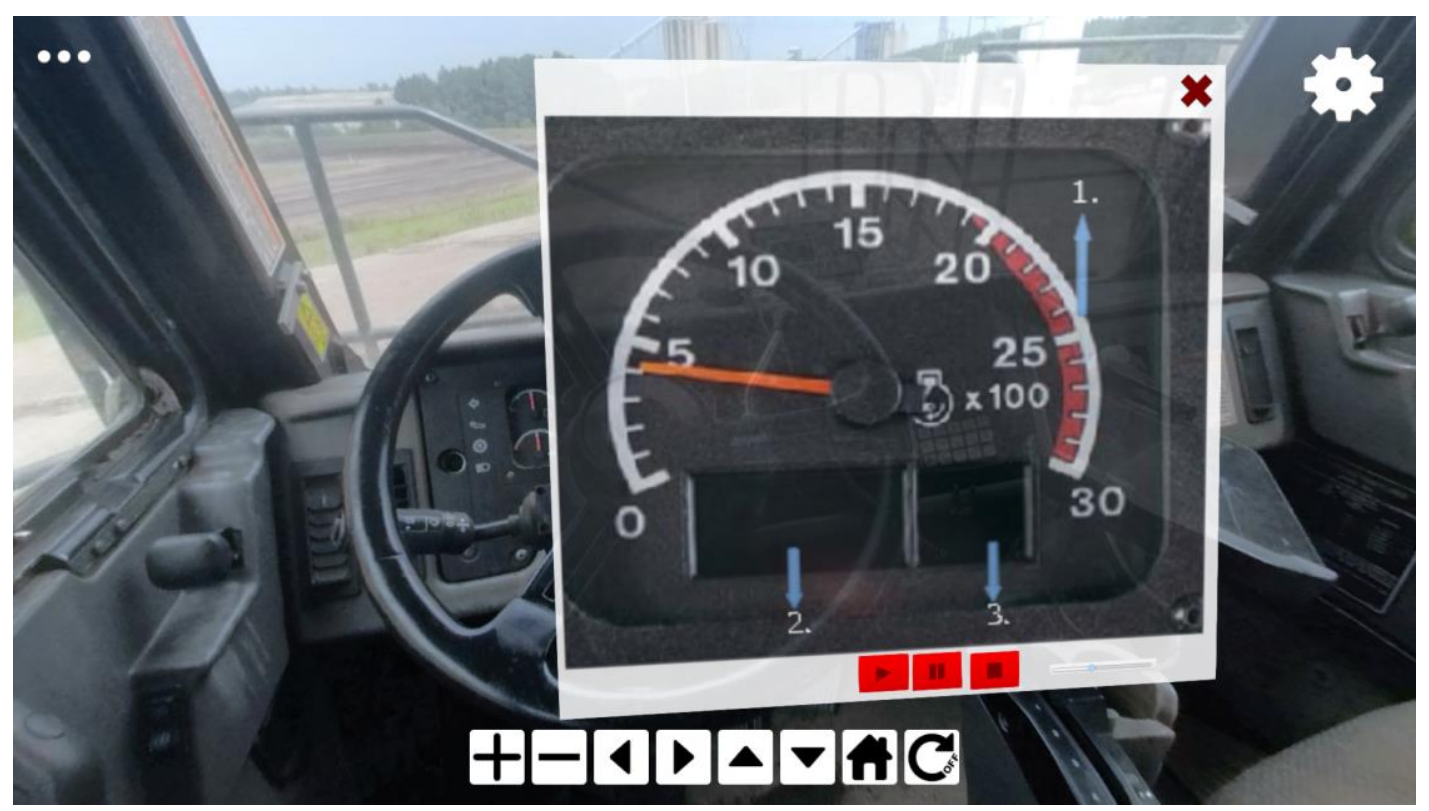

Figure 65 - Speedometer

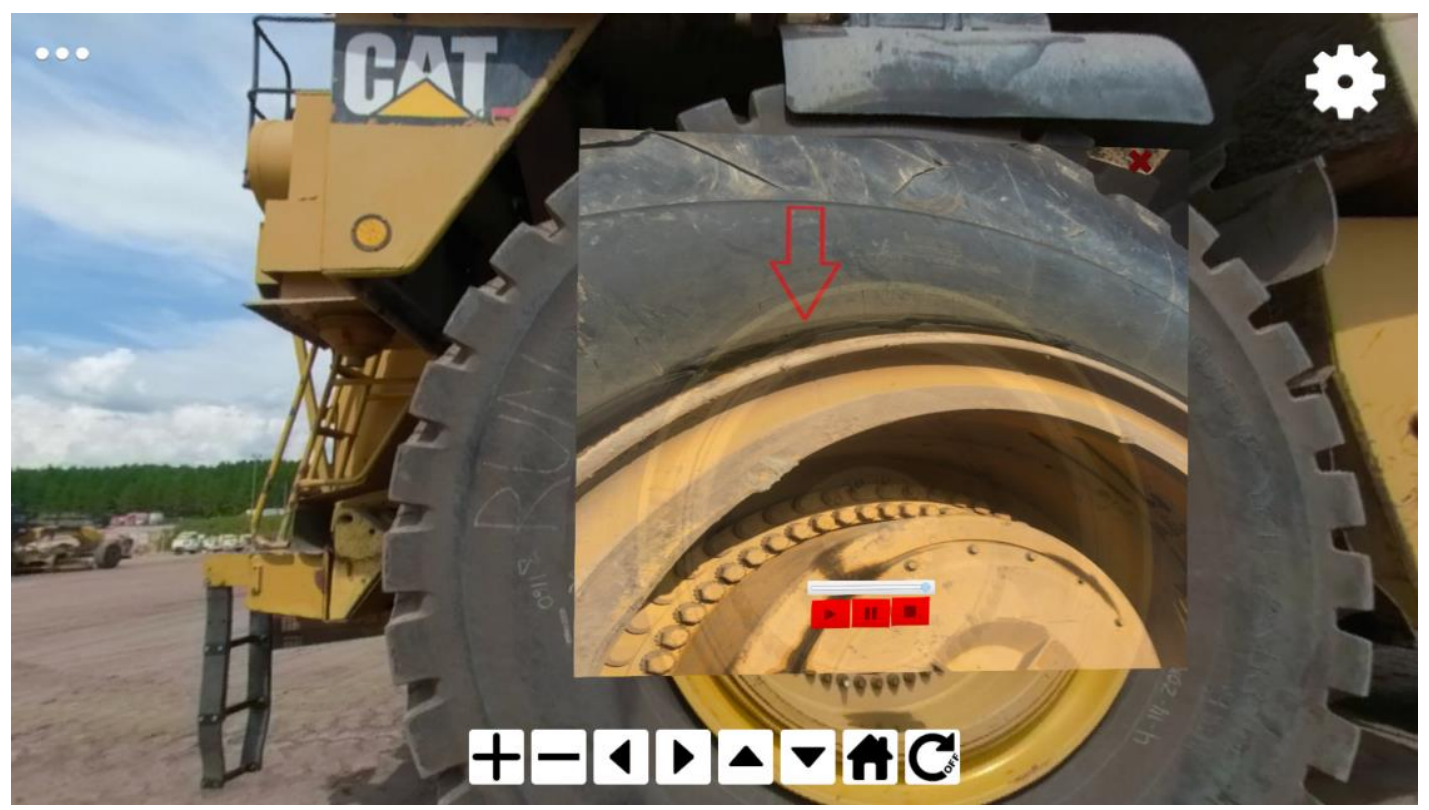

Figure 66 - Tire Problem 


\section{Chapter 4}

\section{Summary, Conclusion, and Recommendations for Future Research}

Chapter 1 provided an introduction to the importance of training Heavy Equipment Operators (HEO) in the mining industry. Emphasis was put on pre-shift machine inspections as one of the crucial tasks of HEOs in the field. Chapter 1 also provided a problem statement and the scope of work on development of the Computer-Based Task-Training and Virtual Reality (VR) application for HEO training.

Chapter 2 proposed a technical approach to creating the training materials, including 360 -degree images and videos, Computer-Based Task-Training (CBTT), a template for creating a training course, and VR applications. Camera positions were determined based on the types of machines. Afterwards, images and videos were captured with GoPro Fusion camera; these images and videos were then edited with the help of editing software. One of the most popular Content Management Systems, WordPress, was used to develop CBTT and the training template. Several plugins were used to help users create a training course without extensive programming skills. For the VR application, Unity3D software was used to create Virtual Tours. Such tours can be used on desktop PCs and with Head-Mounted Display (HMD) Oculus Rift CV1. In total, training courses for seven machines were created.

Chapter 3 provided the results of the process of gathering 360-degree images and videos, showing examples of what those images and videos looked like. This chapter gave an explanation on how new training courses and VR application can be created within the CBTT system. Created courses can then be taken by a trainee; they can also be edited by an administrator or editor. This chapter also showcased the developed virtual tours of machine inspections. 
Finally, Chapter 4 will provide a brief summary of the main topics of this thesis, in addition to making several recommendations for future research.

The CBTT and VR application developed through this research established training for HeavyEquipment Operators that will allow for better understanding of the procedures and the importance of pre-shift inspections. This has been achieved through interactive and structured lessons. Training software is convenient and flexible, compatible with PCs, mobile devices, and HMD.

The results of training via the CBTT and VR application can be summarized as follows:

- Training materials including 360-degree images and videos, 2D images, and sound information were created for seven machines.

- User friendly Interface for Computer-Based Task-Training software was developed.

- Training template for developing a new training course with CBTT was created.

- Instructions on how to create a new training course for a mining equipment were given.

- Knowledge assessment quizzes were created.

- CBTT was customized for use on mobile devices.

- Virtual Reality application was created for use on Desktop PCs or with Head-Mounted Display Oculus Rift CV 1.

- Seven training courses with virtual tours and videos for HEOs were created.

Further research should investigate improvements of CBTT and VR as follows: 
- Calculating return on investment (ROI) and assessing the impact of training software through surveys.

- Introducing cutting-edge photography and videography equipment to collect more advanced images and videos. Focus should be placed on editing such materials to reach semi-professional level and incorporating them into developed software.

- Developing more interactive knowledge assessment quizzes to create more interplay between user and software; this especially includes improving the VR worlds by developing advanced quizzes in a game format.

- Upgrading the VR application by applying particular, newly published HMDs, and by establishing the wireless connection between PC and VR headsets. This can make the user feel more comfortable while being immersed in a VR world. 


\section{References}

1. Acer. (2019). Acer. Retrieved April 2019 from www.acer.com: https://www.acer.com/ac/en/US/content/series/nitro5

2. Bahn, S. (2013). Workplace hazard identification and management: The case of an underground mining operation. Safety Science, Vol. 57. pp. 129-137.

3. Burke, M. J., Sarpy, S., Smith-Crowe, K., Chan-Serafin, S., Salvador, R. O., and Islam, G. (2006). Relative Effectivness of Worker Safety and Health Training Methods. American Journal of Public Health, pp. 315-324.

4. Christopoulou, E., and Xinogalos, S. (2017). Overview and Comparative Analysis of Game Engines for Desktop and Mobile Devices. International Journal of Serious Games, Volume 4, Issue 4. pp. 21-36.

5. Colin, M. (2017). Incident prevention tools - incident investigations and pre-job safety analyses. International Journal of Mining Science and Technology. Vol 27. pp. 635-640.

6. Fahy, P. J. (2004). Web-based training. In I. Encyclopedias, The Internet Encylopedia Vol. 3. pp. 661-673. Hoboken, New Jersey: John Wiley and Sons, Inc.

7. Google. (2019). Retrieved November 2019 from store.google.com: https://store.google.com/product/google cardboard

8. GoPro Fusion. (2018). Retrieved March 2018 from https://www.forbes.com/sites/paulmonckton/2018/03/07/gopro-fusion-vs-hero6-blackwhats-the-difference/\#3d5a2e607776 
9. Haas, J. K. (2014). A History of the Unity Game Engine. INTERACTIVE QUALIFYING PROJECTS (ALL YEARS), pp. 32.

10. Hui, Z. (2017). Head-mounted display-based intuitive virtual reality training system for the mining industry. International Journal of Mining Science and Technology, pp. 717-722.

11.iPanorama360. (2018). Retrieved July 2018 from codecanyon.net: https://codecanyon.net/item/ipanorama-360-virtual-tour-builder-for-wordpress/17028820

12. Kizil, M. S., and Joy, J. (2001). "What can Virtual Reality do for Safety?". Queensland Mining Industry Health and Safety Converence: Managing Safety to Have a Future. Queensland Mining Council Publication, pp.173-181.

13. Kowalski, K. M., and Vaught, C. (2002). Principles of adult learning: Application for mine trainers. Strategies for Improving Miners' Training. Publication No. 2002-156, pp. 3-8.

14. Liu, X., Xiao, Q., Qian, F., Indiana , U., Han, B., Varvello, M., . . AT\&T Labs, -R. (2017). 360 degree Innovations for Panoramic Video Streaming. NatNets-XVI, pp. 50-56.

15. Mallet, L., and Unger, R. (2007). Virtual Reality in Mine Training. SME Annual Meeting and Exhibit, February 25-28, Denver, Colorado, preprint 07-031. Society of Mining, Metallurgy, and Exploration.

16. Manoj, S., and Asoke, N. (2016). Web Content Management System. International Journal of Innovative Research in Advanced Engineering, pp. 51-56.

17. McMahan, P. R., Schafrik, S., Bowman, D. A., and Karmis, M. (2008). Virtual Environments for Surface Mining Powered Haulage Trucks to Improve Mining Safety. First International Future Mining Conference, Sydney, NSW, pp. 167-173. 
18. McMahan, P. R., Schafrik, S., Bowman, D. A., and Karmis, M. (2008). Virtual Environments for Surface Mining Powered Haulage Training. Extracting the Science: A Century of Mining Research, Society for Mining, Metallurgy, and Exploration, pp. 520528.

19. Mine Safety Associates. (2007). 30 CFR Part 48 - Training and Retraining of Miners. Mine Safety Associates, Utah, 2007.

20. MSHA. (2019). September "Guidelines for Effective Task Training", online resource. Retrieved September 2019 from

https://www.msha.gov/sites/default/files/Training_Education/task-training-guidelines.pdf

21. Niora. (2019). Retrieved November 2019 from www.niora.net: https://www.niora.net/en/p/oculus_rift_cv1

22. Oculus. (2019). Retrieved April 2019 from www.oculus.com: https://support.oculus.com/248749509016567/

23. Oculus Accessories. (2019). Retrieved April 2019 from ww.oculus.com: https://www.oculus.com/rift/accessories/

24. Oculus Integration. (2019). Retrieved April 2019 from assetstore.unity: https://assetstore.unity.com/packages/tools/integration/oculus-integration-82022

25. Patterson, J. M., and Shappell, S. A. (2010). Operator error and system deficiencies: Analysis of 508 mining incidents and accidents from Queensland, Australia using HFACS. Accident Analysis and Prevention 42, pp. 1379 - 1385.

26. Polcar, J., and Horejsi, P. (2015). Knowledge Acquisition and Cyber Sickness: A Comparison of VR Devices in Virtual Tours. MM Science Journal, pp. 613-616. 
27. Quiz Master. (2018) Retrieved July 2018 from wordpress.org: https://wordpress.org/plugins/quiz-master-next/

28. Rohilla, N. (2017). CONTENT MANAGEMENT SYSTEM FOR E-COMMERCE WEBSITE DEVELOPMENT . International Journal of Engineering Sciences \& Research Technology, pp. 490-495.

29. Squelch, A. (2001). Virtual reality for mine safety training in South Africa. The Journal of the South African Institute of Mining and Metallurgy, pp. 209-216.

30. Unity. (2018). assetstore.unity. Retrieved July 2018 from Unity.com: https://assetstore.unity.com/packages/templates/systems/mobile-vr-tour-360-75266

31. Van den Broeck, M., Kawsar, F., and Schoning, J. (2017). It's All Around You: Exploring $360^{\circ}$ Video Viewing Experiences on Mobile Devices. MM '17 Proceedings of the 25th ACM international conference on Multimedia, pp. 762-768. Mountain View, California, USA: ACM New York, NY.

32. Wang, S., Mao, Z., Zeng, C., Gong, H., Li, S., and Chen, B. (2010). A new method of virtual reality based on Unity3D. Institute of Electrical and Electonics Engineers.

33. WordPress Features. (2018). Retrieved July 2018 from wordpress.org: https://wordpress.org/about/features/

34. Wyk, E. v., and Villiers, R. d. (2009). Virtual Reality Training Applications for the Mining Industry. In Proceedings of the 6th International Conference on Computer Graphics, Virtual Reality, Visualisation and Interaction in Africa, pp. 53-63. Pretoria: ACM New York, NY, USA. 
35. Wyk, E. v., and Villiers, R. d. (2019). An evaluation framework for virtual reality safety training systems in the South African mining industry. The Journal of the Southern African Institute of Mining and Metallurgy, 427-436. 